
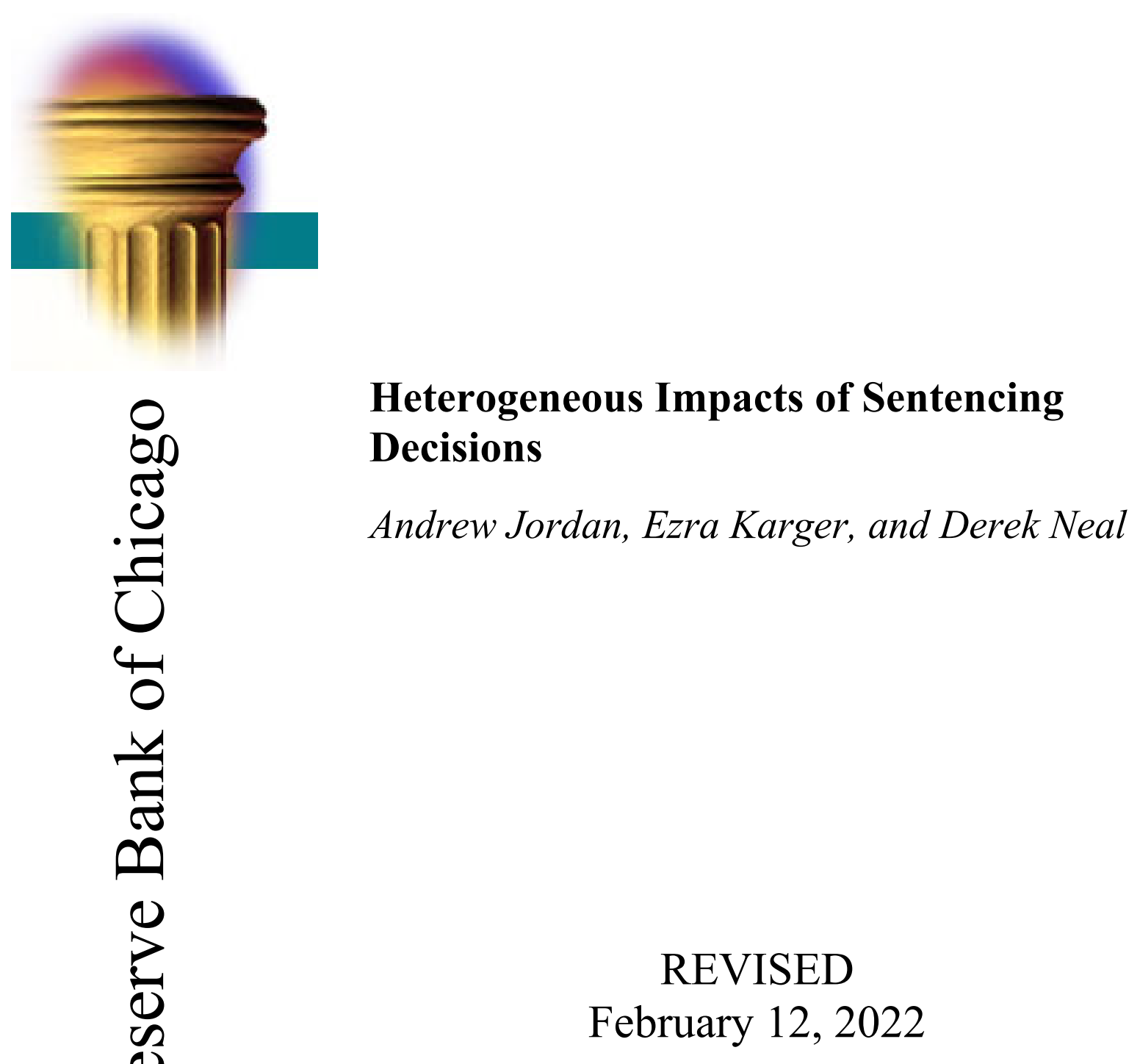

\title{
Heterogeneous Impacts of Sentencing
} Decisions

\author{
Andrew Jordan, Ezra Karger, and Derek Neal
}

\author{
REVISED \\ February 12, 2022
}

WP 2022-02

https://doi.org/10.21033/wp-2022-02

${ }^{*}$ Working papers are not edited, and all opinions and errors are the responsibility of the author(s). The views expressed do not necessarily reflect the views of the Federal Reserve Bank of Chicago or the Federal Reserve System. 


\title{
Heterogeneous Impacts of Sentencing Decisions
}

February 12, 2022

\author{
Andrew Jordan \\ Washington University in St. Louis \\ Ezra Karger \\ Federal Reserve Bank of Chicago \\ Derek Neal \\ University of Chicago and NBER
}

\begin{abstract}
We examine 70,581 felony court cases filed in Chicago, IL, during the period 1990-2007. We exploit case randomization to assess the impact of judge assignment and sentencing decisions on the arrival of new charges. Our estimates of the impact of incarceration on recidivism show that, in marginal cases, incarceration creates large and lasting reductions in recidivism among first offenders. Yet, among repeat offenders, incarceration sentences for marginal offenders create only modest short-run incapacitation effects and no lasting reductions in the incidence of new felony charges. Our results raise concerns about sentencing reforms, enacted in most states over recent decades, that encourage or mandate incarceration sentences for many offenders with prior criminal records.
\end{abstract}

We thank Ilan Wolff, Maximiliano Gonzalez, Julien Bendelac, and Ora Halpern for excellent research assistance. We owe thanks to many people who gave generously of their time to help us better understand how the Illinois criminal justice system operates and records its activities: Jordan Boulger, Michael Cooney, Jennifer Dohm, Kendy Elberson, Ian Jantz, Alan Mills, Michael Moore, Evan Rose, Max Schanzenbach, Jason Sweat, Gwyn Troyer, and Rob Warden. We owe special thanks to Stephen M Brandt, the Director of Legal research for the Chief Judge, Judge Lawrence P. Fox, Sarah Staudt of the Chicago Appleseed Fund for Justice, and Forest Gregg of the Chicago Data Collaborative. We thank Magne Mogstad, Evan Rose, Azeem Shaikh, seminar participants at Brown Economics, the Opportunity \& Inclusive Growth Institute at the Federal Reserve Bank of Minneapolis, the Institute for Research on Poverty's Summer Research Workshop, and Northwestern Law School's Law and Economics Workshop for useful feedback. We thank The Hymen Milgrom Supporting Organization's Successful Pathways from School to Work project for support. We thank Robert Goerge and Chapin Hall for supporting our work. Any views expressed in this paper do not necessarily reflect those of the Federal Reserve Bank of Chicago or the Federal Reserve System. 


\section{Contents}

1 Literature Review 2

2 Data $\quad 4$

2.1 Pathways in the Criminal Justice System . . . . . . . . . . . . . . . . . . 4

2.2 Court Data: Randomized Cases and Probation Procedures . . . . . . . . . . . . . . . . 5

2.3 IDOC Data: Effective Sentences and Prior Cases . . . . . . . . . . . . . . . . . . . 6

2.4 IDOC Data: Mandatory Supervised Release and Recidivism . . . . . . . . . . . . . . 7

$\begin{array}{lll}3 & \text { Empirical Model } & 7\end{array}$

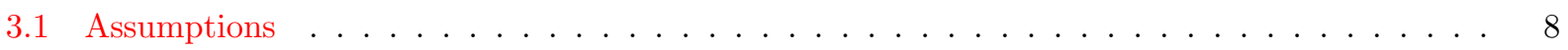

4 Variable Construction, Descriptive Statistics, and Balance 9

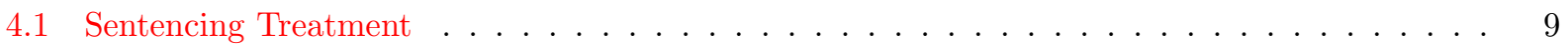

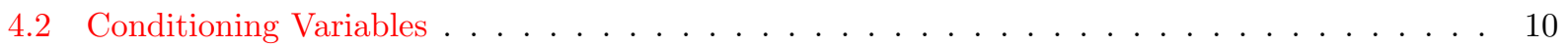

4.3 LOM Measure of Severity $\ldots \ldots \ldots \ldots$

4.4 Outcome Measures . . . . . . . . . . . . . . . . . . . . 11

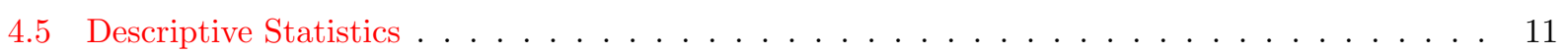

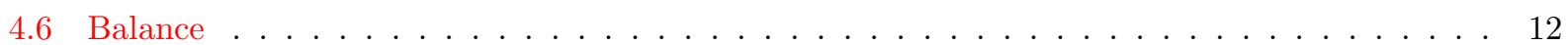

5 Impacts of Incarceration on Recidivism 12

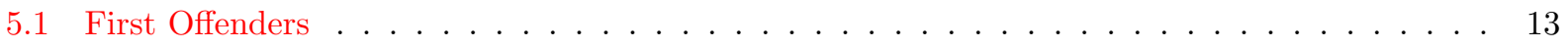

5.2 Repeat Offenders . . . . . . . . . . . . . . . . . . . . 13

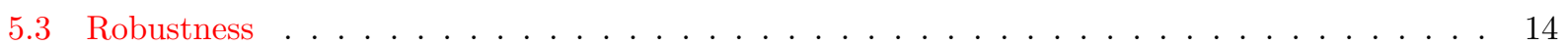

6 Maintained Assumptions $\quad 15$

6.1 Independence . . . . . . . . . . . . . . . . . . . . . . 15

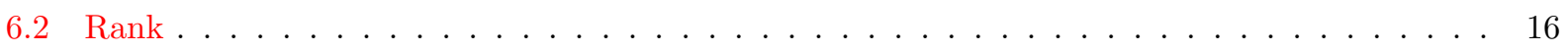

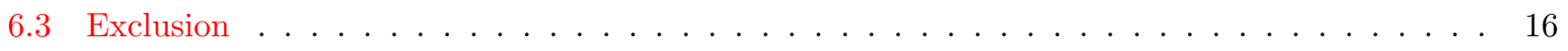

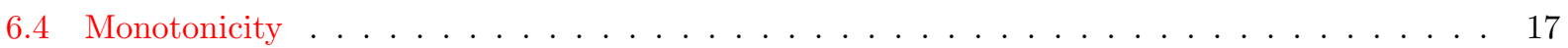

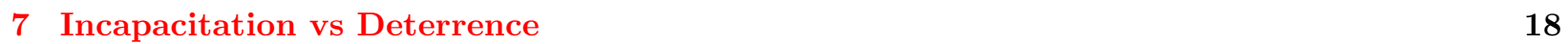

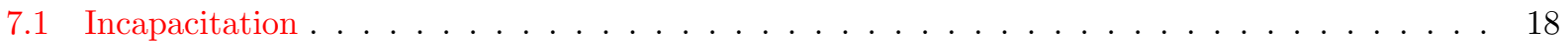

7.2 Beyond Incapacitation to Deterrence . . . . . . . . . . . . . . . . . . . . . 19

8 Heterogeneous Impacts Within First and Repeat Offenders 21

8.1 Results for Black Offenders . . . . . . . . . . . . . . . . . . . . . . . . 21

8.2 Drug Offenders versus Non-Drug Offenders . . . . . . . . . . . . . . . . . . . 21

8.3 High-Crime versus Low-Crime Neighborhoods . . . . . . . . . . . . . . . . . . 22 
14 Appendix Tables $\quad 44$

14.1 Balance . . . . . . . . . . . . . . . . . . . . . . . . . . 44

14.2 Alternative Models . . . . . . . . . . . . . . . . . . . . . . . . . 45

14.3 Exclusion Tests . . . . . . . . . . . . . . . . . . . . . . . . . . 48

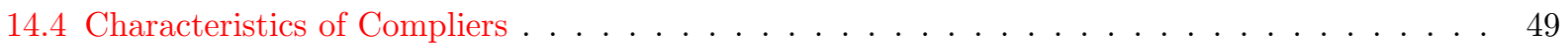

14.4.1 Expected Recidivism Given No Incarceration . . . . . . . . . . . . . . . . . . . 49

14.4.2 Expected Time-Served Given Incarceration $\ldots \ldots \ldots \ldots$

15 Data Appendix $\quad 51$

15.1 Initial Cleaning . . . . . . . . . . . . . . . . . . . 51

15.2 Identifying Sentences . . . . . . . . . . . . . . . . . . . . . . . 52

15.3 Constructing a Case-Level Dataset . . . . . . . . . . . . . . . . . 53

15.4 Tracking Individuals . . . . . . . . . . . . . . . . . . . . . . . 54

15.5 Matching Court Records to Prison Records . . . . . . . . . . . . . . . . . . . . 54

15.6 Combining Cases into Episodes . . . . . . . . . . . . . . . . . . . . 54

15.7 Treatment Variable Creation $\ldots \ldots \ldots \ldots \ldots \ldots \ldots \ldots$

15.8 Artificial Records of Recidivism Events . . . . . . . . . . . . . . . . . . . 55

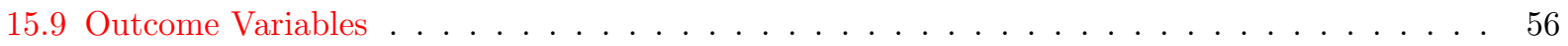

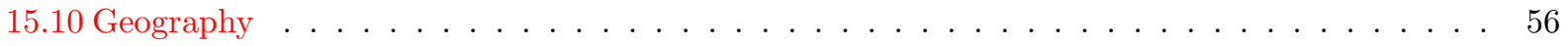

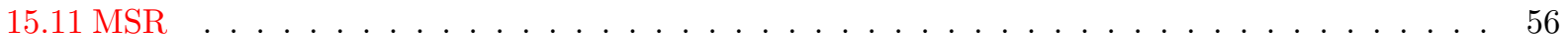

15.12 Waterfall of Data Restrictions . . . . . . . . . . . . . . . . . . 57

15.13 Leave-Out Mean Creation . . . . . . . . . . . . . . . . . . . . . . . . 58

16 Theory Appendix: Incapacitation and Deterrence $\quad 60$ 


\section{Introduction}

Between 1970 and the Great Recession in 2008, per-capita prison populations in the United States grew by roughly $400 \% .{ }^{1}$ Since then US incarceration rates have fallen, but they remain roughly $300 \%$ higher than their 1970 levels. A significant literature explores both the causes and consequences of this prison boom. Raphael and Stoll (2013) and Neal and Rick (2016) show that changes in sentencing policies, adopted by states during the 1980s and 1990s, drove the rise in prison populations. Advocates of these sentencing reforms argued that more severe sentences would both incapacitate and deter offenders. Many of the studies we review in the next section find that, in the short term, prison sentences reduce the likelihood of new charges by incapacitating offenders. However, existing studies reach different conclusions about the value of prison time as a deterrent for future criminal behavior. Theory offers no clear guidance concerning the expected impacts on incarceration on long-term recidivism rates. Prison likely increases the salience of punishment, and some prison systems may provide valuable rehabilitation programs. On the other hand, prison interrupts ties to employment, family, and community while exposing offenders to persons with long histories of criminal activity.

We exploit the random assignment of judges to felony court cases in Chicago, IL, to evaluate the overall impacts of incarceration on future offending. Relative to much of the previous literature, we have larger samples and the capacity to measure recidivism over longer horizons. These features allow us to explore heterogeneous responses to incarceration and also to document that a number of judges who are relatively harsh when sentencing first offenders are relatively lenient when sentencing repeat offenders, and vice versa. Thus, in a departure from the previous literature, we employ sample-specific measures of judge severity and estimate separate models for first offenders and repeat offenders.

Our Local Average Treatment Effect (LATE) estimates of the impacts of incarceration on recidivism are quite different among first offenders versus repeat offenders. ${ }^{2}$ Many readers may expect this result. Repeat offenders are the select sample of former first offenders who were not deterred by whatever punishment they received for their first offense. Given this form of dynamic selection, the distributions of unobserved offender traits that shape how incarceration impacts future recidivism are likely different among first offenders as opposed to repeat offenders. In addition, many sentencing rules or guidelines either require or encourage judges to sentence repeat offenders more harshly. Given existing data, we cannot know exactly how these two factors interact, but both suggest that first offenders who are marginal candidates for incarceration sentences may be quite different than their counterparts in the repeat-offender sample.

We report impacts of incarceration on recidivism rates at annual horizons that extend to seven years after sentencing. At all horizons, we find that incarceration reduces recidivism rates among first offenders. At longer horizons, the magnitudes of these reductions are greatest among first offenders who are not charged with drug crimes and among first offenders who do not live in high-crime areas. Among repeat offenders, we see evidence that incarceration creates incapacitation effects during the first three years after sentencing. However, we find no lasting impact of incarceration on recidivism rates. At the five-year mark and beyond, we find no evidence that incarceration impacts recidivism rates of repeat offenders.

We then examine the characteristics of the compliers in our first and repeat offender samples. Compliers are marginal in the sense that whether they receive incarceration sentences hinges on the severity of the judges assigned to their cases. The compliers in the first-offender sample who do not receive an incarceration sentence have high expected rates of recidivism. Further, among incarcerated compliers in both the first and repeat-offender samples, over half serve less than one year, and over ninety percent serve less than 4 years. Taken together, these patterns indicate that our results for first offenders imply large negative impacts of incarceration on recidivism at all horizons because incarceration treatment generates both important incapacitation effects and long run deterrence among first offenders who are marginal

\footnotetext{
${ }^{1}$ See Carson (2019).

${ }^{2}$ We define a repeat offender as a defendant who has been charged with a felony in a prior case. In our data, over ninety percent of cases end with some type of conviction, but cases end in many different ways that are all associated with different disposition codes. Our repeat offender definition is easier to implement and less prone to measurement error than one that defines repeat offenders as those convicted of previous felonies or convicted in previous cases that began as felony cases.
} 
candidates for incarceration. We see no evidence that incarceration produces lasting deterrence effects among compliers in the repeat-offender sample.

We show that our key results hold when we restrict attention to only Black defendants. We also find suggestive evidence that the deterrence effects we document among first offenders are particularly large among first offenders who are not part of the drug trade or did not grow up in a high-crime neighborhood. We find no evidence that incarceration creates lasting reductions in recidivism among any group of repeat offenders.

Black defendants from high-crime areas are over-represented in our sample of repeat offenders relative to our sample of first offenders. Thus, we investigate the possibility that over-policing may raise measured recidivism rates in our repeat-offender sample. Specifically, we examine how supervision by parole officers impacts the arrival of new charges and conclude that potential over-policing of repeat offenders during parole does not explain the differences between our results for first and repeat offenders. ${ }^{3}$

In sections 11 and 12, we connect our results to previous research and discuss how our results inform debates about the large recidivist premium that is encoded in most sentencing rules and guidelines. Over the past four decades, legal systems around the world have made sentencing more punitive for repeat offenders relative to first offenders, and our findings indicate that this trend may have gone too far.

\section{Literature Review}

We seek to understand how future criminal justice outcomes of an offender change when he receives more or less severe punishment because the court randomly assigned a more or less severe judge to his case. These results help us better understand how actual punishments impact the life courses of different types of offenders, but we would require additional assumptions about the supply of criminal behavior to map our results into questions about the impacts of broad changes in sentencing or parole policies on the evolution of market-level measures of crime over time. Here, we review previous attempts to answer the narrow set of questions that we address. ${ }^{4}$

Loeffler (2013) also employs randomized cases from Cook County to examine the impact of prison sentences on recidivism. His data cover cases assigned during the years 2000-2003. He examines five-year recidivism rates, but he does not report separate results for first versus repeat offenders. For reasons we explain in our Data Appendix (section 15), Loeffler's sample is much older than our sample, and we believe that around 80 percent of the offenders in Loeffler's sample are repeat offenders. Loeffler reports no significant impact of prison on five-year re-arrest rates. Among repeat offenders, we also find no impact of prison on the five-year incidence of new charges.

Green and Winik (2010) exploit random assignment to one of eight judicial calendars in the District of Columbia during 2002-2003. Their sample contains roughly one thousand cases, and while they find some evidence that incarceration increases future recidivism, their treatment impact estimates are generally insignificant. Nagin and Snodgrass (2013) employ data on random judge assignments from six counties in Pennsylvania. The authors examine impacts of incarceration on recidivism at several different time horizons and find no evidence of significant impacts. Compared to much of the related literature, the sample of offenders in this study contains smaller fractions of minority offenders and economically disadvantaged offenders.

Mueller-Smith (2015) exploits random judge assignment in Harris County, Texas. He estimates a panel data model where the probability of committing a crime in this quarter is a function of not only

\footnotetext{
${ }^{3}$ We do find evidence that post-release supervision increases the rate at which former inmates re-enter prison. More than one-third of returns to prison during post-release supervision do not result from new criminal charges but arise instead from technical violations of rules concerning housing, mobility, employment, drug testing, etc. that former inmates must follow.

${ }^{4}$ We focus on individual treatment impacts. We are not attempting to quantify the equilibrium impact of policies that increase the likelihood of incarceration for all offenders. We do not address the rate at which other potential criminals increase their criminal activities when criminal competitors are incapacitated, whether the prospects of more severe sanctions deter criminal conduct among those who have never been charged, or how larger adult prison populations impact criminal behavior among youth from communities with high adult incarceration rates.
} 
incarceration status in this quarter but also several measures of the person's incarceration history. Muller-Smith uses the history of past courtroom assignments for offenders and the historical patterns of sentencing severity in different courtrooms to develop instruments for each endogenous measure of current incarceration or incarceration history. He concludes that incarceration reduces crime in the short-term through incapacitation but raises long-term re-offending rates.

Dobbie et al. (2019) exploit random judge assignment in Sweden. They find that incarceration has little impact of criminal behavior six years after sentencing, but incarceration does lower future earnings and have negative impacts on family structure. Norris et al. (2021) examine thirty years of court records from three counties in Ohio. They examine a large sample of criminal cases randomly assigned to judges and conclude that incarceration generates incapacitation effects that reduce crime for three years following sentencing. However, beyond three years, they find no impacts of incarceration on recidivism. ${ }^{5}$

Bhuller et al. (2020) employ variation from random judge assignment in Norway. They follow offenders for five years and find that, overall, incarceration creates noteworthy drops in recidivism. They do not estimate separate models for both first versus repeat offenders but do present appendix results that document particularly large negative impacts of incarceration treatment among first offenders. They conclude that incarceration reduces recidivism in Norway, in part, because prison time increases employment rates among persons who were not employed prior to arrest. Compared to corrections systems in the US, prisons in Norway place greater emphasis on training and rehabilitation programs.

Roodman (2017) surveys the literature on random assignment of judges as well as other designs that seek to identify causal links between the punishment offenders receive and their future behaviors. He concludes that incarceration does produce an initial reduction in the new crimes committed by an offender. However, he argues that this incapacitation effect does not generally translate into lower rates of offending post incarceration.

Harding et al. (2017) use data from the Michigan Department of Corrections to compare convicted offenders who are sentenced to probation versus prison by randomly assigned judges. Their design differs from many others in the literature because only defendants who receive prison or probation remain in the sample. Cases that end in dismissal or not guilty verdicts are not included. Nonetheless, like many other studies, they find that prison creates short-term incapacitation effects but no long-term impact of prison on recidivism.

Another literature explores random assignment of criminal cases in juvenile court. Aizer and Doyle (2015) use random judge assignment to examine the impacts of incarceration among juvenile offenders in Cook County, IL. They find that incarcerating juvenile offenders increases rates of adult incarceration resulting from future criminal charges. They argue that this outcome may be driven in part by the fact that juvenile incarceration also reduces high school completion rates. Eren et al. (2018) use a similar research design to explore the impacts of juvenile incarceration on future education and criminal justice outcomes among juvenile offenders in Louisiana. They find no overall impact of juvenile incarceration on high school completion. However, the state adopted a reform that raised graduation requirements during their sample period, and among cohorts not affected by this reform, they do find evidence that juvenile incarceration reduces high school completion. They find that juvenile incarceration raises adult convictions for drug crimes, but they also find that juvenile incarceration reduces adult convictions for property crime. Taken together, these two studies offer little evidence of long-term gains from incarcerating marginal juvenile offenders and several results that are consistent with the hypothesis that juvenile incarceration enhances the likelihood that a young offender will be involved in crime as an adult.

A different literature explores the impacts of variation in time-served in prison that arises from discontinuities in rules that govern sentencing or release from prison. Rose and Shem-Tov (2021) exploit sharp discontinuities in North Carolina's sentencing guidelines and use regression discontinuity models to estimate the impact of receiving additional prison time, among defendants whose prior record places them just over thresholds that mandate more severe sanctions. They report that prison time reduces future rates

\footnotetext{
${ }^{5}$ Both Norris et al. (2021) and Dobbie et al. (2019) are primarily concerned with the impact of parental incarceration on children. They exploit similar research designs, but report quite different results. In Ohio, parental incarceration often benefits children. In Sweden, parental incarceration harms children, especially those from less advantaged families
} 
of recidivism, and incapacitation appears to be the most important force driving these reductions. Since the sentencing grid system in North Carolina leans heavily on an offender's criminal record, those impacted by these discontinuities are mostly repeat offenders. ${ }^{6}$

Kuziemko (2013) exploits discontinuities in Georgia Parole Board guidelines to study the impacts of differences in time-served on recidivism. Here, the study population is not defendants facing charges but sentenced inmates in prison. She finds that an extra month in prison reduces recidivism rates three years after release by 1.3 percentage points. If Georgia prisons resemble Illinois prisons, most inmates have substantial criminal records. Thus, at first glance, the noteworthy impact of prison time on recidivism that Kuziemko (2013) reports appears to be in conflict with our results for repeat offenders, but in fact, the two studies address different questions that need not have similar answers. We return to these results in section $11 .^{7}$

\section{Data}

We employ two key data sources. Our most important data are electronic records from the office of the Clerk of the Circuit Court of Cook County, IL. We employ records that describe felony criminal proceedings held between 1984 and 2018 in the Leighton Criminal Court Building. Leighton is the main criminal courthouse for the Criminal Division of the Circuit Court of Cook County. Defendants charged with felonies in Chicago, IL, are almost always arraigned in this court. Here, we focus on a set of felony cases that the Presiding Judge of the Criminal Division assigned to judges using a computer program called the randomizer. ${ }^{8}$ We also employ records from the Illinois Department of Corrections (IDOC) that provide information about admissions to prison, exits from prison, and expected terms of Mandatory Supervised Release (MSR), which is Illinois' parole system. The data cover 1990 through 2014. We use these data in concert with court records to create measures of sentencing treatments and recidivism that are cleaner than measures based on the court records alone. We examine recidivism over seven year horizons, so our analysis sample contains cases that began during the years 1990 through 2007.

\subsection{Pathways in the Criminal Justice System}

We combine records from several different sources to create our measures of incarceration sentences, recidivism, and future imprisonment. Institutional details specific to Cook County, IL, inform how we do this. Figure 1 is a diagram of the criminal justice system in IL.

The starting point for our work is the Criminal Division of the Circuit Court of Cook County. Courts assign cases to judges, and almost all defendants make one of four possible transitions. First, they may face no consequences and leave court under no supervision. This happens if the case does not result in a conviction. Second, the defendant may be assigned to a small program run by the Cook County Sheriff called the Cook County Department of Corrections (CCDOC) Bootcamp. This program involves four months of local incarceration and participation in special programs, followed by eight months of regular contact with persons working under the Sheriff. However, these defendants never receive formal supervision from a regular probation or parole officer. ${ }^{9}$

\footnotetext{
${ }^{6}$ Estelle and Phillips (2018) exploit sentencing guidelines in Michigan, but their data do not allow them to calculate marginal sentences. They have the nominal sentence "uttered" in court but do not have information about credits for time-served awaiting a verdict. They report varied results concerning the impact of nominal sentences. Results vary with crime category, gender, and region of the state.

${ }^{7}$ In section 11, we also discuss Agan et al. (2021). They too find stark contrasts between treatment impacts for first offenders versus repeat offenders. However, treatment in their context is not imprisonment. They consider decisions by prosecutors to drop charges against misdemeanor defendants. As we explain in section 11, differences in treatments and differences in the compositions of complier sets make it difficult to say how our results should compare to theirs.

${ }^{8}$ We purchased electronic records from the Clerk's Office. These records do not provide complete demographic information for defendants who are not convicted. So, we supplement these records with data that the Chicago Data Collaborative has complied from public court records. See Appendix section 15 for more details.

${ }^{9}$ This program was in operation during much of our sample period, but it is no longer an option for sentencing in Cook County.
} 
Third, some defendants receive probation. The county assigns these defendants a probation officer who monitors their compliance with the conditions of their probation. If these defendants violate the terms of their probation or face charges for new crimes, the judge that sentenced them to probation decides whether to revoke their probation and send them to prison. If these defendants complete probation successfully, they face no further supervision.

Fourth, some defendants receive prison sentences. These defendants never go straight from prison to living with no supervision. All prisoners released from IDOC must serve a period of MSR under the direct supervision of a parole officer, and a Prisoner Review Board (PRB) conducts hearings that evaluate alleged MSR violations. ${ }^{10}$ As with probation, those who complete MSR without incident face no further supervision. However, those who violate the terms of their MSR can end up in court again (where they will be assigned to a new judge), in a hearing before the PRB, or both.

The Appendix materials in section 15 provide more details, but two key features of the system figure prominently in the creation of our analysis sample and the rules we use to code both sentences and criminal histories for offenders. First, persons who face charges for new crimes while on probation return to their original sentencing judge, but persons who face new charges while on MSR do not. Second, the punishments assigned to persons who commit new crimes while on MSR often reflect the input of two decision makers: their new judge and the PRB.

\subsection{Court Data: Randomized Cases and Probation Procedures}

In Cook County, the Presiding Judge of the Criminal Division assigns cases randomly among a set of judges who occupy positions known as calls. A judge with a call is in charge of a courtroom and a calendar of cases. Judges without a permanent call are known as floaters. Floaters fill in when judges who do have a call are sick, on vacation, or temporarily absent. Section 15 describes how we identify judges who have their own calls and the cases that the court randomly assigned to these calls. Here, we briefly discuss the types of cases that are not eligible for random assignment. ${ }^{11}$

Criminal cases go through several review steps before they are eligible for random assignment, and some cases never make it to the randomization step. Local police arrest and charge defendants, but the State's Attorney (SA) may drop cases during a process called felony review. Felony review involves only a cursory examination of the case. So, among cases that pass felony review, prosecutors quickly drop some cases and preliminary hearing judges dismiss others. Finally, among cases that remain, the court does not randomly assign every case.

The Presiding Judge assigns several types of cases directly to specific calls. First, as we note above, persons who commit a new crime while on probation return to the judge who sentenced them to probation. Second, for much of our sample period, the court diverted many drug cases to special narcotics courts. Third, the Criminal Division also operates Problem Solving Courts that give defendants opportunities to participate in programs that address specific rehabilitation needs. The Rehabilitation Alternative Probation (RAP) program offers drug treatment. The Mental Health and Veterans courts offer special services as well. Fourth, the Attorney General of Illinois, not the local SA, prosecutes all cases that involve fraud against the State of Illinois, and these cases also appear to be exempt from random assignment to judges.

Although randomization is the norm for all other cases, no state law requires random assignment. So, the Presiding Judge of the Criminal Division can legally assign any case directly to a judge. Nonetheless, the prosecutors, judges, and defense attorneys we interviewed all believe that such exemptions are exceedingly rare and restricted to a small number of high-profile cases. ${ }^{12}$ If a case is eligible for random assignment, the assignment occurs three business days before the arraignment date set during the preliminary hearing.

\footnotetext{
${ }^{10}$ The PRB has no discretion over when MSR begins or the length of MSR spells. The sentencing statutes and sentencing credits given by the prison system for satisfactory behavior determine release dates and the scheduled length of MSR.

${ }^{11}$ Our discussion of cases assignments draws on several sources. Yet, we are most grateful to Judge Lawrence J. Fox who invited us to attend arraignment hearings with him and generously answered numerous questions.

${ }^{12}$ We do not include cases that involve the most serious violent crimes. So, we have no reason to believe that the cases in our analysis sample were not randomized. Randomization is clearly the default procedure. See Bogira (2005).
} 
Representatives of the Presiding Judge, the Clerk of Court, and the SA supervise the random assignment of each case to a call. The Presiding Judge announces each assignment during the subsequent arraignment hearing.

We start our judge selection process by identifying judges who held their own call in the Leighton Criminal Court Building during the period 1990 to 2007. We exclude two of these judges because they also held calls linked to Problem Solving Courts, and we exclude eight judges who, at some point, were clearly tasked with handling overflow drug cases as part of their primary call. ${ }^{13}$ Finally, we eliminate judges who did not receive at least 500 randomly assigned cases during our sample period that involve male defendants. We employ this rule to increase the precision of various measures of judge severity that we employ in our empirical work. These restrictions yield a sample of 44 judges. Our analysis sample contains 70,581 cases assigned to these judges. These cases involved 55,285 unique defendants.

We include only male defendants in our estimation samples. Some judges may treat male and female defendants differently, and the impacts of incarceration may be gender-specific. Further, we do not have enough female cases to test for these forms of heterogeneity. In Cook County, just over one in ten cases involve female defendants. No judge in our sample received 500 randomized cases involving female defendants, and less than half handled as many as 50 such cases.

Our court data begin in 1984 and contain all felony charges filed in any court in Cook County. Our empirical models separate first and repeat offenders, and then track future recidivism events that occur after randomly assigned judges deliver initial sentences to defendants. In order to correctly identify first offenders, we must look back in time to make sure that a given defendant has not been charged with a felony in the past. Since Illinois defendants age 17 and over usually face criminal charges in adult courts and our court data begin in 1984, we restrict our attention to defendants born after 1966. Given this restriction, we see all prior felony charges filed in Cook County against any defendant in our estimation samples.

As we explain next, we combine court records and prison records to create more accurate measures of sentencing outcomes and more complete charge histories for the defendants in our analysis samples. IDOC data are not available before 1990 or after the end of 2014. Since we track recidivism events for seven years after sentencing, we examine randomly assigned cases filed between 1990 and the end of 2007.

\subsection{IDOC Data: Effective Sentences and Prior Cases}

Here, we explain how we employ prison records when creating measures of sentencing outcomes for individual cases as well as charge histories for individual offenders. Defendants rarely serve their full sentence. While in prison, inmates receive good time credits and other credits awarded by the prison warden. Further, even before entering prison, most receive credit for time in jail between arrest and sentencing. Court records provide only indirect evidence concerning total jail time and often fail to reveal how much time, if any, a judge is effectively sentencing an offender to serve in state prison. IDOC data contain explicit records of time-served credits that allow us to gain more precise information about the time that sentenced prisoners are expected to serve as well as admission and exit records that often reveal how much time prisoners did serve.

Some defendants in our data receive so much credit for the time they served in jail before sentencing that their sentences to IDOC do not require them to serve an additional spell of incarceration. We do not count their sentences as incarceration treatments. ${ }^{14}$ IDOC records concerning credits for jail time, admission

\footnotetext{
${ }^{13}$ We have attempted to document these assignments. However, the Clerk of Court's Office failed to locate the Special Orders of the Presiding Judge of the Criminal Division for the years covered by our sample. So, we do not have written records of these assignments. However, these eight judges all had years where drug cases accounted for at least 78 percent of their cases, and seven had years where drugs cases accounted for more than 90 percent of their cases. Some judges in our sample began their careers in special narcotics courts but later occupied their own regular calls. We keep these judges in our sample, but we only use cases assigned to their regular call.

${ }^{14}$ Media reports discuss a practice called dress-in-dress-out. Defendants who dress-in-dress-out go through the admission process at a state prison only to be released a few hours later. See https://www.chicagotribune.com/investigations/ct-jailprison-turnaround-met-20150412-story.html and Troyer (2014).
} 
dates, and exit dates allow us to better identify these cases.

IDOC admission and exit records also help us identify all persons who, between 1990 and 2014, entered or left prison after being sentenced to prison by a judge outside Cook County. Thus, we are able to identify some individuals who are facing their first charge in Cook County but are not really first offenders because they have already served prison time associated with a sentence from a court outside Cook County. Further, these records allow us to identify defendants who were randomly assigned to a judge in Cook County, sentenced to probation or prison, and then later sentenced to prison by a judge in another county. The charge that created this latter prison sentence would never appear in our Cook County court records, but the prison records allow us to mark the offender as a recidivist.

\subsection{IDOC Data: Mandatory Supervised Release and Recidivism}

IDOC data on admissions to prison from MSR are also useful. When police arrest someone on MSR, they often notify the defendant's parole officer. In many cases, the parole officer arranges to have the offender released from jail and returned to prison for a hearing before the PRB. The PRB often revokes the offender's MSR and keeps him in prison. IDOC may transport the offender back and forth between prison and court as his case proceeds, and often the judge assigned to this new case will hand down a new prison sentence. Or, the judge may dismiss the case and let the prison time associated with the PRB's MSR revocation stand as the punishment for the new crime. In such cases, we still record the dropped charge as a new recidivism event, and we code the outcome of the cases as a sentence to prison. However, we do not count prison admissions linked to purely technical MSR violations as recidivism events. ${ }^{15}$

Among offenders who are on probation, it is easier to separate recidivism events from technical violations. Cook County probation officers have no police powers. They do not investigate potential crimes. They cannot arrest probationers who are under their supervision, and they cannot file warrants that require the Sheriff to detain probationers whom they suspect of wrongdoing.

A person on probation in Cook County reports regularly to his probation officer, but he is ultimately under the supervision of the judge who sentenced him to probation. In the vast majority of instances where an offender commits a new crime while on probation and a Cook County judge revokes the offender's probation, the court will record a new case associated with the new crime, and these same records will provide the outcome of the case and any resulting sentence. In Cook County, a probation revocation linked to a technical violation of probation is not evidence that the offender committed a new crime. ${ }^{16}$

\section{$3 \quad$ Empirical Model}

Most of our empirical work involves 2SLS regression models that estimate the impact of sentencing decisions on future charges for defendants. The treatment variable in these models is an indicator variable that equals one if the defendant receives a sentence that requires him to serve an incarceration spell in either the CCDOC Bootcamp or an IDOC prison. Our first stage is

$$
\tau_{j(i, t)}=z_{j(i, t)} \delta+x_{i t} \gamma+e_{i t}
$$

where,

\footnotetext{
${ }^{15}$ During our sample period, there were always more than a dozen ways to violate parole without committing a new crime. Prison spells that begin because a parolee violates a technical condition of MSR typically last just a month or two. However, MSR admissions that we link to new charges usually produce much longer spells of incarceration.

${ }^{16}$ Kuziemko (2013), Rose and Shem-Tov (2021), and Yang (2017) assert that when a defendant is sentenced to probation and later the sentencing judge revokes the probation sentence and sends him to prison, the judge likely has evidence that the offender engaged in additional criminal activity while on probation, even if the court records the probation revocation as the result of a technical violation of probation. While this may be true in many jurisdictions, experts within the Adult Probation Department informed us that this is not true in Cook County.
} 
- $j(i, t)$ is a mapping that returns the judge $j$ that the court assigns to defendant $i$ at time $t$.

- $\tau_{j(i, t)}$ is the treatment that judge $j(i, t)$ assigns to defendant $i$ at time $t$.

- $z_{j(i, t)}$ is the severity of judge $j(i, t)$.

- $x_{i t}$ is a matrix of characteristics that describe defendant $i$ and the charges against him at $t$.

- $e_{i t}$ captures unobserved factors that influence sentencing for $i$ at $t$.

Here, $i$ does not index cases within a time period $t$. Rather, $i$ is an index over all defendants in our data. We use the notation $j(i, t)$ to remind readers that the same defendant $i$ may appear in many different cases that are randomly assigned to different judges at different points in time, $t$. Thus, when we present results for first offenders, we report HAC standard errors that reflect clustering at the judge level, but we use two-way clustering at the defendant and judge level when producing standard errors for our repeat offender results. ${ }^{17}$

Our second stage equation is

$$
y_{i t s}=\tau_{j(i, t)} \theta_{s}+x_{i t} \beta_{s}+v_{i t s}
$$

$y_{i t s}$ is an indicator that equals one if defendant $i$ sentenced at time $t$ is charged with a new crime before $t+s$. $v_{i t s}$ captures unobserved factors that influence criminal justice outcomes between $t$ and $t+s .{ }^{18}$ We also present results from the following reduced form equation:

$$
y_{i t s}=z_{j(i, t)} \alpha_{s}+x_{i t} \pi_{s}+u_{i t s}
$$

In all models, we employ the leave-out mean (LOM) of the treatment measure, $\tau_{j(i, t)}$, for judge $j(i, t)$ assigned to $i$ at $t$, as our measure of judge severity, $z_{j(i, t)} \cdot{ }^{19}$

$$
z_{j(i, t)}=\frac{\sum_{t^{\prime}} \sum_{\substack{i^{\prime} \neq i \\ j\left(i^{\prime}, t^{\prime}\right)=j(i, t)}} \tau_{j\left(i^{\prime}, t^{\prime}\right)}^{*} 1}{\sum_{t^{\prime}} \sum_{\substack{i^{\prime} \neq i \\ j\left(i^{\prime}, t^{\prime}\right)=j(i, t)}} 1}
$$

Here, $\tau_{j\left(i^{\prime}, t^{\prime}\right)}^{*}$ is the deviation of $\tau_{j\left(i^{\prime}, t^{\prime}\right)}$ from its expected value given the date the case is assigned and possibly other characteristics of the case. We discuss how we create $\tau_{j\left(i^{\prime}, t^{\prime}\right)}^{*}$ in section 4.3.

\subsection{Assumptions}

We maintain the standard assumptions that define valid instruments in our setting.

\footnotetext{
${ }^{17} \mathrm{HAC}$ standard errors, clustered at the judge level, are appropriate if we think of the asymptotic distribution of our 2SLS estimator as the limit achieved by letting the number of judges grow, while holding the cases the each judge handles fixed. In this case, our LOM measures of judge severity, $z_{j(i, t)}$, always share a common estimation error component within judge. If instead, we consider holding the number of judges fixed and letting the number of cases handled by each judge grow, there is no reason to cluster, given random case assignment. We have also produced Huber-White standard errors for our results. In some cases these standard errors are slightly larger, and in others they are slightly smaller. None of these differences change the conclusions our results imply.

${ }^{18}$ We engage in a slight abuse of notation. $t$ marks both the date of assignment and the date that the judge announces a verdict and, given a verdict of guilty, a sentence.

${ }^{19}$ We leave out the sentence assigned to $i$ at $t$, and we leave out sentences assigned at $t$ to any co-defendants of $i$. Among repeat offenders who appear in multiple cases, we leave out all cases that involve $i$.
} 
Assumption 1 - Independence: $\quad\left(e_{i t}, v_{i t s}\right) \Perp z_{j(i, t)}, \quad \forall i, j, t, s$

Assumption 2 - Rank: $\delta \neq 0$

Taken together, our first assumption and the specification of equation 2 impose an important exclusion restriction. Holding $\tau_{j(i, t)}$ constant, $z_{j(i, t)}$ has no impact on $y_{i t s}$. No unobserved decisions that judges make are components of $v_{i t s}$ that are correlated with judge severity.

Assumption 3 - Exclusion: $E\left(y_{i t s} \mid \tau_{j(i, t)}\right)=E\left(y_{i t s} \mid \tau_{j(i, t)}, z_{j(i, t)}\right) \quad \forall i, j, t$

Assumption 1 does not rule out the possibility that individual defendants may respond differently to incarceration. It simply requires that any individual heterogeneity in treatment impacts is orthogonal to $z_{j(i, t)}$. Nonetheless, how we interpret our $\hat{\theta}_{s}$ results does hinge on how individual-specific determinants of the impacts of incarceration are related to the sentences that judges assign to individual offenders.

As an illustration, let $v_{i t s}=v_{i t s}^{0}+\Delta_{i t s} \tau_{j(i, t)}$, and assume that $E\left(v_{i t s}^{0} \mid z_{j(i, t)}\right)=0$ and $E\left(\Delta_{i t s} \mid z_{j(i, t)}\right)=0$. Here, the error term in our recidivism equation takes on the value $v_{i t s}^{0}$ if the defendant receives a probation sentence and $v_{i t s}^{0}+\Delta_{i t s}$ if the defendant receives an incarceration sentence. If we also assume that $E\left(\Delta_{i t s} \mid \tau_{j(i, t)}, x_{i t}, z_{j(i, t)}\right)=0$, then our 2SLS method produces consistent estimates of $\theta_{s}$ for each horizon $s$, and $\theta_{s}$ is the Average Treatment Effect (ATE) of incarceration on recidivism over a horizon of length $s$. However, if judges assign offenders to treatments, $\tau_{j(i, t)}$, based on unmeasured defendant traits that are correlated with $\Delta_{i t s}$, then $E\left(\Delta_{i t s} \mid \tau_{j(i, t)}, x_{i t}, z_{j(i, t)}\right) \neq 0$, and 2SLS is not a consistent ATE estimator.

Imbens and Angrist (1994) demonstrate that, in this setting, 2SLS is a consistent estimator of the Local Average Treatment Effect (LATE) of incarceration. In our case, this local average is a weighted average of the expected impacts of treatment among compliers. Compliers are marginal candidates for incarceration. They would not receive prison from the most lenient judge but would receive prison from at least one more severe judge.

The Imbens and Angrist (1994) interpretation of our 2SLS results requires that we impose an additional assumption. The relationship between true judge severity and sentencing outcomes must be monotonic.

Assumption 4 - Monotonicity: If judge $j$ is more severe than $j^{\prime}$, then $\tau_{j(i, t)} \geq \tau_{j^{\prime}(i, t)} \forall(i, t)$.

In section 6.4, we present evidence that supports this assumption and also present evidence that supports the weaker assumption of average monotonicity spelled out in Frandsen et al. (2019).

\section{Variable Construction, Descriptive Statistics, and Balance}

Here, we discuss how we create the variables we employ in these empirical models and present basic descriptive statistics. We then present balance tests that support our claim that the cases in our sample were randomly assigned to judges.

\subsection{Sentencing Treatment}

The treatment indicator, $\tau_{j(i, t)}$, equals one if judge $j(i, t)$ assigns defendant $i$ a sentence at $t$ that requires $i$ to serve time in an IDOC prison or to serve four months in the CCDOC Bootcamp facility. This indicator is zero if the SA drops the case, the Court dismisses the case or reduces the charges to misdemeanors, the Court finds the defendant not guilty, or the Court finds the defendant guilty and sentences the defendant to probation. The indicator is also zero if the defendant receives a nominal sentence to prison but receives credit for time served in jail prior to sentencing that equals or exceeds the prison time required by his sentence. 


\subsection{Conditioning Variables}

The vector $x_{i t}$ contains characteristics of the defendant and the case filed against him. It contains a full set of controls for year, the offense class of the most serious charge against defendant $i$ at time $t$, and a full set of interactions between year and class. The year controls are needed to capture differences in unmeasured characteristics of offenders over time. The interactions between year*class control for changes over time in the mapping between the crime that defendants are convicted of committing and the punishments that judges are required or allowed to assign.

In Illinois, if a defendant is found guilty of a crime, both the minimum and maximum sentences that a judge may assign to the defendant are determined by the class of the crime. Over our sample period, the legislature changed the class designations for some offenses. Thus, in some years, the law affords judges fewer opportunities to exercise discretion. Taken together, the controls for year, class, and the interactions between year and class address the fact that randomized cases are drawn from different distributions of defendants over time, and for some types of cases, the sentencing rules that constrain judicial discretion also change over time.

The vector $x_{i t}$ also contains indicators for interactions between class and category of the most serious charge, as well as a set of indicator variables for the age of a defendant when his case begins. We include indicators for cases that involve multiple charges and cases that involve multiple defendants, and we include an indicator for defendants who live in high-crime neighborhoods. ${ }^{20}$

\subsection{LOM Measure of Severity}

We create $z_{j(i, t)}$, the leave-out mean (LOM) of $\tau_{j(i, t)}$ by first running regressions of $\tau_{j(i, t)}$ on our full set of defendant and charge characteristics, $x_{i t}$. We capture the residuals from these regressions and then average these residuals at the judge level, leaving out defendant $i$ 's case. We employ our full set of defendant and charge characteristics because, even within a given year, the average characteristics of randomly assigned cases may vary significantly among judges. ${ }^{21}$ While these LOMs are our preferred measures of $z_{j(i, t)}$, we also create a set of sentencing residuals by regressing $\tau_{j(i, t)}$ on just a vector of indicators for year of case assignment. Given random assignment, judge-specific averages of these sentencing residuals also provide consistent estimators of relative judge severity. In section 5.3, we demonstrate that these two methods for constructing LOM measures of sentencing severity, $z_{j(i, t)}$, yield similar 2SLS estimates of the impact of incarceration on recidivism at different horizons.

We average residuals over other first offenders if $i$ is a first offender and over other repeat offenders if $i$ is a repeat offender. As we note above, repeat offenders are, by definition, former first offenders who have already re-offended at least once. Further, we demonstrate below that the estimated impacts of incarceration treatment differ substantially for first versus repeat offenders. As a result, judges likely face different distributions of trade-offs when sentencing first offenders versus repeat offenders, and it would not be surprising to find that some judges who are relatively severe when sentencing first offenders may not be when sentencing repeat offenders, and vice versa.

Figure 2 shows that many judges do exhibit different relative severities when sentencing first versus repeat offenders. Panel A presents mean residuals by judge among cases that involve first offenders. Panels B and $\mathrm{C}$ present mean residuals by judge among cases that involve repeat offenders. In all three panels of Figure 2, we number judges by their severity rank in the first-offender sample, i.e. judge 44 is the most severe when dealing with first offenders. In Panels A and B, we order judges by these first offender severity measures, but in Panel C, we order judges by their average severity when dealing with repeat offenders.

\footnotetext{
${ }^{20}$ The Appendix materials in section 15 describe several different ways to define high-crime geographies. We use Chicago Community Areas as geographic units and rely heavily on homicide rates as an indicator of criminal activity. However, given several different approaches, we reach similar conclusions concerning which Chicago community areas are high-crime neighborhoods. These designations vary little over time during our 1990-2007 sample period, which ends before gentrification induced large shifts in spatial patterns of crime.

${ }^{21}$ We run these regressions separately for our samples of first and repeat offenders. See Appendix section 15.13 for details.
} 
We see considerable differences in the relative severity of judges when dealing with first offender versus repeat offender cases. For cases involving first offenders, Panel A shows that the difference between the most and least severe judge is roughly 14 percentage points. For cases involving repeat offenders, Panel C shows an even larger spread of about 21 percentage points. Further, in both panels, many of the positive and negative estimated judge effects are statistically different from zero.

However, Panel B, which plots the average judge severity when dealing with repeat offenders against the rank of judge severity when dealing with first offenders, clearly shows that judges who are severe with first offenders are not always severe with repeat offenders. The correlation between the judge effects presented in panels A and B is .32. This correlation is significant, with $p<.0324$, but it is well below one. Judge 39 is the sixth most severe judge when dealing with first offenders, but Panel $\mathrm{C}$ shows that judge 39 ranks in the bottom quartile of judge-severity when cases involve repeat offenders. Also note that four of the eight most lenient judges for first offenders record positive mean residuals in cases involving repeat offenders. ${ }^{22}$ Taken as a whole, these figures support our decision to calculate separate LOM measures within firsts offenders and repeat offenders.

\subsection{Outcome Measures}

Our key outcome measures are indicators for the presence of felony charges that arise from future alleged crimes. $y_{i t s}$ is an indicator for the presence of at least one new charge against defendant $i$ within $s$ months of sentencing. We report results for $s=12,24,36,48,60,72$, and 84 . We are able to see all charges filed in Cook County as well as all charges filed in other IL counties that result in recorded admissions to the state prison system, IDOC.

We also present results that describe how the MSR system in IL may impact measured recidivism and prison re-entry among offenders released from prison. We use information from both IDOC admission files and court records to date returns to prison. Roughly 40 percent of offenders who enter MSR during our sample period re-enter prison before they complete their MSR terms, and more than one-third of these re-entries are the result of technical violations of MSR conditions, e.g. failure to seek employment, failing a drug test, etc., that are not linked in any way to a new criminal charge.

\subsection{Descriptive Statistics}

Table 1 provides descriptive statistics for our two main analysis samples: first offenders and repeat offenders. Just under 48 percent of our total cases involve repeat offenders, and 41 percent of these cases began when the defendant was under MSR supervision. On average, repeat offenders are almost five years older than first offenders and have faced 2.64 prior felony charges.

Repeat offenders are more likely to be Black and more likely to live in high-crime areas. Repeat offenders are less likely to face charges in the lowest offense class, Class 4 , and they are more likely to face drug charges.

The differences in the demographic makeup of the two samples are noteworthy because the vast majority of prison inmates are repeat offenders. ${ }^{23}$ Repeat offenders are more than three times as likely to receive incarceration sentences, and conditional on receiving an incarceration sentence, repeat offenders are less likely to go to CCDOC Bootcamp and more likely to go to a state prison.

\footnotetext{
${ }^{22}$ All four differences between the point estimates in these pairs are significant at a .05 level.

${ }^{23}$ IDOC posts snapshots of the state prison population each June. The earliest file is for June 30, 2005. These data do not mark offenders who entered prison as a result of their first charge, but they do mark offenders who are serving their first prison terms. Based on these data and sentencing patterns in the court data we feel confident that, in June 2005, roughly four of every five IDOC inmates were repeat offenders.
} 


\subsection{Balance}

Our research design rests on the assertion that we have identified cases that the court randomly assigned. Table 2 presents regression results that speak to the validity of this assertion. In each regression, we project our LOM measure of sentencing severity on a set of year dummies and one of the defendant or case characteristics.

For reasons we discuss above, we estimate these empirical models separately for first and repeat offenders. Thus, if a case involves a first offender, we assign a LOM measure calculated within the sample of first offenders, and if a case involves a repeat offender, we assign an LOM measure calculated within the sample of repeat offenders. The standard deviation of our severity measure is .028 in the first offender sample and .043 in the repeat offender sample.

Table 2 presents balance tests for the combined sample, the first offender sample, and the repeat offender sample. The table contains 65 parameter estimates and associated p-values, and only one p-value is less than 0.1 .

We view these results as support for our claim that we have constructed a sample of cases that the court assigned to judges using the randomizer program. However, because our main LOM severity measures are created by summing residuals taken from projections of $\tau_{j(i, t)}$ on $x_{i t}$, and $x_{i t}$ contains many of the case and defendant characteristics in Table 2, some readers may doubt the power of these tests. We have therefore conducted additional balance tests. We repeated these balance tests using LOM measures that are averages of residuals taken from regressions of sentencing outcomes on only a vector of dummies for year of case assignment. Appendix Table 14.1 contains the results, and they are quite similar to those in Table 2. Once again, we present 65 parameter estimates and associated p-values, and only one p-value is less than 0.1.

In section 5.3, we present additional evidence that supports our claim that the judges in our samples receive randomly assigned cases.

\section{Impacts of Incarceration on Recidivism}

Table 3 presents our estimates of the impacts of incarceration on future recidivism. Panel A presents results for cases that involve first offenders. Panel B presents results for repeat offenders. Each panel presents results from seven 2SLS models. The dependent variable in each model is an indicator variable that equals one if an offender is charged with a new felony within $s$ months of sentencing, and the seven rows in each table present results for $s=12,24,36,48,60,72$, or 84 . Within each panel, the first stage is the same. See equation (1). In panel A, we employ LOM severity measures derived from sentences assigned to first offenders. In panel $\mathrm{B}$, we calculate $z_{j(i, t)}$ using sentences for repeat offenders.

The information below each panel provides context. $\bar{\tau}$ is the fraction of each sample that receives an incarceration sentence. As we note above, less than one in five first offenders faces incarceration, but two-thirds of repeat offenders receive incarceration sentences.

The $f(l)$ values give the density of expected incarceration times implied by the sentences assigned to defendants. Among first offenders, only about two percent receive a sentence with an expected time-served of more than four years. This represents just over ten percent of all prison sentences among first offenders. Among repeat offenders, incarceration sentences are more common, but long sentences are still rare. Less than five percent of repeat offenders receive sentences that produce expected prison spells greater than four years.

In both the first and repeat-offender samples, our LOM measures do predict variation in sentencing outcomes given our extensive controls for defendant and case characteristics. The F-stats associated with the null hypothesis that $\delta=0$ are 246 and 748 among first and repeat offenders, respectively. 


\subsection{First Offenders}

Among first offenders, the OLS and 2SLS results always share the same sign, but they are quite different. At all horizons, our 2SLS estimates of the impact of incarceration treatment on recidivism are more negative than the corresponding OLS estimates. For example, at horizons of 48 to 84 months, the OLS results indicate that first offenders who were sentenced to prison were four to eight percentage points less likely to have been charged with a new felony. Over the same horizons, the 2SLS results indicate that an incarceration sentence lowers future recidivism rates 23 to 30.6 percentage points.

This pattern is expected given common conjectures about judge behavior. Suppose judges are more likely to assign an offender to prison if the offender possesses unmeasured traits that raise the likelihood of re-offending when not incapacitated. In this scenario, the positive correlation between assignment to prison and unobserved propensities to re-offend bias OLS estimates of the impact of incarceration on future recidivism in a positive direction.

The LATE interpretation of our results indicates that, among first offenders who are marginal candidates for incarceration, incarceration generates substantial and statistically significant reductions in recidivism at all horizons. Even at horizons of 60 to 84 months, our negative treatment impacts imply reductions in recidivism, relative to the overall recidivism rates among first offenders, that range from just over $40 \%$ to a little more than $60 \%{ }^{24}$ Further, these results are not only statistically different from zero but also statistically different from the results we report for repeat offenders. In this table and others that compare results for first versus repeat offenders, estimates of treatment impacts that are statistically different among first versus repeat offender samples at a .1 significance level appear in bold font, while impact estimates that are different at a .05 level appear in bold italic.

In section 7 below, we provide a more detailed discussion of potential mechanisms that could generate these large negative impacts of incarceration on recidivism at long horizons. Here, we note that these results almost certainly reflect more than simple incapacitation effects. Only about seven percent of first offenders sentenced to incarceration remain incarcerated 60 months after sentencing. At 84 months, less than five percent remain.

The reduced form results for first offenders are also noteworthy. Consider two identical defendants who are randomly assigned to judges whose LOM severity measures differ by $.1 .{ }^{25}$ After seven years, the defendant assigned to the more severe judge is 1.86 percentage points less likely to have received a new felony charge, and the average recidivism rate at this point is .52. Thus, assignment to a harsh rather than lenient judge generates a lasting reduction in recidivism of roughly 3.6 percent relative to the population average. ${ }^{26}$

Our interpretation of these reduced form results does not require our monotonicity or exclusion assumptions. These results are not local average impacts for compliers. They are forecasting results that apply to the full sample of first offenders. If we randomly assign a judge with greater measured severity to a first offender, we reduce the likelihood that he will receive a new charge over the next seven years.

\subsection{Repeat Offenders}

However, the vast majority of incarceration sentences are punishments that judges assign to repeat offenders, and our results for repeat offenders are quite different. Over the first three years following sentencing, our reduced form results do indicate that judge assignment predicts recidivism, but the short-term reductions in recidivism associated with assignment to a severe judge are smaller among repeat

\footnotetext{
${ }^{24}$ Bhuller et al. (2020) follow Norwegian offenders for 60 months after sentencing. Their estimated average treatment impacts among all offenders are quite similar to our results for first offenders from Cook County at horizons of 48 and 60 months.

${ }^{25}$ Figure 2 shows that this is roughly the gap in average severity between the four most severe and the four least severe judges.

${ }^{26}$ The standard errors for the RF results may be too small, since we are using estimated proxies rather than true severity measures in the OLS regressions. We have also created Bootstrap confidence intervals for these RF coefficients. We resampled residuals within each judge, $j$, and created $2,000 \mathrm{LOM}$ severity measures for each $j(i, t)$ case. These Bootstrap confidence intervals are never larger than the confidence intervals implied by the RF standard errors in Table 3.
} 
offenders than among first offenders. In addition, judge assignment is completely uncorrelated with long-term recidivism among repeat offenders.

Our 2SLS results follow the same pattern. At every horizon, we report smaller impacts of incarceration sentences on recidivism among repeat offenders than among first offenders, and while our results for compliers in our repeat-offender sample do indicate that incarceration sentences create statistically significant reductions in the arrival of new charges over the first three years following sentencing, there is no evidence that incarceration sentences impact long-term recidivism among these compliers. At 60 months and beyond, the relevant estimated impacts of incarceration treatment on the likelihoods of a new charge are all .01 or less in absolute value.

In section 7, we further probe the stark contrasts between our first and repeat offender results and discuss what mechanisms are likely responsible for these patterns. Yet, first we establish that the results presented in Table 3 are quite robust.

\subsection{Robustness}

Table 3 shows that incarceration incapacitates compliers in both our first and repeat-offender samples over short horizons. Among first offenders, prison time also creates long-term reductions in recidivism rates. However, among repeat offenders, we find no evidence that incarceration impacts long-term recidivism.

Appendix Table 14.2 examines the robustness of these conclusions. Panel A contains results from three different 2SLS models. Model (1) employs the same LOM measures we use as instruments in the 2SLS models presented in Table 3, but this model includes indicators for year of case assignment as the only conditioning variables, $x_{i t}$. These results provide another check on our assumption that our LOM severity measures are orthogonal to individual case characteristics conditional on date of assignment. Among first offenders, these results follow the exact same patterns we observe in Table 3, but each estimated reduction in recidivism rates is roughly five percentage points greater. Since the standard errors on the treatment impacts estimates average .1 or more, these changes are small relative to the sampling distributions of these estimators. The results for repeat offenders are even more robust to changes in the conditioning set, $x_{i t}$. At all seven horizons, the results given only controls for year of assignment are within .02 of those reported in Table 3.

Models (2) and (3) employ LOM severity measures derived from residuals taken from regressions of sentencing outcomes on only a set of indicator variables for year of case assignment. ${ }^{27}$ Model (2) employs indicators for year of case assignment as the only conditioning variables, and Model (3) employs the full set of defendant and case characteristics that we employ in our main specification. Among first offenders, we again see that the absolute values of the implied reductions in recidivism created by incarceration sentences are smaller given our full set of conditioning variables. However, given both conditioning sets, we still find compelling evidence that incarceration produces long-term reductions in recidivism among first offenders. The results for 60, 72, and 84 months given Model (3), which employs our full conditioning set, are quite close the results we report for first offenders in Table 3. Further, none of the models presented in Panel A of Appendix Table 14.2 provide any evidence that incarceration produces lasting reductions in recidivism among repeat offenders, and at every horizon, the results for repeat offenders, given Models (1), (2), and (3), are quite similar to those reported in Table 3. No treatment impact estimate in these three columns differs by even .02 in absolute value from the corresponding entry in Table 3.

Panel B of Appendix Table 14.2 presents four different 2SLS models that employ the entire matrix of judge assignment indicators as instruments. We begin by running a standard 2SLS model, and again we run two different versions. The first employs only year of assignment indicators as conditioning variables and the second employs our full conditioning set. Although Figure 2 indicates that a significant number of our judges are clearly either more or less stringent than the average judge, we still fall short of guidelines that previous researchers have offered as rules of thumb for identifying potential bias in 2SLS estimators that

\footnotetext{
${ }^{27}$ Appendix Table 14.1 shows that these LOM measures are not correlated with defendant or case characteristics
} 
employ a large set of instruments. ${ }^{28}$ To address this bias concern, we re-estimate both 2SLS models using the UJIVE estimator developed in Kolesar (2013).

Whether we use standard 2SLS or UJIVE, we again find that controlling for the full set of conditioning variables yields results that imply slightly smaller reductions in recidivism among first offenders who receive incarceration sentences. However, as before, every set of results indicates that incarceration creates large and lasting reductions in recidivism among first offenders, and given our full conditioning set, the bias-corrected UJIVE results are almost identical to our main results for first offenders in Table 3. Over the seven horizons, the largest absolute difference between the two sets of treatment impacts is .014.

As in Panel A, our results for repeat offenders given the different models presented in Panel B are all quite similar, and no set of results differs in any noteworthy way from the results for repeat offenders reported in Table 3. Further, each bias-corrected UJIVE result, given the full conditioning set, is also within .014 of the corresponding estimate in Table 3.

The results in Panels A and B of Appendix Table 14.2 cover many estimators that are common in the literature that exploits random assignment of cases to judges or examiners to identify treatment impacts associated with their decisions. Loeffler (2013), who also worked with Cook County data explores another alternative estimator. He first creates residual severity measures for each judge. Given this set of measures, he defines a set of high-severity judges and a set of low-severity judges. Next, he drops cases assigned to judges that are not in either set. He then defines the following indicator as an instrument for treatment: $z_{j(i, t)}=1$ if $j$ is a high-severity judge, and $z_{j(i, t)}=0$ if $j$ is a low-severity judge. Finally, he runs 2SLS on the remaining sample.

We implement this procedure separately for first and repeat offenders by assigning the 15 judges with lowest measured severity to our low severity group and assigning the 15 judges with highest measured severity to our high severity group. We drop cases assigned to the remaining 14 judges.

Panel C of Appendix Table 14.2 presents the results. The sets of compliers in these analyses are slightly different. Here, the compliers are defendants who would receive no incarceration from the most severe judge in the $z_{j(i, t)}=0$ judge set but would receive an incarceration sentence from one or more judges in the $z_{j(i, t)}=1$ set. Nonetheless, the 2SLS results are quite similar to those in Table 3. At horizons greater than 36 months, the largest absolute difference is less than .022 .

Taken as a whole, the results from the eight alternative models presented in Panels, B, and C indicate that the patterns we highlight in Table 3 are quite robust. Incarceration sentences generate lasting reductions in recidivism for compliers in our sample of first offenders but not for compliers in our sample of repeat offenders. In the following section, we explore several other specification checks before digging deeper into the interpretation and significance of this clear difference between the responses of first and repeat offenders to incarceration sentences.

\section{Maintained Assumptions}

In section 3, we listed four maintained assumptions in our empirical work. Here, we discuss evidence that speaks to the plausibility of each assumption.

\subsection{Independence}

We assert that we have identified cases that the court randomly assigned to judges. Both balance tables, Table 2 and Appendix Table 14.1, show that our two sets of LOM severity measures are not correlated

\footnotetext{
${ }^{28}$ If we employ OLS standard errors, the first-stage F-statistics associated with the joint significance of the judge assignment indicators in our first stage are 4.64 and 7.32 respectively for first and repeat offenders, when we condition only on a vector on indicators for year of case assignment. The corresponding results are 5.64 and 7.87 if we condition on our full set of case and defendant characteristics. Staiger and Stock (1997) argue that values below 10 indicate that the asymptotic bias in 2SLS estimators may be significant.
} 
with measured defendant characteristics. In addition, Panels A and B of Appendix Table 14.2 show that the results from our various 2SLS estimators do not vary greatly when we change the conditioning set, $x_{i t}$. We always get similar results whether we condition on our full set of case and defendant characteristics or only a vector of indicators for year of case assignment. These patterns are consistent with our claim that cases are randomly assigned to judges.

\subsection{Rank}

A significant literature addresses the concern that the partial correlation between $z_{j(i, t)}$ and $\tau_{j(i, t)}$ may be non-zero but also small enough that our 2SLS estimates $\hat{\theta}_{s}$ are asymptotically biased. The F-statistics for the null $\delta=0$ are 246 for the first offender model and 748 for the repeat offender model. These values are well beyond the range of values that raise researcher concerns about weak instruments.

Further, the reduced form results, $\hat{\alpha}_{s}$, in Table 3 provide additional evidence that our instruments are not weak. Among both first and repeat offenders, the reduced-form impact of $z_{j(i, t)}$ on recidivism outcomes at 12 months is highly significant, $p<.01$. Since $\alpha_{s}=\theta_{s} * \delta$, these results provide additional evidence against the null $\delta=0 .{ }^{29}$

Finally, in Panel B of Appendix Table 14.2, we present results from 2SLS models that employ a vector of indicators for judge assignment as instruments. To address any concerns about bias that may arise from weak instruments, we also present bias-corrected UJIVE results. The UJIVE specification that contains our full set of controls for case and defendant characteristics produces results that are almost identical to our main results in Table 3. This agreement provides additional evidence that our results are not significantly affected by asymptotic biases associated with weak instruments.

\subsection{Exclusion}

In equation 2, judge $j(i, t)$ impacts $y_{i t s}$ by choosing whether to sentence defendant $i$ to incarceration, $\tau_{j(i, t)}$, but $j(i, t)$ makes no other decisions that impact $y_{i t s}$ conditional on $x_{i t}$. In Cook County and other court systems in the US, this exclusion restriction is quite strong. Felony convictions create a public record that may hamper a defendant's future efforts to obtain housing, employment, or education, and these harms may foster recidivism. ${ }^{30}$ In Illinois, judges not only assign sentences to guilty defendants, they also make many decisions that influence whether defendants are found guilty. Judges may dismiss cases they deem weak, and the SA may drop cases because he anticipates that a particular judge is going to dismiss the case. Finally, the vast majority of trials in Cook County are bench trials. In these trials, there is no jury. Judges decide whether the SA has proven the defendant guilty beyond a reasonable doubt.

Some judges whom we characterize as lenient, based on our LOM measure of sentencing severity, may also be quite prone to dismiss weak cases or impose relatively high burdens of proof in bench trials. These tendencies could impact recidivism among the defendants who enter their courtrooms by lowering the chances that these defendants acquire felony convictions.

To examine the impact of excluding the impact of judges on verdicts, we follow Bhuller et al. (2020) and estimate versions of our empirical models that include an additional control for the LOM of judge-specific conviction rates in both the first and second-stage equations. Appendix Table 14.3 presents results. The results are quite similar to those in Table 3. The pattern of results among both first and repeat offenders is the same, and in 11 of the 14 cases, the absolute differences between the estimated 2SLS impacts and the corresponding impact estimates in Table 3 are .02 or less. All 14 are within $.036 .{ }^{31}$

\footnotetext{
${ }^{29}$ As we note above, we have also created Bootstrap confidence intervals for these RF coefficients. These Bootstrap confidence intervals are never larger than the confidence intervals implied by the RF standard errors in 3.

${ }^{30} \mathrm{~A}$ large literature documents that many employers are reluctant to hire convicted felons. See Agan and Starr (2018), Holzer et al. (2003), and Holzer et al. (2006) as examples.

${ }^{31}$ Bhuller et al. (2020) note that as long as the LOM on incarceration does not help predict convictions conditional on the LOM on convictions and other controls for case and defendant characteristics, this approach is sufficient. There is no need to
} 


\subsection{Monotonicity}

Monotonicity fails if judge $j$ would be more severe than $j^{\prime}$ for some cases but not for others. We perform separate analyses for first and repeat offenders because Figure 2 provides evidence that some judges who are severe with first offenders are not severe with repeat offenders. However, it is still possible that monotonicity may not hold within samples of first offenders or repeat offenders.

To explore this issue, we create $\hat{\tau}_{j^{*}(i, t)}$, the likelihood that each offender $i$ faces incarceration given his characteristics, $x_{i t}$, and assignment to a reference judge, $j^{*}{ }^{32}$ We create these predicted values separately within our samples of first and repeat offenders. We then rank defendants in each sample by $\hat{\tau}_{j^{*}(i, t)}$ and divide both samples into quartiles. We run our first-stage regression within each of these eight quartile samples, and for both first and repeat offenders within each quartile, we find that the conditional correlation between $\tau_{j(i, t)}$ and our full sample LOM measure for $z_{j(i, t)}$ is positive and highly significant. The smallest p-value associated with these eight estimated positive slopes is less than .0001 .

We have repeated this exercise for both first and repeat offenders on subsamples of Black defendants and subsamples defined by the presence of drug charges in the case or whether the defendant lives in a high-crime neighborhood. In all 10 first-stage equations, we again find positive and highly significant conditional correlations between $\tau_{j(i, t)}$ and our full sample LOM measure severity measures. ${ }^{33}$

These results provide evidence in favor of our monotonicity assumption, but none represent a formal test of monotonicity. Frandsen et al. (2019) suggest replacing monotonicity with a weaker assumption that they call average monotonicity. Consider the following thought experiment. For each defendant $i$ in our first offender sample, consider the 44 sentencing outcomes that would result from assigning $i$ to each of our 44 judges. Then, calculate the correlation between these 44 defendant- $i$-specific outcomes and the 44 judge-specific measures of overall severity when sentencing first offenders, i.e. the measures plotted in Panel A of Figure 2 above. Repeat the exercise for repeat offenders using the overall judge severity measures in Panel C. If for each offender $i$, the correlation between the relevant measure of overall judge severity and the 44 defendant- $i$-specific outcomes is positive, then average monotonicity holds. Frandsen et al. (2019) argue that one way to judge the plausibility of average monotonicity is to (a) assume that strict monotonicity holds within a group that shares an observed characteristic, (b) calculate a set of judge-specific severity measures using only within-group variation, and (c) compute the correlation between the set of full sample judge severity measures and the group specific judge severity measures.

In section 8, we create LOM severity measures for both first offenders and repeat offenders that are specific to subsamples of Black offenders as well as subsamples defined by the presence of drug charges or residence in a high-crime neighborhood, and given these subsample-specific severity measures, we produce subsample-specific estimates of the impacts of incarceration on recidivism. Among both first and repeat offenders, we compute the correlations between our subsample-specific judge severity measures and our full-sample severity measures presented in Figure 2. These ten correlations range from .73 to .98, and the median is .85 .

These results suggest that, given our data, the weaker average monotonicity condition proposed by Frandsen et al. (2019) is a reasonable assumption. Under this assumption, our estimates of the impacts of incarceration on recidivism are still local average treatment effects (LATE), but the weights placed on the treatment impacts for different defendants in our complier sets may differ from the weights under strict monotonicity. ${ }^{34}$

estimate a model with both incarceration and conviction as endogenous treatments. We pass this test easily among both first and repeat offenders. The coefficients on the incarceration LOM severity measures are both small, and the associated p-values are .52 among first offenders and .25 among repeat offenders.

${ }^{32}$ Bhuller et al. (2020) perform a similar test. We define this hypothetical reference judge using the condition $z_{j *(i, t)}=0 \forall i, t$, but the choice of reference judge does not alter the percentile ranks of $\hat{\tau}_{j^{*}(i, t)}$.

${ }^{33}$ Among these ten slope coefficients, the three smallest are $.57, .69$. and .76 . The rest are .86 or higher.

${ }^{34}$ See page 16 in Frandsen et al. (2019). Given average monotonicity, compliers whose relative treatments, given assignment to different judges, are most highly correlated with relative differences in average severity among judges receive higher weights. 


\section{Incapacitation vs Deterrence}

In Table 3, our estimates of the impact of incarceration on recidivism are statistically different at longer horizons, but our estimates of the impacts of incarceration on recidivism are greater in magnitude among first offenders at every horizon. In this section, we present results concerning the compliers in our first and repeat-offender samples that allow us to flesh out the LATE interpretation of our results.

\subsection{Incapacitation}

At short horizons, we expect the impacts of incarceration on recidivism to be greater among first offenders if the returns from incapacitating compliers in the first offender sample are greater. We explore this issue by using a linear extrapolation method presented in Dahl et al. (2014). This method allows us to recover expected rates of recidivism, given a non-incarceration sentence, for both compliers and never takers. ${ }^{35}$ The method exploits the observation that all defendants who receive non-incarceration sentences from the most severe judge are never takers, while the defendants who receive an incarceration sentence from the least severe judge are a mixture of compliers and never takers. We apply this method separately to first and repeat offenders.

Appendix Table 14.4.1 presents the results. Several patterns are noteworthy. First, among both first and repeat offenders, compliers who receive a non-incarceration sentence because the court assigned their case to a lenient judge are more likely than never takers to receive new felony charges, and this pattern holds at each horizon. This result makes sense if the decision to assign incarceration to a defendant, at least in part, reflects a judge's assessment of the likelihood that the specific defendant will commit new crimes if he is not incarcerated. Consider a simple model where each defendant is characterized by a constant risk of recidivism given a non-incarceration sentence. Further, assume that each judge establishes a sentencing risk threshold and then sentences all defendants who pose recidivism risks greater than the threshold to incarceration. Finally, assume that more severe judges set lower risk thresholds. Given this model of judicial decision making, compliers are, by definition, marginal defendants who are more risky than never takers.

Second, the never takers in the repeat-offender sample exhibit higher rates of recidivism than the never takers in the first offenders sample. This result does not follow directly from any simple model of sentencing. However, we estimate that roughly 73 percent of first offenders are never takers but only 26 percent of repeat offenders are never takers. It may well be that, relative to the set of never-takers among repeat offenders, the never-takers in the first-offender sample contain a larger group of low-risk offenders. The criminology literature contains clear evidence that unobserved heterogeneity in individual propensities to engage in crime contribute to variation in individual criminal histories, and our repeat offenders are the select sample of former first offenders who have already been charged with at least one additional felony.

Finally, in contrast to our results for never takers, the compliers in the first-offender sample are more likely than compliers in the repeat-offender sample to receive a new felony charge, and this patterns holds at every horizon. This result would be expected in a world where judges show greater leniency when sentencing first versus repeat offenders. In terms of the simple model of sentencing described above, leniency could take the form of setting a higher risk threshold for sentences to incarceration. Such leniency for first offenders could be rooted in a desire to give defendants a "second chance," at least in part, because the sentencing guidelines in Illinois instruct judges to consider a lack of prior convictions as a mitigating factor that weighs against assigning incarceration. Further, when sentencing first offenders, judges may often have less information and therefore less confidence in their own assessments of the risks these defendants present. This uncertainty or ambiguity could make some judges more reluctant to assign incarceration sentences. ${ }^{36}$

\footnotetext{
${ }^{35}$ Never takers are the defendants who would not receive an incarceration sentence given any judge assignment.

${ }^{36}$ The fractions of always takers, those who would be sentenced to incarceration by all 44 judges, are .13 among first offenders and .52 among repeat offenders. This difference could reflect differences in the distribution of individual recidivism propensities among first and repeat offenders, but it likely also reflects that both legal rules and norms encourage judges to sentence repeat offenders more harshly.
} 
We do not have the data needed to discover exactly why compliers in the first-offender sample who receive non-incarceration sentences pose greater recidivism risks, but these gaps imply that the incarceration sentences for compliers in the first-offender sample should produce incapacitation effects that are larger than the corresponding effects among compliers in the repeat-offender sample, and the results in Table 3 are consistent with this expectation.

\subsection{Beyond Incapacitation to Deterrence}

Appendix section 16 presents a model of the impacts of incarceration on recidivism. Consider convicted offenders who are about to receive sentences. We summarize the sentence assigned to each defendant by the number of periods of incarceration, $m$, that his sentence requires. In Illinois, almost all non-incarceration sentences for felonies involve probation supervision. So, in this example, we associate the sentence $m=0$ with probation.

Given this environment, consider two groups of offenders. All offenders in both groups have just been convicted of the same crime at the same age. Further, given any sentencing treatment, all offenders share a common risk of recidivism at each future age, if they are not currently incapacitated by incarceration. Next, randomly assign one group to a sentence of $m=\tilde{m}>0$ periods of incarceration and assign the other group to probation, i.e. $m=0$. Assume that prison fully incapacitates potential offenders. So, if a prisoner is going to spend the current period in prison, the probability that he survives the current period without receiving a new charge is one. However, if an offender is not in prison, the probability that he survives the current period without a new charge is a function of age alone. Past experiences in prison or the community have no impact on age-specific offending rates among persons who are not incapacitated. ${ }^{37}$

This setup allows us to explore what the impacts of incarceration on recidivism would be in an environment where prison incapacitates offenders and shifts their risk of recidivism to later ages, but differences in past exposure to prison, to employment, to family, or to community networks have no impacts on the age-specific offending rates of non-incarcerated persons. Given this setting, we derive three results that place restrictions on how incarceration impacts recidivism through incapacitation and how these impacts of incapacitation evolve over time.

Our results for first offenders clearly violate one of these restrictions, while our results for repeat offenders do not. We interpret our results for first offenders as evidence that the experience of prison lowers age-specific offending rates after release.

Again, let $t$ equal the date of sentencing. Define $S\left(n \mid m, a_{t}\right)$ as the probability that an offender sentenced at age $a_{t}$ to an incarceration sentence of $m$ periods survives $n$ periods without receiving a new charge. Our three results characterize differences between the survivor functions for two groups of offenders who share a common age at sentencing and a common set of age-specific re-offending rates when not incarcerated. The first, $S\left(n \mid \tilde{m}, a_{t}\right)$, measures survival among the group sentenced to incarceration for $\tilde{m}>0$ periods. The second, $S\left(n \mid 0, a_{t}\right)$ measures survival among the group sentenced to probation. Section 16 demonstrates the following:

1. $\Delta\left(n \mid \tilde{m}, a_{t}\right) \equiv S\left(n \mid \tilde{m}, a_{t}\right)-S\left(n \mid 0, a_{t}\right)>0 \quad \forall n>0$

2. $\Delta\left(n \mid \tilde{m}, a_{t}\right)$ is increasing in $n$ for $n \leq \tilde{m}$

3. $\Delta\left(n \mid \tilde{m}, a_{t}\right)$ is decreasing in $n$ for $n>\tilde{m}$

\footnotetext{
${ }^{37}$ We do not require that all non-incarcerated persons of the same age face identical recidivism risks. This restriction simply makes it easier to verbally describe the logic behind our results. The proofs in Appendix 16 require two key assumptions. First, age-specific offending rates never reach zero for any offender type. Second, among compliers, any unobserved traits that impact age-specific offending rates are independent of sentencing treatment. Since we restrict our attention to randomly assigned cases and employ extensive controls for defendant and case characteristics, this assumption is a natural starting point. We also discuss qualifications to our results that could arise given specific violations of this assumption.
} 
The survivor function for those sentenced to incarceration, $m=\tilde{m}>0$, is always above the survivor function for those who are not, $m=0$. The difference between the two functions grows with time for $n \leq \tilde{m}$ because the number of new charges in the $m=0$ sample grows with time while the $m=\tilde{m}$ sample remains fully incapacitated. However, in period $n=\tilde{m}+1$, the same age-specific, one-period risk of offending applies to all offenders in both groups who have not yet received a new charge. Since the entire $m=\tilde{m}$ group is at risk at this point, but only a fraction of the $m=0$ sample remain at risk, we expect more new charges in the $m=\tilde{m}$ group during period $n=\tilde{m}+1$. Given a common age-specific risk of offending, these additional charges shrink but cannot eliminate the survival gap $\Delta\left(n \mid \tilde{m}, a_{t}\right)$. The same argument implies that the gap shrinks again in period $n=\tilde{m}+2$ and each subsequent period, but the gap never vanishes.

If we ever observe $\Delta\left(n \mid \tilde{m}, a_{t}\right) \leq 0$, we know that history matters. Through some mechanism, the experience of serving prison time rather than a spell of probation supervision must have generated a relative increase in age-specific offending rates, for at least some ages. Further, if $\Delta\left(n \mid \tilde{m}, a_{t}\right)$ remains constant or grows wider over horizons $n>\tilde{m}$, the experience of prison must have generated a relative reduction in some age-specific offending rates. ${ }^{38}$

The length of the incarceration spell, $\tilde{m}$, is the key variable that pins down what we expect to observe in Table 3 under the assumption that the experience of incarceration does not impact age-specific offending rates for those released from prison. Therefore, we again employ the methods presented in Dahl et al. (2014) to estimate the fraction of each set of compliers given incarceration sentences that remains in prison $1,2,3, . .7$ years after sentencing. We also create parallel results for both samples of always takers. ${ }^{39}$

Appendix Table 14.4.2 presents the results. Among both first and repeat offenders, compliers sentenced to incarceration are more likely than always takers to be released within one year, which some may expect since these offenders are marginal candidates for incarceration. Among both first and repeat offenders, the expected fractions of incarcerated compliers who will remain incarcerated after 36 months are ten percent or less. Among compliers who receive incarceration sentences in both the first and repeat-offender samples, there are roughly nine formerly incarcerated offenders for every initially incarcerated offender who remains incapacitated at the 36 month horizon. Given this pattern, we do not expect incapacitation effects to drive the results we report in Table 3 for horizons of 48, 60, 72, or 84 months.

Yet, Table 3 shows that, among compliers in the first-offender sample, incarceration reduces recidivism by 29 to 30.6 percentage points at horizons of 48, 60, and 72 months. Given the results derived in Appendix 16 and summarized above, this pattern of large and roughly constant reductions in recidivism over a period of at least 24 months strongly suggests that, among compliers in the first offender sample, incarceration does reduce age-specific recidivism rates following release, at least temporarily.

Future work is needed to learn more about the mechanisms at work here. Prison may reduce relative contact with criminal networks, make punishment more salient, or offer opportunities to participate in valuable rehabilitation and training programs. Yet, whatever mechanisms are at work among first offenders, they are not having similar impacts among repeat offenders.

We see no evidence that incarceration reduces age-specific recidivism rates among repeat offenders. After one year, our Table 3 estimates imply that compliers in our repeat-offender sample are more than 20 percentage points less likely to have received a new charge than they would have been given a non-incarceration sentence, but between the 12 and 60 month observation windows, this gap is almost completely eliminated. At 60 months, our results imply that incarceration sentences reduce recidivism by 1.2 percentage points, even though Table 14.4.2 shows that we expect three percent of incarcerated compliers among repeat offenders to serve prison spells longer than 60 months.

We note above that total recidivism rates for persons randomly assigned to probation, $m=0$, versus a prison spell, $m=\tilde{m}$, should grow closer over $t>\tilde{m}$, but the gap created over the first $\tilde{m}$ periods should never vanish. However, in Table 3 the implied LATE impact of incarceration on recidivism among repeat offenders collapses to zero before all of those sentenced to incarceration are released from prison, i.e. while

\footnotetext{
${ }^{38}$ Since every day in prison is a day not spent in the community, all of our results are best understood as estimates of how incarceration impacts recidivism relative to baseline recidivism rates associated with community supervision.

${ }^{39}$ Always takers are the defendants who would receive an incarceration sentence given any judge assignment.
} 
$t \leq \tilde{m}$ for a small group of prison inmates. These results seem to rule out the possibility that, on average, prison time creates lasting reductions in age-specific recidivism rates among compliers in the repeat-offender sample. For these offenders, incarceration sentences produce short-run incapacitation effects but little else.

\section{Heterogeneous Impacts Within First and Repeat Offenders}

We have established that the treatment effects of incarceration sentences on the arrival of future charges are different for first offenders versus repeat offenders. Here, we examine whether we see heterogeneous responses to incarceration within samples of first or repeat offenders.

\subsection{Results for Black Offenders}

Two factors limit our capacity to examine whether the patterns we document in Table 3 vary with the race of the defendant. During our sample period, the Court changed the way it recorded information about Hispanic ethnicity, so we are not able to create separate samples of white defendants versus Hispanic defendants. Further, even if we restrict ourselves to two race categories, Black and non-Black, we do not have enough non-Black defendants to produce reasonably precise estimates of the impacts of incarceration on recidivism among non-Blacks. ${ }^{40}$

However, we are able to produce results using the sample of Black defendants only, since more than two-thirds of our first-offender sample is Black and almost $85 \%$ of our repeat-offender sample is Black. Table 4 presents these results. Here, we not only restrict the sample to Black defendants, but we also define our LOM measures of severity within samples of Black first offenders and Black repeat offenders.

The results in Table 4 follow the same pattern we observe in Table 3. Among first offenders, the .149 reduction in recidivism at 84 months is smaller than the .226 reduction reported in Table 3 and the p-value associated with this 84 month impact is .11 instead of .02, but overall the results in Tables 3 and 4 are quite similar. Among repeat offenders, the largest absolute difference between any two estimated treatment impacts at a given horizon is .022 , and in six of seven cases, the absolute difference is roughly .01 or less. These small differences are expected, to some extent, since roughly 5 out of 6 repeat offenders in our sample are Black. ${ }^{41}$

\subsection{Drug Offenders versus Non-Drug Offenders}

As a rule, we do not have enough data to estimate charge-specific models within our samples of first and repeat offenders. However, drug charges are an exception to this rule. In both our first and repeat-offender samples, more than $40 \%$ of defendants face drug charges.

Table 5 presents results from four separate models. We estimate models for drug offenders and non-drug offenders within the samples of first and repeat offenders. Among both first and repeat offenders, defendants facing drug charges are less likely to receive incarceration sentences and more likely to be recidivists at each horizon. This pattern is particularly noteworthy among first offenders. Here, drug offenders are 44 percent less likely to receive an incarceration sentence but 23 percent more likely to face a new charge within seven years of sentencing. ${ }^{42}$

\footnotetext{
${ }^{40}$ At horizons of 48 months or more the standard errors on treatment impacts among non-Blacks range from roughly two to more than three times the corresponding standard errors in Table 3. For both first and repeat offenders, the 95\% confidence intervals surrounding our estimates of treatment impacts at 48,60,72, and 84 months contain noteworthy positive and negative impacts.

${ }^{41}$ We also produced results for these Black only samples using the LOM severity measures we employ in Table 3, i.e. those defined over all first or all repeat offenders. The results are quite close to those in Table 3.

${ }^{42}$ Here, the instruments are LOM measures created within cells defined by the interaction between first offenders status and an indicator variable that marks cases with a drug charge as the leading charge. We have also created these four sets of results using the all first and all repeat offender LOM instruments that we employ in Table 3. The resulting treatment impact estimates
} 
The results in Table 3 above indicate that, among compliers who are first offenders, incarceration creates significant long-term reductions in recidivism, and the results in Panel A and Panel B of Table 5 suggest that outcomes among first offenders charged with non-drug crimes may drive this result. Although none of our seven estimated treatment impacts among drug offenders are statistically different than the corresponding results for non-drug offenders, the time patterns among these estimated impacts are quite different. Among drug offenders, the magnitude of the implied reduction in recidivism rates falls by almost 30 percentage point between 48 and 72 months. Further, none of the estimated impacts for 60 months and beyond are statistically significant, although the standard errors on these impact estimates are large. Yet, among non-drug first offenders, the magnitude of the reduction in recidivism associated with incarceration treatment grows from 48 to 84 months. Finally, at 84 months, the 95 percent confidence interval for our estimate of the impact of incarceration on the rate of recidivism is $[-.10,-.62]$.

Panels C and D of Table 5 present parallel results for repeat offenders. Here, we see no clear evidence that incarceration sentences reduce recidivism at any horizon beyond 48 months for repeat drug offenders or repeat offenders charged with non-drug crimes. This result is in line with the overall results for repeat offenders in Table 3. However, at longer horizons, the qualitative difference between the results for repeat offenders charged with drug versus other crimes is the same difference we see in Panels A and B among first offenders. At horizons beyond 48 months, each estimated treatment impact within the sample of repeat drug offenders is positive, while the corresponding result for repeat offenders who are not charged with drug crimes is negative. At 84 months, we just fail to reject the null that the treatment impacts among repeat non-drug offenders and the treatment impacts among repeat drug offenders are the same, given $p=.1$. However, at this horizon, we can reject the null that the treatment impacts among repeat drug offenders and first non-drug offenders are the same given $p<.01$.

Our treatment impact estimates among first offenders charged with non-drug crimes stand out. The sizes of the implied recidivism reductions do not diminish over time, and at 84 months, we can rule out reductions that are less than 10 percentage points in magnitude. These impact estimates reflect more than direct incapacitation effects. They are too large and too long-lasting.

In future research, we plan to probe why non-drug offenders appear to drive the deterrence effects of incarceration among first offenders. It is possible that drug charges are correlated with gang affiliation and therefore correlated with the strength of ties to criminal networks. Given our data, we cannot test this conjecture directly. However, in the next section, we explore another source of treatment heterogeneity that may be correlated with gang affiliation.

\subsection{High-Crime versus Low-Crime Neighborhoods}

During our sample period, crimes rates in Chicago varied greatly among different parts of the city. The Census Bureau divides Chicago into 77 Community Areas, and we explored several different rules for creating an indicator variable that designates high-crime community areas. In the end, each method produced remarkably similar results. ${ }^{43}$ Table 6 presents four sets of estimated treatment impacts within samples defined by the interaction of first-offender status and our indicator for defendants whose first address in the court data is located in a high-crime neighborhood.

In Table 5, first offenders who are not charged with drug crimes stand out. In Table 6, our treatment impact estimates for first offenders who live outside the higher crime areas of Chicago stand out. We must note that the standard errors on these treatment impact estimates are large, but again, we see the implied reductions in recidivism associated with incarceration treatment grow steadily from the 48 month to the 84 month horizon. Also, at 84 months, the confidence interval on the treatment impact estimate implies that incarceration reduces recidivism rates among first-offender compliers from lower crime neighborhoods by at least 20 percentage points, and the estimated treatment impacts for first offenders in higher versus lower

are similar to those presented in Table 5. The relationships between horizon length and treatment impacts follow the same pattern, and none of the 28 estimated impacts differ by even two-thirds of a standard error.

${ }^{43}$ Our high-crime community areas are also areas that Bruhn (2021) identifies as areas that contained territory controlled by street gangs in 2004 . 
crime areas are statistically different, $p=.05 .{ }^{44}$ Among repeat offenders, we again see incapacitation effects at short horizons. However, at horizons beyond 48 months, we see no evidence that incarceration reduces long-term recidivism rates among repeat offenders from high or low-crime neighborhoods.

\section{Over-Policing and Measures of Recidivism}

In our empirical work, sentenced offenders become recidivists when they receive a new felony charge. We employ this proxy because we cannot observe criminal activity directly and because we do not have access to electronic arrest data for much of our sample period. Other researchers who work on criminal justice data in IL have suggested that associating recidivism with new charges may cause us to overstate relative recidivism among offenders who receive prison sentences. ${ }^{45}$ They argue that we may be finding no impact of incarceration on recidivism among repeat offenders, in part, because incarcerated repeat offenders are over-policed and over-charged relative to repeat offenders who receive probation.

As we note above, the post-prison supervision program in Illinois is called Mandatory Supervised Release (MSR) rather than parole. This terminology reflects the fact that, during our sample period, new prison inmates exited prison when their determinate sentence was complete, and not at the discretion of a parole board. In addition, the lengths of their MSR spells upon release were fixed at one, two, or three years depending on the felony classes associated with their convictions. For our purposes, the most important feature of the IDOC system is that, during our sample period, the agents who supervised offenders on MSR enjoyed extensive police powers. These agents could arrest their supervisees directly or issue warrants for the arrest of their supervisees based on their own assessments of whether a given supervisee had likely committed a new crime or violated a technical MSR condition.

Given these features of MSR in IL, we now investigate whether we fail to find that incarceration reduces recidivism among repeat offenders simply because MSR agents direct additional scrutiny to offenders with significant criminal records. We are motivated, in part, by the fact that the literature on over-policing often focuses on police activity in minority neighborhoods, with particular concerns surrounding the enforcement of drug laws. ${ }^{46}$ Almost 85 percent of our repeat offenders and more than 90 percent of repeat offenders who face drug charges are Black. Further, among Black repeat offenders in our data who face drug charges, more than 85 percent grew up in high-crime neighborhoods.

To investigate concerns about over-policing by MSR officers, we employ data on exits from prison during 1990 and 2015. We use IDOC data to determine the term of MSR assigned to each offender released from IDOC. We then calculate separate empirical hazard rates of recidivism for offenders assigned to one, two, and three year MSR terms. We use the same recidivism definition that we employ in our previous analyses, and we restrict the sample to repeat offenders from Cook County.

Figure 3 presents the results. The plotted empirical hazards are lagged 60 day moving averages of the daily recidivism hazards. The three lines describe results for repeat offenders assigned to one, two, or three year MSR spells respectively. The pairs of vertical lines mark the scheduled end of MSR spells and 60 days following these scheduled end dates.

The figure provides no evidence that recidivism rates are higher while repeat offenders are under MSR supervision. In fact, the hazard rate among offenders assigned to one year spells increases slightly relative to the hazard rates among offenders assigned to two year spells during the second year, i.e. when the former group is no longer under supervision but the latter still is. Further, the hazard rate for offenders assigned to three year spells remains below the other two hazards for almost all of the first three years, and

\footnotetext{
${ }^{44}$ We create the Table 6 results using LOM variables that are specific to each of the four subsamples. We have also produced a parallel set of results that employ LOM measures defined over all first offenders or all repeat offenders. Results derived using these instruments follow the same patterns we see in Table 6. The most significant difference is that among first offenders in low crime areas, the implied reduction in recidivism rates at horizons of 72 and 84 months is around 50 percentage points, which is smaller than the .599 and .649 reductions in Table 6, but in both cases, still within one standard error.

${ }^{45}$ Sarah Staudt of the Chicago Appleseed Fund for Justice raised specific concerns with us about the potential for over-policing among offenders recently released from prison.

${ }^{46}$ See Cox and Cunningham (2021) and Ba et al. (2021) for examples of recent work in this area.
} 
then it converges to the other hazards. Beyond year three, when all surviving offenders have exited MSR, all three hazards follow a common path.

A complete exploration of these patterns is beyond the scope of our paper, but Figure 3 does not support the hypothesis that we find no long-term impact of incarceration on recidivism among repeat offenders simply because repeat offenders are over-policed by MSR agents. In fact, the figure suggests that MSR supervision may reduce recidivism slightly, possibly by making the prospects of re-arrest more salient for those who may consider committing new offenses. However, these effects are small. We have conducted several simulation exercises based on the patterns in Figure 3 and conclude that any reductions in recidivism that may be attributed to additional scrutiny during MSR produce only minor reductions in long-term recidivism rates. ${ }^{47}$

Figure 3 suggests that MSR supervision does not increase measured recidivism, and relative to a no supervision regime, likely has small impacts on re-offending rates. Another literature evaluates the impact of probation supervision on recidivism and reaches similar conclusions. Hyatt and Barnes (2017) review the existing literature on Intensive Supervision Probation (ISP) programs for offenders on probation, and they also conduct a new randomized control trial to evaluate a specific (ISP) program. Their results confirm earlier studies that found no link between the intensity of supervision and rates of recidivism.

However, Hyatt and Barnes (2017) did find that ISP greatly increased the likelihood that offenders on probation would experience a new incarceration spell as the result of a technical violation of probation conditions. We find that MSR supervision has a similar impact on returns to prison associated with technical violations of supervision conditions.

\section{Post-Release Supervision and Prison Re-entry}

Among men under MSR supervision, more than forty percent of all prison re-admissions are the results of technical violations of MSR conditions, and among those serving two or three year terms, the proportion of admissions associated with technical violations increases during the final year of MSR supervision. Figure 4 presents results that parallel those in Figure 3, but here the failure event is not the receipt of a new felony charge but re-admission to prison.

The patterns in Figure 4 suggest that MSR supervision does increase prison re-entry rates for repeat offenders. During the first 365 days following a prison exit, those under one year of MSR supervision have the highest re-entry rates, but if those assigned to one year of MSR supervision complete MSR successfully, their hazard of prison re-entry drops below the rates for those assigned to two or three-year MSR terms. In year two, between 366 and 730 days, those assigned to two years of MSR have the highest average rates of prison re-entry, and after 730 days, the prison re-entry rates for persons assigned to two years of MSR quickly converge to the rates of those assigned to one year of MSR. During year three, those assigned to three years of MSR are the only offenders who remain under MSR supervision, and they have the highest re-entry rates. After three years, when no surviving offenders remain on MSR, all three lines converge.

Further, the magnitudes of the changes in re-entry hazards associated with release from MSR that Figure 4 documents are significant. In the four month period between 10 and 14 months after release, the re-entry rate among those assigned to 12 months of MSR falls by almost 50\%. Between 22 and 26 months, we see a similar 50\% decline in the re-entry hazard among those assigned to two years of MSR. Finally, among those assigned to three years of MSR, the average re-entry hazard during year three is roughly double the rate observed during year four.

We have estimated these same hazards for persons who are leaving prison as first offenders, i.e. those who received a prison sentence as a result of their first felony charge. We see the same patterns. Re-entry

\footnotetext{
${ }^{47}$ Only about one sixth of our sample receives a three year MSR term, and the small difference between the hazard rates for offenders assigned to one versus two-year MSR spells has little impact on overall survival rates at longer horizons. We have produced similar figures for persons who are exiting prison after receiving a prison sentence in their first felony case. The sample sizes are much smaller since prison sentences for first offenders are not the norm, but the results are quite similar.
} 
hazards drop around thresholds that mark the end of MSR supervision. However, the magnitudes of these drops are not as large.

Our data does not provide a source of exogenous variation in MSR status that would allow us to measure the causal impact of MSR supervision on prison re-entry, holding re-offending behavior constant, but several recent studies suggest that the correlations we document may reflect causal impacts of supervision on prison re-entry. Harding et al. (2017) and Franco et al. (2020) find similar patterns in Michigan. The former paper exploits random judge assignment, while the latter exploits discontinuities in the mapping between scores that describe an offender's criminal history and the likelihood of a prison sentence. Both papers find that, relative to probation supervision, parole supervision generates much higher rates of prison entry. In addition, technical violations, not differences in recidivism rates, drive this result. ${ }^{48}$

Although most prison spells that result from technical violations of MSR conditions are short, the frequency of these prison spells among repeat offenders makes it more noteworthy that our results for repeat offenders show no long-term impact of incarceration on recidivism. The vast majority of prison inmates and parolees are repeat offenders, and even though many of these parolees are re-incapacitated for brief periods after they leave prison, we still find no significant impacts of incarceration on repeat offender recidivism after the 36 month horizon.

\section{Comparisons with Previous Work}

Our results demonstrate the importance of analyzing first and repeat offenders separately when examining the impacts of sentencing treatments on future recidivism. Among compliers in our sample of first offenders, incarceration sentences create large and lasting reductions in recidivism. However, our results for compliers in our repeat-offender sample provide evidence that incarceration produces modest short-term incapacitation effects and no lasting reductions in recidivism.

Roughly three fourths of the incarceration sentences in our sample go to repeat offenders. Roughly seventy percent of compliers who receive incarceration sentences are repeat offenders, ${ }^{49}$ and both of these repeat-offender proportions would be larger if we had not removed all defendants born before 1967, to make sure that we could accurately identify first versus repeat offenders. Thus, given our results for repeat offenders, we are not surprised that section 1 reviews several papers that pooled samples of first and repeat offenders and found little evidence that incarceration sentences reduce long-term recidivism rates.

The results from Bhuller et al. (2020)'s study of the impact of incarceration on recidivism among Norwegian offenders are similar to our results in some respects. Their main results, which come from a pooled sample of first and repeat offenders, imply impacts of incarceration on recidivism at 48 and 60 months that are quite similar to our results for first offenders. Further, in appendix results, they analyze first offenders separately and report even larger negative impacts of incarceration on recidivism among first offenders at these longer horizons. These long-term, first-offender treatment impacts are statistically significant and at least one third greater in absolute value than the impacts they report in their full-sample results. ${ }^{50}$

In contrast, some readers may conjecture that our results for repeat offenders are in conflict with results in Kuziemko (2013). She finds that prisoners released early from Georgia prisons exhibited higher rates of recidivism post-release than observationally similar prisoners who were required to serve longer prison

\footnotetext{
${ }^{48}$ Our results are not exactly comparable because we are not comparing MSR outcomes to counterfactual prison re-entry rates given probation. These counterfactuals are difficult to construct since prison sentences require that supervision take place at a later time when the offender is older. Further, Cook County court records do not provide complete or accurate information about the end dates of probation supervision spells. Rose (2020) reports that, prior to the enactment of a 2011 reform, a substantial fraction of probation revocations in North Carolina that led to incarceration were revocations linked to technical violations of probation conditions and not new crimes.

${ }^{49}$ About six percent of the first-offender sample are persons sentenced to incarceration who are not always takers. Roughly 15 percent of repeat offenders receive incarceration sentences even though they are not always takers. Our sample of first offenders is slightly larger than our sample of repeat offenders.

${ }^{50}$ The Bhuller et al. (2020) sample is just under half the size of our sample. Splitting the sample by first versus repeat offenders increases their standard errors, and they do not report separate results for repeat offenders.
} 
spells. Since most prison inmates are repeat offenders, this result appears at odds with our results for repeat offenders. Still, when comparing our results with those of Kuziemko (2013), several differences in research design are noteworthy. To begin, the treatment in Kuziemko (2013) is not incarceration versus probation or some other non-incarceration treatment. Kuziemko (2013) is measuring the treatment impact of additional prison time. Also, the inmates affected by this treatment are not marginal candidates for incarceration. She leverages a discontinuity in the parole guidelines that moves inmates from roughly 21 months in prison to 24 months in prison, and two years is a substantial prison term. In Illinois, far less than half of criminal defendants sentenced to prison serve two years.

By combining the Cook County court records with IDOC data, we estimate that roughly 4 of 5 inmates in Illinois state prisons are repeat offenders by our definition, i.e. they have faced felony charges on multiple occasions in the past. However, Panel B of Appendix Table 14.4.2 shows that just over seventy percent of repeat offenders who serve initial prison terms of at least two years are always takers. Thus, if the Georgia and Illinois prison systems operate in similar ways, most of the inmates affected by the discontinuity that Kuziemko (2013) leverages were repeat offenders, but most of these repeat offenders were not marginal candidates for incarceration at sentencing. More research is needed to fully understand how changes in incarceration treatments at both the intensive and extensive margins impact recidivism, but it is clear that, compared to Kuziemko (2013), our study answers questions about different treatments that likely impact different types of offenders.

Other readers may worry that our results are in conflict with recent findings in Agan et al. (2021). They employ a research design that exploits random assignment of non-violent misdemeanor cases to prosecutors. They find that, among defendants on the margin of having their misdemeanor cases dropped, nonprosecution lowers recidivism over the next two years, and these reductions are largest among first-time defendants. We find that incarceration creates large and lasting reductions in recidivism among defendants who are facing felony charges for the first time and are marginal candidates for incarceration. We report in Appendix 14.4 that almost 74 percent of our sample of first offenders are never takers, who would not be sentenced to incarceration by any of the judges in our samples. The compliers in our first-offender sample have committed more serious offenses than the typical defendant facing his first felony charge and are therefore likely quite different than defendants who are facing their first misdemeanor charge and can expect this first misdemeanor case to be dropped if it is assigned to a lenient prosecutor.

\section{Conclusions and Policy Implications}

In Illinois, carrying a handgun without a permit in a public gathering is a felony that is punishable by one to three years in prison, but in 2018, Illinois enacted the First Time Weapons Offender ${ }^{51}$ program that allows persons charged with this and other felony weapons charges to enter a diversion program. Those who complete the program successfully avoid prison time and avoid a felony conviction. Yet, as the name implies, only persons without a prior conviction for a violent felony are eligible for diversion.

This law is one of many in Illinois that either require or encourage judges to sentence convicted felons more harshly than first-time offenders. In Illinois, judges are instructed to consider a history of prior criminal activity as an aggravating factor when sentencing those found guilty. ${ }^{52}$ Further, in many instances where a first offender and previously convicted felon are convicted of the same crime, probation is possible for the first offender while prison time is mandatory for the repeat offender. ${ }^{53}$

Illinois is not unique. Most states in the US, most English-speaking countries, Scandinavian countries, China, India, South Korea, and others almost always encourage and often require judges to impose a recidivist premium when sentencing. Over the past forty years or more, this practice has become ubiquitous, but legal scholars are raising concerns about it. Some argue that it is not just to assign

\footnotetext{
${ }^{51}$ See Illinois Compiled Statutes 5/5-6-3.6.

${ }^{52}$ See Illinois Compiled Statutes 5/5-5-3.2. A history of prior criminal activity is one factor that "shall be accorded weight in favor of imposing a term of imprisonment."

${ }^{53}$ Links between an offender's prior record and the class of the charge filed against him or his designation as a habitual criminal often make prison time mandatory in cases where first offenders convicted of the same crime are eligible for parole.
} 
punishment for a current offense, in part, based on records of past offenses that have already been punished. Others argue that recidivist premiums are not producing noteworthy reductions in recidivism. ${ }^{54}$

Our results indicate that the recidivist premium in Illinois is likely too large. Among the marginal defendants in our complier sets, prison sentences for repeat offenders generate modest incapacitation effects and nothing else. Yet, among first offenders in our complier sets, incarceration sentences generate larger incapacitation effects and significant deterrence. Thus, it may be possible to hold Illinois prison populations constant and reduce overall recidivism rates by sentencing marginally more first offenders to prison and marginally fewer repeat offenders to prison.

The details of how to optimally recalibrate sentencing laws and guidelines that differentiate between first and repeat offenders are topics for future research. We have not estimated a full life-cycle model of offending, and we have not addressed general equilibrium impacts of changes in sentencing policies. Our results have implications for marginal shifts in the composition of existing incarceration sentences, but they offer no insights concerning the optimal use of incarceration sentences or the optimal sizes of prison populations. To credibly address these questions, we require more information about charge-specific impacts of incarceration sentences, the social costs of different offenses, and expected equilibrium supply responses when some existing criminals increase, decrease, or cease their criminal activities.

While we cannot offer precise guidance concerning optimal sentencing rules or the optimal sizes of prison populations by offense categories, we must note that our results for repeat offenders should not be used to justify the overall severity that many states have baked into guidelines and rules that govern the sentencing of chronic offenders. ${ }^{55}$ Almost fifty years ago, Martinson (1974) reviewed an earlier literature in a commentary that some credit with bolstering the view that "nothing works," i.e. that the variety of rehabilitation and re-entry programs that were in place during the 1960s and early 1970s had little impact on recidivism. This view created calls to put less emphasis on rehabilitation and more on using prison to incapacitate dangerous offenders, especially those with long criminal histories, and a wave of sentencing reforms began that sparked the prison boom of the following decades. ${ }^{56}$

While our results do support the contention that, in Illinois, prison only incapacitates repeat offenders while offering them no programs or services that create permanent reductions in recidivism, this conclusion does not imply that optimal criminal justice policies mandated the confinement of more than 35,000 chronic offenders in Illinois prisons at the end our sample period. Incapacitation is a costly crime reduction strategy, and the failures of current and previous rehabilitation and re-entry programs are not per se reasons to shrink from vigorous efforts to develop services for inmates and parolees that provide better education, training, drug treatment, employment opportunities, and housing placement.

The available evidence suggests there is much room for improvement in public programs charged with promoting the rehabilitation of convicted offenders. Our results in section 10 and the broader literature on probation and parole supervision indicates that community supervision programs often operate as paths to prison rather than paths to stable housing and employment, even among offenders who have not committed new crimes. ${ }^{57}$ Further, recent evidence shows that post-release supervision regimes that place less emphasis on bringing former inmates back to prison need not harm public safety. Lofstrom et al. (2014) study a 2011 reform in California that greatly restricted the ability of parole officers to return parolees to prison for technical violations of parole conditions. They find a sharp reduction in prison re-entry rates, a significant negative impact on the size of prison populations, and no significant harms to public safety.

Our results do not justify the policies that created the prison boom. Rather, they point to the need for different and better approaches to training and rehabilitation in prison, especially for repeat offenders, as well as new approaches to post-release supervision that foster re-entry into jobs and community life rather than re-entry into prison. Our results also suggest that scholars and policy makers should take seriously the likelihood that the recidivist premiums built into many sentencing rules and guidelines are now so large that they are counterproductive.

\footnotetext{
${ }^{54}$ See Reitz (2014), Hester et al. (2018), and D'Alessio and Stolzenberg (2019).

${ }^{55}$ See Neal and Rick (2016) for a review of sentencing reforms in the 1980s and 1990s. The "three-strikes" rule in California received much media attention, but related rules were adopted in other states, and many remain in force.

${ }^{56}$ See Raphael and Stoll (2013) and Neal and Rick (2016).

${ }^{57}$ See Harding et al. (2017), Franco et al. (2020), and Rose (2020).
} 


\section{References}

Agan, Amanda, Doleac, Jennifer and Harvey, Anna. (2021), Misdemeanor Prosecution, Technical report, NBER WP 28600.

Agan, Amanda and Starr, Sonja. (2018). 'Ban the box, criminal records, and racial discrimination: A field experiment', The Quarterly Journal of Economics 133.

Aizer, Anna and Doyle, Jr. Joseph J. (2015). 'Juvenile Incarceration, Human Capital, and Future Crime: Evidence from Randomly Assigned Judges', Quarterly Journal of Economics 130(2), 759-803.

Ba, Bocar A, Knox, Dean, Mummolo, Jonathan and Rivera, Roman. (2021). 'The role of officer race and gender in police-civilian interactions in Chicago', Science 371(6530), 696-702.

Bhuller, Manudeep, Dahl, Gordon B., Loken, Katrine V. and Mogstad, Magne. (2020). 'Incarceration, Recidivism and Employment', Journal of Political Economy 128(4), 1269-1324.

Bogira, Steve. (2005), Courtroom 302: A Year Behind the Scenes in an American Criminal Courthouse, Vintage Books.

Bruhn, Jesse. (2021), Competition in the Black Market: Estimating the Causal Effect of Gangs in Chicago, Technical report, Bravo WP 2021-004.

Carson, E. Ann. (2019), Prisoners in 2019, Technical report, Bureau of Justice Statistics.

Cox, Robynn and Cunningham, Jamein P. (2021). 'Financing the war on drugs: the impact of law enforcement grants on racial disparities in drug arrests', Journal of Policy Analysis and Management 40(1), 191-224.

Dahl, Gordon B., Kostol, Andreas Ravndal and Mogstad, Magne. (2014). 'Family welfare cultures', Quarterly Journal of Economics 129.

D'Alessio, Stewart J. and Stolzenberg, Lisa. (2019). 'Should Repeat Offenders Be Punished More Severely for Their Crimes?', Criminal Justice Policy Review 30, 731-47.

Dobbie, W., G., Hans, N., Susan, P., Martin and Piksk, M. (2019), The Intergenerational Effects of Parental Incarceration, Technical report, NBER WP 24186.

Eren, Ozkan, Lovenheim, Michael F. and Mocan, Naci H. (2018). 'The Effect of Grade Retention on Adult Crime: Evidence from a Test-Based Promotion Policy', NBER WP 25384.

Estelle, Sarah M. and Phillips, David C. (2018). 'Smart Sentencing Guidelines: The Effect of Marginal Policy Changes on Recidivism', Journal of Public Economics 164, 270-93.

Franco, Catalina, Harding, David J., Bushway, Shawn, Sorensen, Lucy and Morenoff, Jeffery. (2020), Failing to Follow the Rules: Can Imprisonment Lead to More Imprisonment Without More Actual Crime? Working Paper.

Frandsen, Brigham R., Lefgren, Lars J. and Leslie, Emily C. (2019). 'Judging Judge Fixed Effects', NBER WP 25528 .

Green, Daniel and Winik, Daniel. (2010). 'Using Random Judge Assignments to Estimate the Effects of Incarceration and Probation on Recidivism among Drug Offenders', Criminology 48(2), 357-387.

Harding, David, Morenoff, Jeffrey, Nguyen, Anh and Bushway, Shawn. (2017). 'Short- and Long-term Effects of Imprisonment on Future Felony Convictions and Prison Admissions', Proceedings of the National Academy of Sciences .

Hester, Rhys, Frase, Richard S., Roberts, Julian V. and Mitchell, Kelly Lyn. (2018). 'Prior Record Enhancements at Sentencing: Unsettled Justifications and Unsettling Consequences', Crime and Justice 47(1), 209-254. 
Holzer, Harry J, Raphael, Steven and Stoll, Michael A. (2003). 'Employment barriers facing ex-offenders', Urban Institute Reentry Roundtable .

Holzer, Harry J, Raphael, Steven and Stoll, Michael A. (2006). 'Perceived criminality, criminal background checks, and the racial hiring practices of employers', The Journal of Law and Economics 49.

Hyatt, Jordan M. and Barnes, Geoffrey C. (2017). 'An Experimental Evaluation of the Impact of Intensive Supervision on the Recidivism of High-Risk Probationers', Crime and Delinquency .

Imbens, Guido and Angrist, Josh. (1994). 'Identification and Estimation of Local Average Treatment Effects', Econometrica 62(2), 467-475.

Kolesar, Michal. (2013), Estimation in an Instrumental Variables Model with Treatment Effect Heterogeneity. Working Paper.

Kuziemko, Ilyana. (2013). 'How Should Inmates be Released from Prison? An Assessment of Parole Versus Fixed-Sentence Regimes', Quarterly Journal of Economics 128(1), 371-424.

Loeffler, Charles E. (2013). 'Does Imprisonment Alter the Life Course? Evidence on Crime and Employment from a Natural Experiment', Criminology 51(1), 137-166.

Lofstrom, Magnus, Raphael, Steven and Grattet, Ryken. (2014), Is Public Safety Realignment Reducing Recidivism in California, Technical report, Public Policy Institute of California.

Martinson, Robert. (1974). 'What Works? -questions and answers about prison reform', The Public Interest .

Mueller-Smith, Michael. (2015), The Criminal and Labor Market Impacts of Incarceration. Working Paper.

Nagin, Daniel S. and Snodgrass, Matthew G. (2013). 'The Effect of Incarceration on Re-Offending: Evidence from a Natural Experiment in Pennsylvania', Journal of Quantitative Criminology 29(4), 601-642.

Neal, Derek and Rick, Armin. (2016). 'The Prison Boom and Sentencing Policy', Journal of Legal Studies 45.

Norris, Samuel, Pecenco, Matthew and Weaver, Jeffrey. (2021). 'The Effects of Parental and Sibiling Incarceration: Evidence from Ohio', American Economic Review 111(9), 2926-63.

Paral, Rob. (2003), Demographic and Epidemiological Profiles of Key Chicago Community Areas and Suburban/Downstate Places, Technical report, Rob Paral and Associates.

Raphael, Steven and Stoll, Michael A. (2013), Why Are So Many Americans in Prison, Russell Sage Foundation.

Reitz, Kevin. (2014), The Illusion of Proportionality: Desert and Repeat Offenders, in Juila V Roberts and Andrew Von Hirsch., eds, 'Previous Convictions at Sentencing: Theoretical and Applied Perspectives', Hart Publishing.

Roodman, David. (2017), The Impacts of Incarceration on Crime, Technical report, Open Philanthropy Project.

Rose, Evan K. (2020). 'Who Gets a Second Chance? Effectiveness and Equity in Supervision of Criminal Offenders', Quarterly Journal of Economics .

Rose, Evan K. and Shem-Tov, Yotam. (2021). 'How Does Incarceration Affect Reoffending? Estimating the Does-Response Function', Journal of Political Economy .

Staiger, Douglas and Stock, James H. (1997). 'Instrumental Variables Regressions with Weak Instruments', Econometrica 65(3), 557-586. 
Troyer, Gwyneth. (2014), 2014 Monitoring Report: Northern Reception and Classification, Technical report, John Howard Association of Illinois.

Yang, Crystal S. (2017). 'Local Labor Markets and Criminal Recidivism', Journal of Public Economics $147(1), 16-29$. 


\section{Figures and Tables}

Figure 1

Criminal Justice in Illinois

8 Month

Post-Release Program

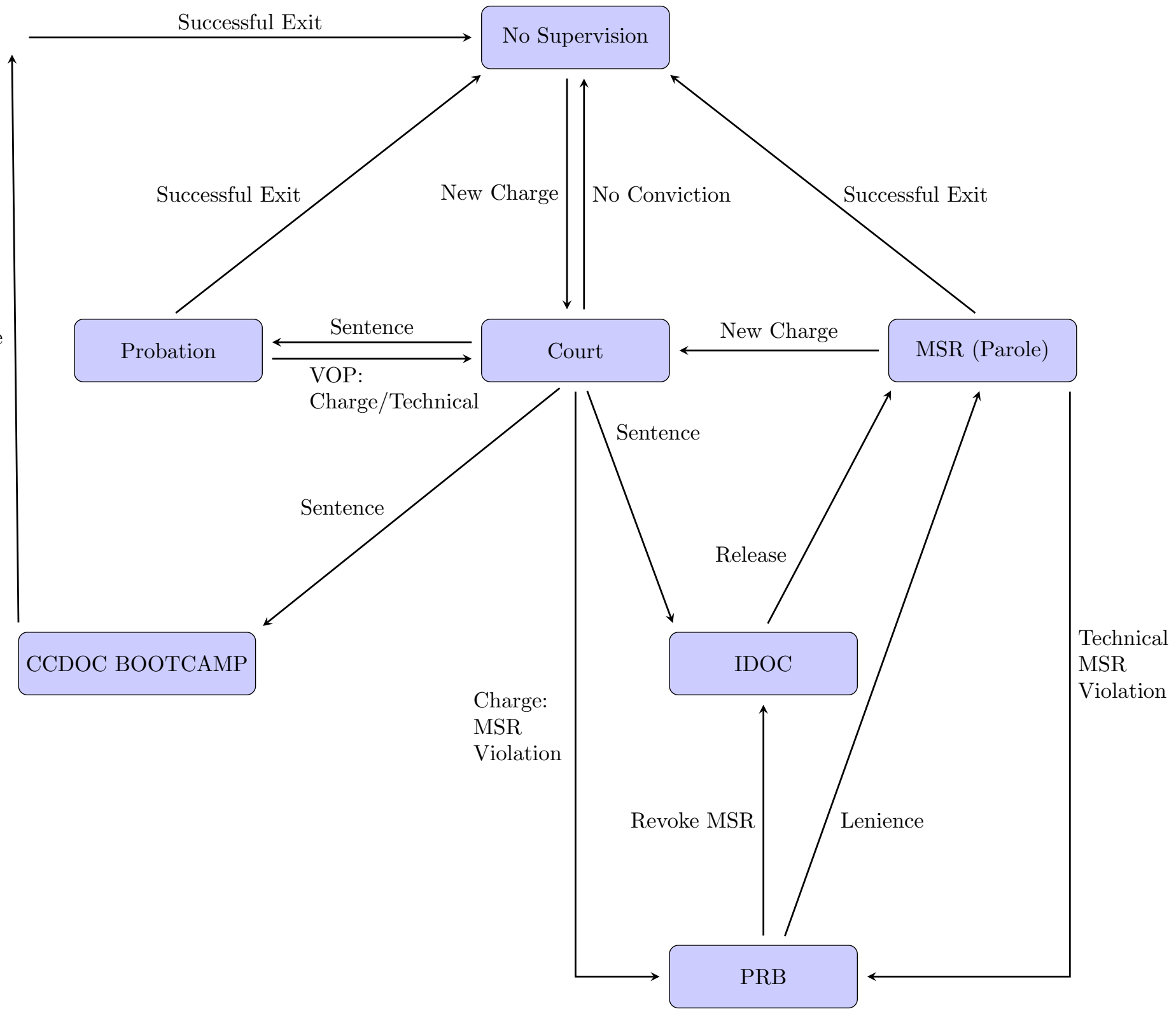

Notes: Each box denotes a state that a defendant may occupy after facing a felony charge in Cook County. The lines explain the transition paths between these states. For example, a defendant moves from the state of No Supervision to Court by receiving a New Charge. The key feature of the system is that there is no direct transition path from prison (IDOC) to No Supervision. MSR supervision is mandatory, and the $P R B$ acts, in many ways, as a parallel justice system while former inmates are under $M S R$ supervision. 


\title{
Figure 2
}

\section{Judge Severity Measures}

\author{
Panel A: First Offenders
}

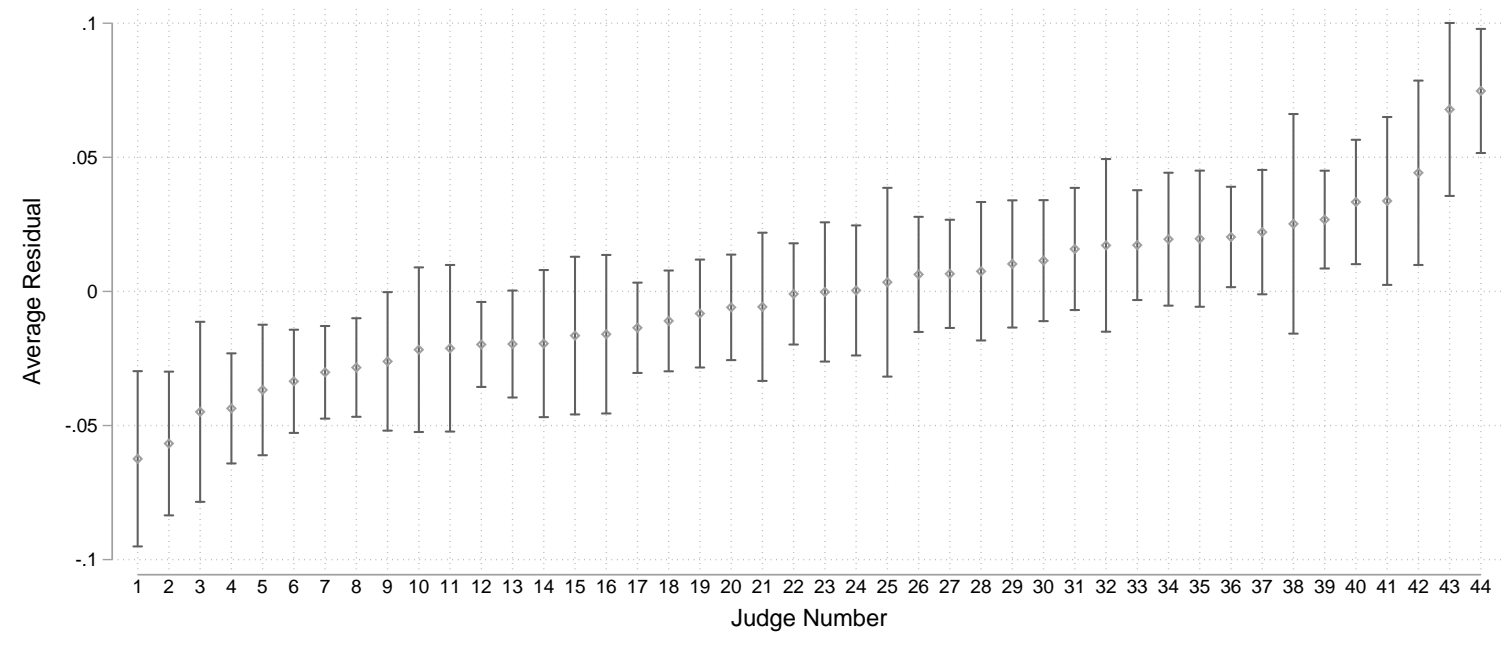

Notes: In all panels, we capture residuals from regressions of $\tau_{j i t}$ on $x_{i t}$. Here, each dot is the average sentencing residual for a judge, taken over the sample of first-offender cases assigned to the judge. We order and number judges on the $\mathrm{x}$-axis according to this measure of severity. Judge 1 is the most lenient judge when dealing with first offenders. Judge 44 is most severe. The error bars are $95 \%$ confidence intervals.

Panel B: Repeat Offenders - Sorted by Judge Severity Among First Offenders

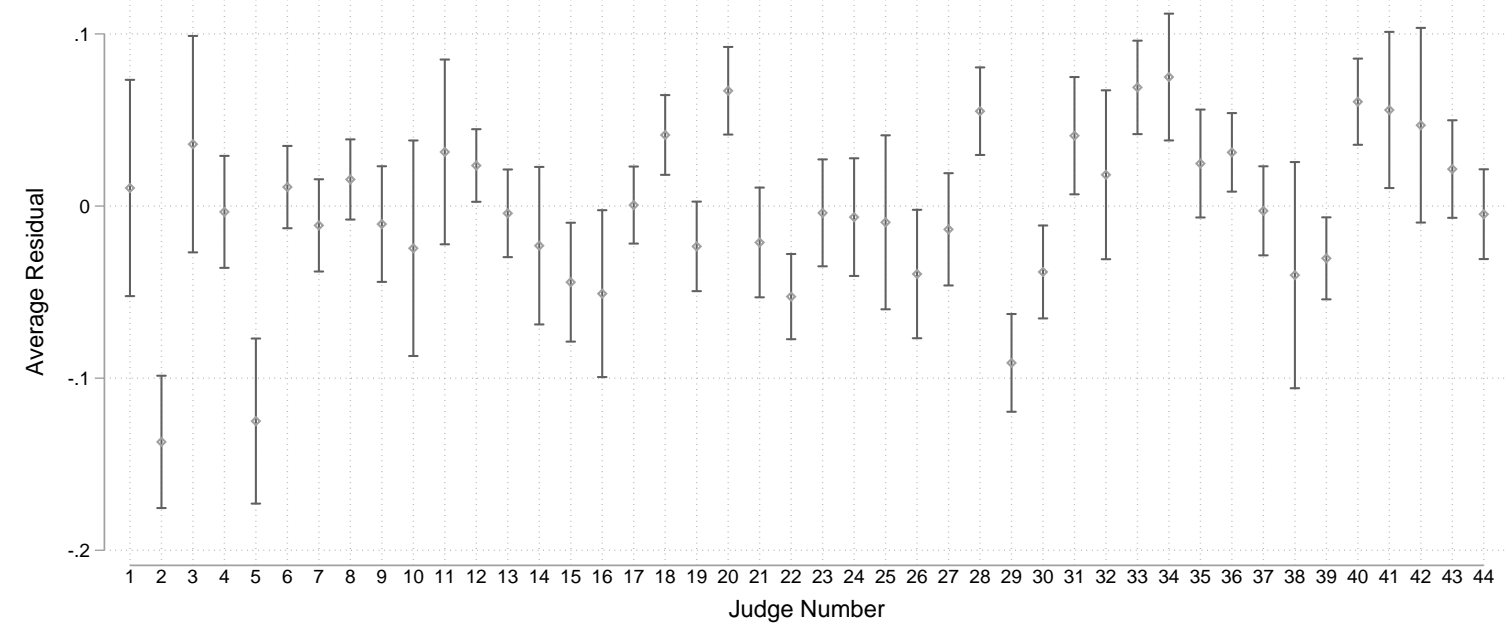

Notes: Each dot is the average sentencing residual for a judge, taken over the sample of repeat-offender cases assigned to the judge. Yet, as in Panel A, we order judges on the x-axis by their severity when dealing with first offenders. 
Panel C: Repeat Offenders

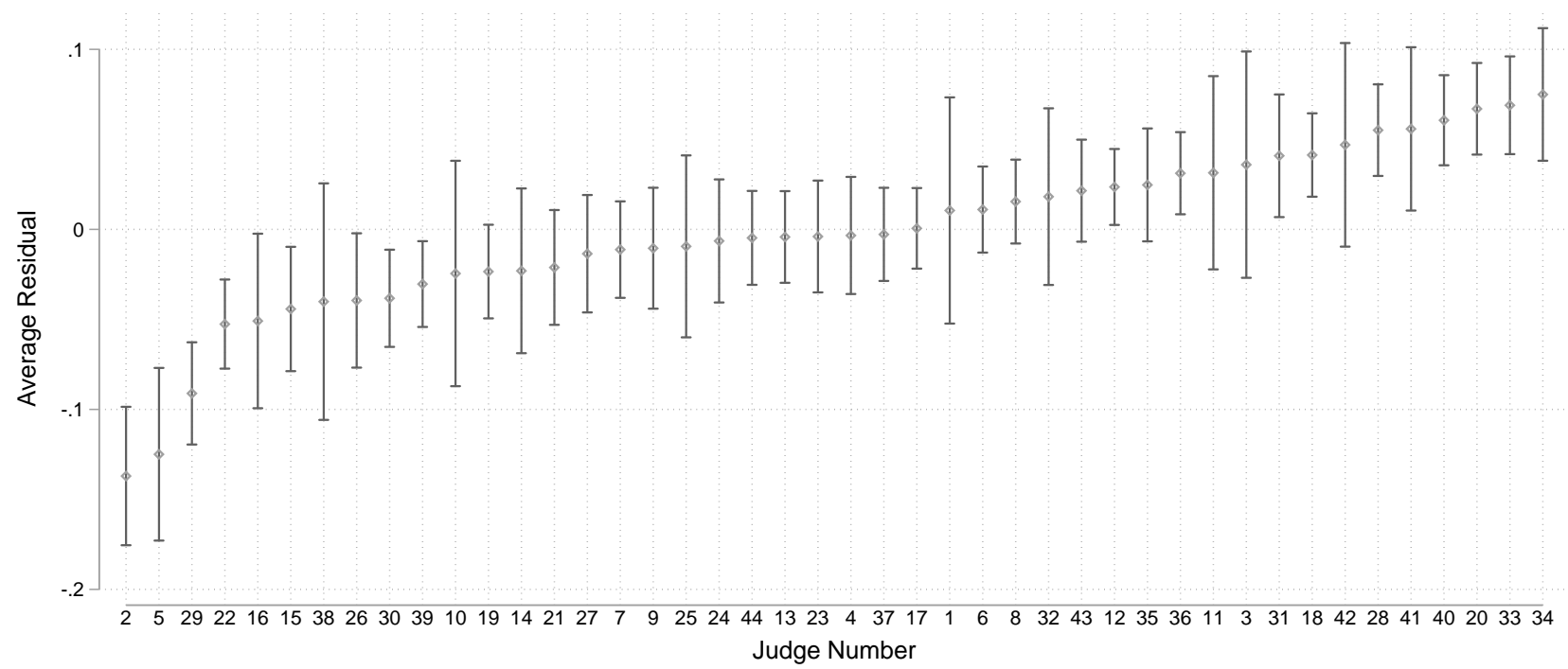

Notes: Each dot is the average sentencing residual for a judge, taken over the sample of repeat-offender cases assigned to the judge. In contrast to Panels A and B, we order judges on the x-axis by their severity when dealing with repeat offenders. However, as in panels A and B, the judge numbers on the $\mathrm{x}$-axis reveal each judge's severity ranking when dealing with first offenders. 
Figure 3

MSR and Recidivism Hazards: Repeat Offenders

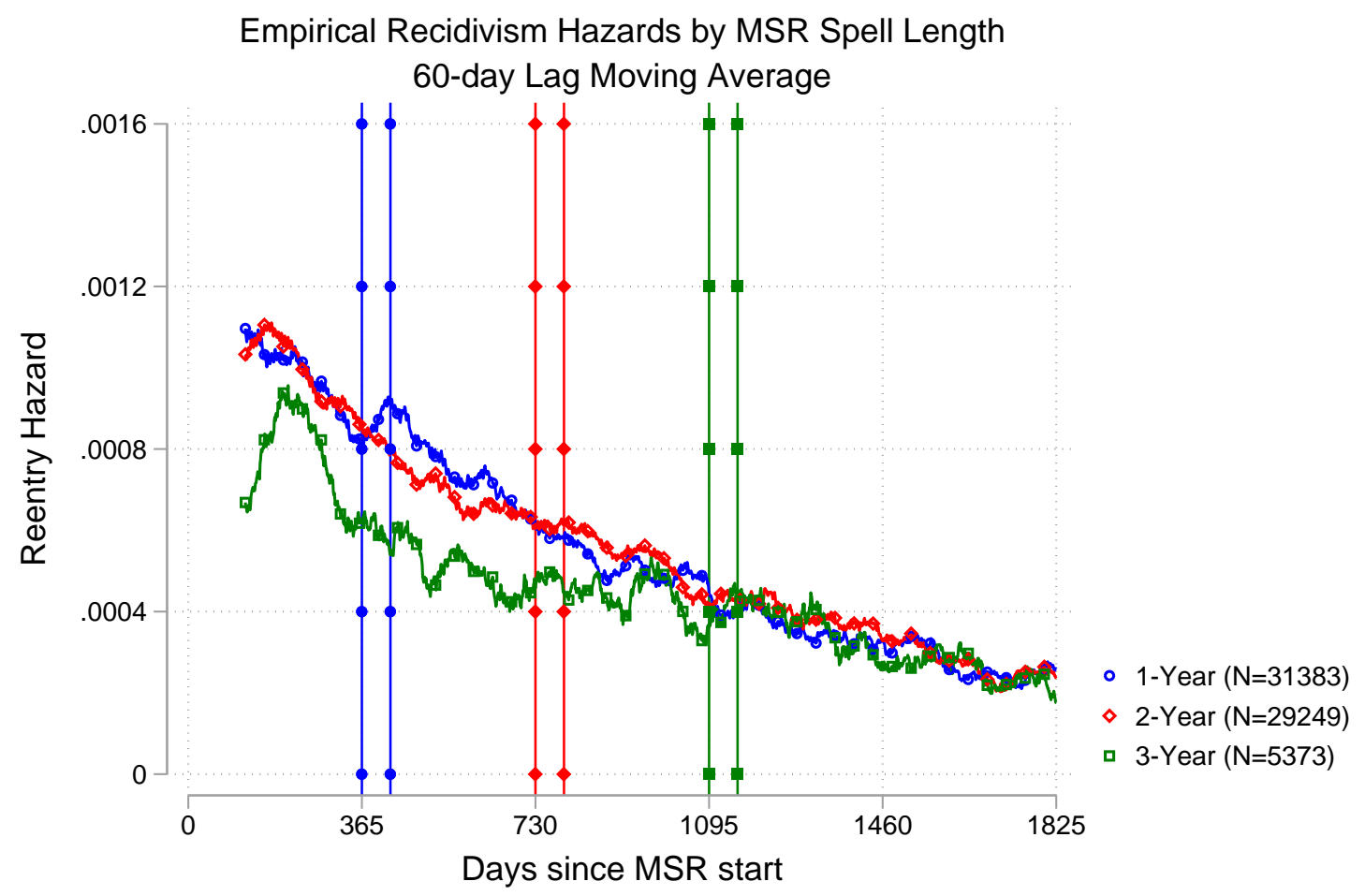

Notes: Each line presents a 60-day moving average of the daily recidivism hazard for a subset of repeat offenders recently released from state prison in Illinois. Failure is defined as receiving a new charge. Blue circles indicate ex-inmates given 1 year of Mandatory Supervised Release. Red diamonds indicate ex-inmates given 2 years of MSR. Green squares indicate ex-inmates given 3 years of MSR. The first vertical line of each type marks the end of the MSR period. The second vertical line marks 60 days after the end of MSR. 
Figure 4

MSR and Prison Re-Entry Hazards: Repeat Offenders

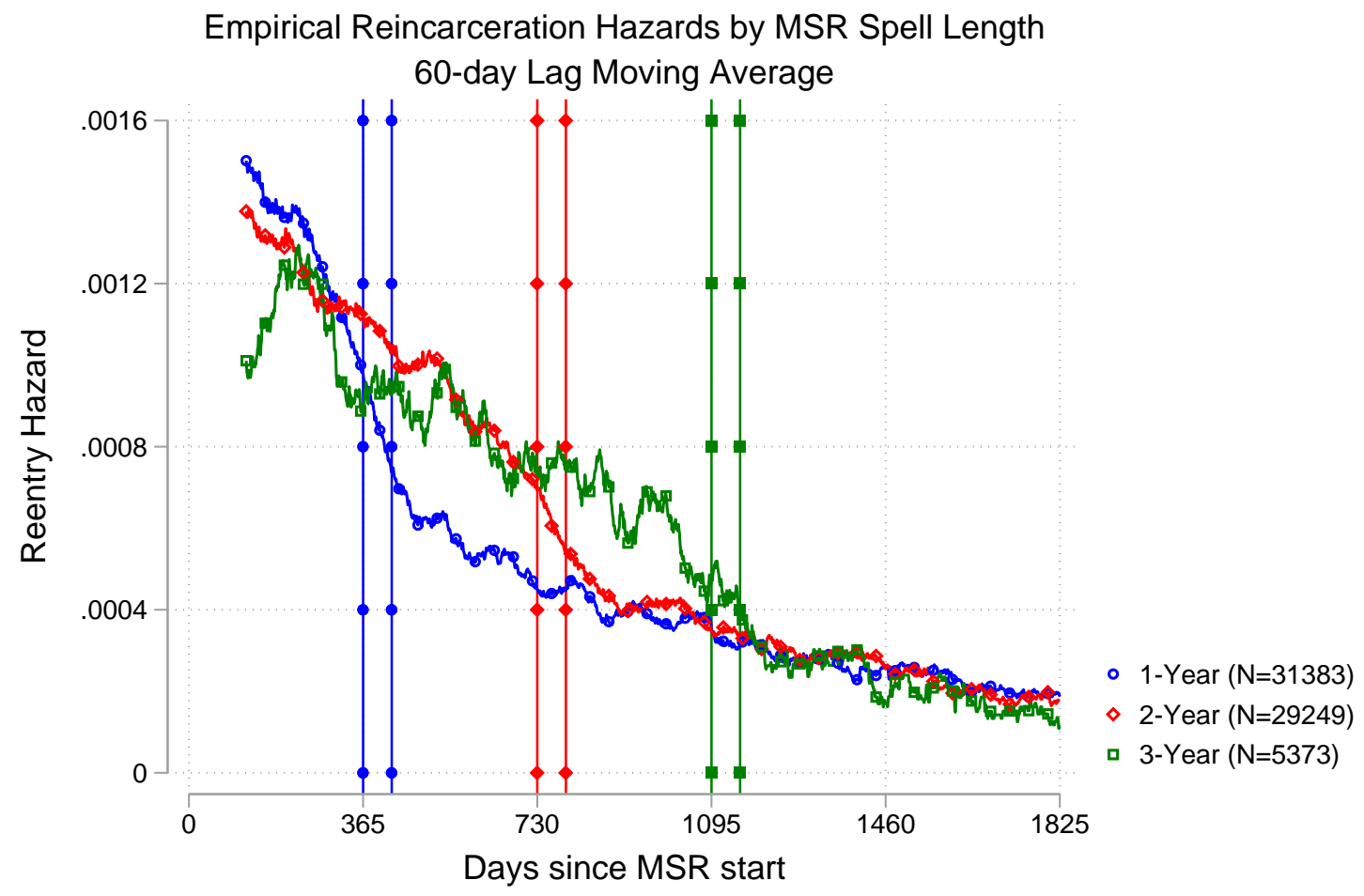

Notes: Each line presents a 60-day moving average of the daily prison re-entry hazard for a subset of repeat offenders recently released from state prison in Illinois. Failure is defined as re-entering prison for any reason, including violation of technical release conditions. Blue circles indicate ex-inmates given 1 year of Mandatory Supervised Release. Red diamonds indicate ex-inmates given 2 years of MSR. Green squares indicate ex-inmates given 3 years of MSR. The first vertical line of each type marks the end of the MSR period. The second vertical line marks 60 days after the end of MSR. 
Table 1 - Descriptive Statistics

\begin{tabular}{lll}
\hline & First Offenders & Repeat Offenders \\
\hline Age & 21.12 & 25.91 \\
Black & 0.68 & 0.84 \\
Prior Charges & $\cdot$ & 2.64 \\
Class X & 0.16 & 0.15 \\
Class 1 & 0.16 & 0.18 \\
Class 2 & 0.30 & 0.33 \\
Class 3 & 0.10 & 0.16 \\
Class 4 & 0.28 & 0.18 \\
High-Crime Area & 0.56 & 0.71 \\
Drug & 0.42 & 0.46 \\
Robbery & 0.12 & 0.10 \\
Burglary & 0.11 & 0.09 \\
Assault & 0.05 & 0.05 \\
Theft & 0.11 & 0.10 \\
Weapon & 0.16 & 0.17 \\
Guilty & 0.90 & 0.89 \\
Probation & 0.71 & 0.22 \\
Prison & 0.17 & 0.65 \\
CCDOC Bootcamp & 0.03 & 0.02 \\
On MSR & $\cdot$ & 0.41 \\
Sample Size & 37,055 & 33,526 \\
\hline
\end{tabular}

Notes: These descriptive statistics describe our two analysis samples. The Appendix materials in section 15 detail the construction of these samples. The entries Guilty, Probation, Prison, and CCDOC Bootcamp describe sentencing outcomes. All other entries are characteristics of the defendant or the case against the defendant. Class X is the most serious offense class. Class 4 is the least serious. 


\section{Table 2 - Balance}

\begin{tabular}{|c|c|c|c|}
\hline & All & First Offenders & Repeat Offenders \\
\hline Black & $-0.000140(\mathrm{p}=0.937)$ & $-0.000252(\mathrm{p}=0.580)$ & $0.000587(\mathrm{p}=0.269)$ \\
\hline Age & $-0.000012(\mathrm{p}=0.975)$ & $0.000040(p=0.174)$ & $0.000029(\mathrm{p}=0.579)$ \\
\hline Height & $0.000047(\mathrm{p}=0.475)$ & $0.000009(\mathrm{p}=0.768)$ & $0.000109(\mathrm{p}=0.132)$ \\
\hline Weight & $0.000000(p=0.994)$ & $0.000001(p=0.724)$ & $0.000002(\mathrm{p}=0.720)$ \\
\hline BMI & $-0.000019(\mathrm{p}=0.839)$ & $0.000010(\mathrm{p}=0.731)$ & $-0.000027(\mathrm{p}=0.590)$ \\
\hline Prior Cases & $-0.000079(\mathrm{p}=0.961)$ & . & $0.000183(\mathrm{p}=0.133)$ \\
\hline Indictment & $-0.000208(\mathrm{p}=0.600)$ & $-0.000109(\mathrm{p}=0.742)$ & $-0.000301(\mathrm{p}=0.590)$ \\
\hline Multiple Defendant & $-0.000342(\mathrm{p}=0.381)$ & $-0.000259(\mathrm{p}=0.485)$ & $-0.000463(\mathrm{p}=0.442)$ \\
\hline Multiple Charge & $0.000040(p=0.927)$ & $0.000182(\mathrm{p}=0.656)$ & $-0.000236(\mathrm{p}=0.696)$ \\
\hline Robbery & $-0.000277(\mathrm{p}=0.663)$ & $-0.000529(\mathrm{p}=0.403)$ & $-0.000309(\mathrm{p}=0.735)$ \\
\hline Assault & $0.000592(\mathrm{p}=0.303)$ & $0.000937(\mathrm{p}=0.182)$ & $0.000212(\mathrm{p}=0.764)$ \\
\hline Burglary & $-0.000357(\mathrm{p}=0.389)$ & $-0.000494(\mathrm{p}=0.189)$ & $-0.000290(\mathrm{p}=0.701)$ \\
\hline Theft & $-0.000268(\mathrm{p}=0.527)$ & $-0.000320(\mathrm{p}=0.560)$ & $-0.000169(\mathrm{p}=0.769)$ \\
\hline Other Non-Violent & $0.000522(p=0.545)$ & $0.000509(\mathrm{p}=0.656)$ & $0.000669(\mathrm{p}=0.630)$ \\
\hline Drug & $0.000179(\mathrm{p}=0.570)$ & $0.000233(\mathrm{p}=0.499)$ & $0.000272(\mathrm{p}=0.401)$ \\
\hline Weapon & $-0.000015(\mathrm{p}=0.976)$ & $0.000091(\mathrm{p}=0.789)$ & $-0.000183(\mathrm{p}=0.632)$ \\
\hline High-Crime Area & $-0.000162(\mathrm{p}=0.909)$ & $-0.000386(\mathrm{p}=0.307)$ & $0.000381(\mathrm{p}=0.414)$ \\
\hline Class 0 & $0.000041(\mathrm{p}=0.928)$ & $-0.000336(\mathrm{p}=0.509)$ & $0.000562(\mathrm{p}=0.473)$ \\
\hline Class 1 & $0.000001(\mathrm{p}=0.998)$ & $-0.000140(\mathrm{p}=0.720)$ & $0.000298(\mathrm{p}=0.579)$ \\
\hline Class 2 & $-0.000261(\mathrm{p}=0.670)$ & $-0.000477(\mathrm{p}=0.194)$ & $0.000343(\mathrm{p}=0.438)$ \\
\hline Class 3 & $0.000962(\mathrm{p}=0.341)$ & $0.001444(\mathrm{p}<0.01)$ & $-0.000166(\mathrm{p}=0.675)$ \\
\hline Class 4 & $-0.000335(\mathrm{p}=0.820)$ & $0.000119(\mathrm{p}=0.719)$ & $-0.001144(\mathrm{p}=0.162)$ \\
\hline
\end{tabular}

Notes: Each row reports three regression coefficients, e.g. the row Age reports the coefficients on our LOM severity measure $z_{j(i, t)}$ from three regressions of age at arraignment on dummies for year of case assignment and $z_{j(i, t)}$. The first regression pools all first and repeat offenders in one regression but employs $z_{j(i, t)}$ measures that are specific to the first-offender status of defendant $i$. The other regressions restrict the sample to cases that involve either first or repeat offenders. We report p-values derived from HAC standard errors, and we cluster at the judge level. 


\title{
Table 3 - Impact of Incarceration on New Charges
}

\author{
Panel A: First Offenders
}

\begin{tabular}{lcccc}
$Y_{s}$ & $\bar{Y}_{s}$ & OLS & RF & 2SLS \\
\hline New Charge $<12 \mathrm{~m}$ & 0.19 & $-0.158(0.006)[\mathrm{p}<0.01]$ & $-0.285(0.065)[\mathrm{p}<0.01]$ & $-0.353(0.079)[\mathrm{p}<0.01]$ \\
New Charge $<24 \mathrm{~m}$ & 0.31 & $-0.142(0.010)[\mathrm{p}<0.01]$ & $-0.301(0.092)[\mathrm{p}<0.01]$ & $-0.371(0.106)[\mathrm{p}<0.01]$ \\
New Charge $<36 \mathrm{~m}$ & 0.38 & $-0.108(0.008)[\mathrm{p}<0.01]$ & $-0.274(0.080)[\mathrm{p}<0.01]$ & $-0.339(0.093)[\mathrm{p}<0.01]$ \\
New Charge $<48 \mathrm{~m}$ & 0.44 & $-0.080(0.008)[\mathrm{p}<0.01]$ & $-0.248(0.087)[\mathrm{p}<0.01]$ & $-0.306(0.101)[\mathrm{p}<0.01]$ \\
New Charge $<60 \mathrm{~m}$ & 0.47 & $-0.063(0.008)[\mathrm{p}<0.01]$ & $-0.238(0.099)[\mathrm{p}=0.02]$ & $-0.294(0.117)[p=0.01]$ \\
New Charge $<72 \mathrm{~m}$ & 0.50 & $-0.049(0.009)[\mathrm{p}<0.01]$ & $-0.235(0.095)[p=0.02]$ & $-0.290(0.114)[p=0.01]$ \\
New Charge $<84 \mathrm{~m}$ & 0.52 & $-0.039(0.008)[\mathrm{p}<0.01]$ & $-0.186(0.080)[\mathrm{p}=0.02]$ & $-0.230(0.095)[\mathrm{p}=0.02]$ \\
\hline
\end{tabular}

$\bar{\tau}=0.19$, Standard Deviation of LOM: .028, F-Statistic: 246, N: 37,055

$f(l): 0(81 \%),(0,12](8 \%),(12,24](4 \%),(24,36](4 \%),(36,48](2 \%),(48,60](1 \%),[60, \infty)(1 \%)$

\section{Panel B: Repeat Offenders}

\begin{tabular}{lcccc}
$Y_{s}$ & $\bar{Y}_{s}$ & OLS & $\mathrm{RF}$ & 2 SLS \\
\hline New Charge $<12 \mathrm{~m}$ & 0.14 & $-0.189(0.007)[\mathrm{p}<0.01]$ & $-0.199(0.068)[\mathrm{p}<0.01]$ & $-0.227(0.073)[\mathrm{p}<0.01]$ \\
New Charge $<24 \mathrm{~m}$ & 0.31 & $-0.152(0.008)[\mathrm{p}<0.01]$ & $-0.154(0.081)[\mathrm{p}=0.06]$ & $-0.176(0.090)[\mathrm{p}=0.05]$ \\
New Charge $<36 \mathrm{~m}$ & 0.44 & $-0.096(0.008)[\mathrm{p}<0.01]$ & $-0.171(0.074)[\mathrm{p}=0.03]$ & $-0.195(0.082)[\mathrm{p}=0.02]$ \\
New Charge $<48 \mathrm{~m}$ & 0.52 & $-0.058(0.009)[\mathrm{p}<0.01]$ & $-0.087(0.062)[\mathrm{p}=0.17]$ & $-0.099(0.070)[\mathrm{p}=0.16]$ \\
New Charge $<60 \mathrm{~m}$ & 0.58 & $-0.039(0.009)[\mathrm{p}<0.01]$ & $-0.005(0.070)[\mathrm{p}=0.94]$ & $-0.006(0.078)[p=0.94]$ \\
New Charge $<72 \mathrm{~m}$ & 0.62 & $-0.022(0.008)[\mathrm{p}<0.01]$ & $\mathbf{0 . 0 0 1}(0.064)[\mathrm{p}=0.99]$ & $\mathbf{0 . 0 0 1}(0.072)[p=0.99]$ \\
New Charge $<84 \mathrm{~m}$ & 0.65 & $-0.012(0.008)[\mathrm{p}=0.13]$ & $-0.003(0.064)[\mathrm{p}=0.97]$ & $-0.003(0.072)[\mathrm{p}=0.97]$ \\
\hline
\end{tabular}

$\bar{\tau}=0.66$, Standard Deviation of LOM: .043, F-Statistic: $748, \mathrm{~N}: 33,526$

$f(l): 0(34 \%),(0,12](35 \%),(12,24](14 \%),(24,36](10 \%),(36,48](3 \%),(48,60](2 \%),[60, \infty)(2 \%)$

Notes: Each panel reports results from seven OLS, RF, and 2SLS models. In the OLS and 2SLS models, each entry is the estimated coefficient on $\tau_{j(i, t)}$, which is an indicator that equals one if judge $j$ assigns an incarceration sentence to defendant $i$ at date $t$. In the RF column, each entry is the estimated coefficient on $z_{j(i, t)}$, the LOM severity measure associated with judge $j$. In each row, the outcome variable is an indicator for the presence of at least one new charge before a given horizon. The F-statistics are test statistics for the null that $z_{j(i, t)}$ does not predict $\tau_{j(i, t)}$ given our controls for case and defendant characteristics. We report HAC standard errors. For first offenders, we cluster at the judge level. For repeat offenders, we two-way cluster at the defendant*judge level. $\bar{\tau}$ gives the fraction of the sample that received an incarceration sentence. Entries in bold type are treatment impacts that are statistically different among first versus repeat offenders given $p=.1$, and entries in bold italics are different given $p=.05 . f(l)$ is a discrete density that describes the distribution of expected incarceration time given the sentences assigned to defendants. Note that $f(0)=1-\bar{\tau}$ by definition. 


\title{
Table 4 - Impact of Incarceration on New Charges Black Defendants Only
}

\author{
Panel A: First Offenders
}

\begin{tabular}{lcccc}
$Y_{s}$ & $\bar{Y}_{s}$ & OLS & RF & 2SLS \\
\hline New Charge $<12 \mathrm{~m}$ & 0.22 & $-0.181(0.007)[\mathrm{p}<0.01]$ & $-0.236(0.075)[\mathrm{p}<0.01]$ & $-0.310(0.092)[\mathrm{p}<0.01]$ \\
New Charge $<24 \mathrm{~m}$ & 0.35 & $-0.169(0.011)[\mathrm{p}<0.01]$ & $-0.244(0.085)[\mathrm{p}<0.01]$ & $-0.321(0.100)[\mathrm{p}<0.01]$ \\
New Charge $<36 \mathrm{~m}$ & 0.44 & $-0.133(0.009)[\mathrm{p}<0.01]$ & $-0.255(0.075)[\mathrm{p}<0.01]$ & $-0.335(0.092)[\mathrm{p}<0.01]$ \\
New Charge $<48 \mathrm{~m}$ & 0.50 & $-0.100(0.009)[\mathrm{p}<0.01]$ & $-0.251(0.073)[\mathrm{p}<0.01]$ & $-0.329(0.085)[p<0.01]$ \\
New Charge $<60 \mathrm{~m}$ & 0.54 & $-0.078(0.010)[\mathrm{p}<0.01]$ & $-0.213(0.083)[\mathrm{p}=0.01]$ & $-0.279(0.102)[p<0.01]$ \\
New Charge $<72 \mathrm{~m}$ & 0.57 & $-0.064(0.011)[\mathrm{p}<0.01]$ & $-0.194(0.079)[\mathrm{p}=0.02]$ & $-0.254(0.102)[p=0.01]$ \\
New Charge $<84 \mathrm{~m}$ & 0.59 & $-0.052(0.010)[\mathrm{p}<0.01]$ & $-0.114(0.074)[\mathrm{p}=0.13]$ & $-0.149(0.094)[\mathrm{p}=0.11]$ \\
\hline
\end{tabular}

$\bar{\tau}=0.20$, Standard Deviation of LOM: .032, F-Statistic: $133, \mathrm{~N}: 25,223$

$f(l): 0(80 \%),(0,12](8 \%),(12,24](4 \%),(24,36](4 \%),(36,48](2 \%),(48,60](1 \%),[60, \infty)(1 \%)$

\section{Panel B: Repeat Offenders}

\begin{tabular}{lcccc}
$Y_{s}$ & $\bar{Y}_{s}$ & OLS & $\mathrm{RF}$ & $2 \mathrm{SLS}$ \\
\hline New Charge $<12 \mathrm{~m}$ & 0.14 & $-0.194(0.006)[\mathrm{p}<0.01]$ & $-0.188(0.067)[\mathrm{p}<0.01]$ & $-0.218(0.074)[\mathrm{p}<0.01]$ \\
New Charge $<24 \mathrm{~m}$ & 0.32 & $-0.158(0.008)[\mathrm{p}<0.01]$ & $-0.133(0.088)[\mathrm{p}=0.14]$ & $-0.154(0.099)[\mathrm{p}=0.12]$ \\
New Charge $<36 \mathrm{~m}$ & 0.45 & $-0.100(0.008)[\mathrm{p}<0.01]$ & $-0.162(0.084)[\mathrm{p}=0.06]$ & $-0.188(0.095)[\mathrm{p}=0.05]$ \\
New Charge $<48 \mathrm{~m}$ & 0.54 & $-0.062(0.009)[\mathrm{p}<0.01]$ & $-0.076(0.070)[\mathrm{p}=0.28]$ & $-0.088(0.079)[p=0.27]$ \\
New Charge $<60 \mathrm{~m}$ & 0.60 & $-0.044(0.009)[\mathrm{p}<0.01]$ & $-0.008(0.078)[\mathrm{p}=0.92]$ & $-0.009(0.090)[p=0.92]$ \\
New Charge $<72 \mathrm{~m}$ & 0.64 & $-0.027(0.008)[\mathrm{p}<0.01]$ & $0.010(0.074)[\mathrm{p}=0.90]$ & $0.011(0.085)[p=0.89]$ \\
New Charge $<84 \mathrm{~m}$ & 0.67 & $-0.017(0.008)[\mathrm{p}=0.04]$ & $0.010(0.076)[\mathrm{p}=0.90]$ & $0.012(0.087)[\mathrm{p}=0.89]$ \\
\hline $\bar{\tau}=0.67$, Standard Deviation of LOM: $.044, \mathrm{~F}-$ Statistic: $542, \mathrm{~N}: 28,087$ \\
$f(l): 0(33 \%),(0,12](37 \%),(12,24](14 \%),(24,36](10 \%),(36,48](3 \%),(48,60](2 \%),[60, \infty)(2 \%)$
\end{tabular}

Notes: See notes below Table 3 for details. In these panels, we restrict the sample to Black defendants. Further, we employ LOM measures, $z_{j(i, t)}$, that are averages over only Black first and repeat offenders respectively. Entries in bold type are treatment impacts that are statistically different among first versus repeat offenders given $p=.1$, and entries in bold italics are different given $p=.05$. 


\title{
Table 5 \\ Impact of Incarceration on New Charges \\ Drug Offenders vs Non-Drug Offenders
}

\author{
Panel A: First Offenders - Drugs Charge
}

\begin{tabular}{lcccc}
$Y_{s}$ & $\bar{Y}_{s}$ & OLS & $\mathrm{RF}$ & $2 \mathrm{SLS}$ \\
\hline New Charge $<12 \mathrm{~m}$ & 0.24 & $-0.158(0.009)[\mathrm{p}<0.01]$ & $-0.224(0.078)[\mathrm{p}<0.01]$ & $-0.340(0.105)[\mathrm{p}<0.01]$ \\
New Charge $<24 \mathrm{~m}$ & 0.37 & $-0.126(0.012)[\mathrm{p}<0.01]$ & $-0.225(0.125)[\mathrm{p}=0.08]$ & $-0.340(0.173)[\mathrm{p}=0.05]$ \\
New Charge $<36 \mathrm{~m}$ & 0.45 & $-0.113(0.011)[\mathrm{p}<0.01]$ & $-0.297(0.113)[\mathrm{p}=0.01]$ & $-0.449(0.155)[\mathrm{p}<0.01]$ \\
New Charge $<48 \mathrm{~m}$ & 0.50 & $-0.091(0.012)[\mathrm{p}<0.01]$ & $-0.266(0.127)[\mathrm{p}=0.04]$ & $-0.402(0.179)[\mathrm{p}=0.02]$ \\
New Charge $<60 \mathrm{~m}$ & 0.53 & $-0.079(0.012)[\mathrm{p}<0.01]$ & $-0.161(0.150)[\mathrm{p}=0.29]$ & $-0.244(0.216)[\mathrm{p}=0.26]$ \\
New Charge $<72 \mathrm{~m}$ & 0.56 & $-0.075(0.011)[\mathrm{p}<0.01]$ & $-0.130(0.134)[\mathrm{p}=0.34]$ & $-0.197(0.195)[\mathrm{p}=0.31]$ \\
New Charge $<84 \mathrm{~m}$ & 0.58 & $-0.068(0.011)[\mathrm{p}<0.01]$ & $-0.083(0.130)[\mathrm{p}=0.52]$ & $-0.126(0.191)[\mathrm{p}=0.51]$ \\
\hline
\end{tabular}

$\bar{\tau}=0.13$, Standard Deviation of LOM: .036, F-Statistic: $59, \mathrm{~N}: 15,542$

$f(l): 0(87 \%),(0,12](6 \%),(12,24](3 \%),(24,36](2 \%),(36,48](1 \%),(48,60](0 \%),[60, \infty)(1 \%)$

\section{Panel B: First Offenders - Non-Drug Charge}

\begin{tabular}{lcccc}
$Y_{s}$ & $\bar{Y}_{s}$ & OLS & $\mathrm{RF}$ & 2SLS \\
\hline New Charge $<12 \mathrm{~m}$ & 0.16 & $-0.139(0.007)[\mathrm{p}<0.01]$ & $-0.207(0.065)[\mathrm{p}<0.01]$ & $-0.325(0.109)[\mathrm{p}<0.01]$ \\
New Charge $<24 \mathrm{~m}$ & 0.26 & $-0.121(0.013)[\mathrm{p}<0.01]$ & $-0.183(0.087)[\mathrm{p}=0.04]$ & $-0.287(0.145)[\mathrm{p}=0.05]$ \\
New Charge $<36 \mathrm{~m}$ & 0.34 & $-0.074(0.012)[\mathrm{p}<0.01]$ & $-0.156(0.091)[\mathrm{p}=0.09]$ & $-0.245(0.150)[\mathrm{p}=0.10]$ \\
New Charge $<48 \mathrm{~m}$ & 0.39 & $-0.043(0.011)[\mathrm{p}<0.01]$ & $-0.169(0.088)[\mathrm{p}=0.06]$ & $-0.264(0.148)[\mathrm{p}=0.07]$ \\
New Charge $<60 \mathrm{~m}$ & 0.43 & $-0.024(0.012)[\mathrm{p}=0.05]$ & $-0.209(0.082)[\mathrm{p}=0.01]$ & $-0.327(0.143)[\mathrm{p}=0.02]$ \\
New Charge $<72 \mathrm{~m}$ & 0.45 & $-0.007(0.012)[\mathrm{p}=0.55]$ & $-0.240(0.088)[\mathrm{p}<0.01]$ & $-0.377(0.154)[\mathrm{p}=0.01]$ \\
New Charge $<84 \mathrm{~m}$ & 0.47 & $0.003(0.012)[\mathrm{p}=0.81]$ & $-0.231(0.075)[\mathrm{p}<0.01]$ & $-0.361(0.134)[\mathrm{p}<0.01]$ \\
\hline
\end{tabular}

$\bar{\tau}=0.23$, Standard Deviation of LOM: .033, F-Statistic: $68, \mathrm{~N}: 21,513$

$f(l): 0(77 \%),(0,12](9 \%),(12,24](5 \%),(24,36](5 \%),(36,48](2 \%),(48,60](1 \%),[60, \infty)(1 \%)$

Notes: These panels present results that parallel the results in Panel A of Table 3. However, here we run separate models for first offenders charged with drug crimes versus first offenders who are not. We employ LOM measures of judge severity that are specific to samples defined by the interaction of first-offender status and an indicator for a lead charge that is a drug crime. 


\title{
Table 5 (continued) Impact of Incarceration on New Charges
}

\author{
Panel C: Repeat Offenders - Drugs Charge
}

\begin{tabular}{lcccc}
$Y_{s}$ & $\bar{Y}_{s}$ & OLS & $\mathrm{RF}$ & $2 \mathrm{SLS}$ \\
\hline New Charge $<12 \mathrm{~m}$ & 0.16 & $-0.174(0.008)[\mathrm{p}<0.01]$ & $-0.175(0.074)[\mathrm{p}=0.02]$ & $-0.206(0.081)[\mathrm{p}=0.01]$ \\
New Charge $<24 \mathrm{~m}$ & 0.35 & $-0.129(0.011)[\mathrm{p}<0.01]$ & $-0.071(0.086)[\mathrm{p}=0.41]$ & $-0.083(0.098)[\mathrm{p}=0.39]$ \\
New Charge $<36 \mathrm{~m}$ & 0.48 & $-0.074(0.011)[\mathrm{p}<0.01]$ & $-0.117(0.072)[\mathrm{p}=0.11]$ & $-0.138(0.081)[\mathrm{p}=0.09]$ \\
New Charge $<48 \mathrm{~m}$ & 0.56 & $-0.038(0.011)[\mathrm{p}<0.01]$ & $-0.022(0.071)[\mathrm{p}=0.76]$ & $-0.026(0.082)[\mathrm{p}=0.75]$ \\
New Charge $<60 \mathrm{~m}$ & 0.61 & $-0.025(0.011)[\mathrm{p}=0.02]$ & $0.032(0.067)[\mathrm{p}=0.64]$ & $0.037(0.078)[\mathrm{p}=0.63]$ \\
New Charge $<72 \mathrm{~m}$ & 0.65 & $-0.013(0.009)[\mathrm{p}=0.19]$ & $0.047(0.069)[\mathrm{p}=0.50]$ & $0.056(0.081)[\mathrm{p}=0.49]$ \\
New Charge $<84 \mathrm{~m}$ & 0.68 & $-0.007(0.009)[\mathrm{p}=0.44]$ & $0.051(0.069)[\mathrm{p}=0.47]$ & $0.059(0.081)[\mathrm{p}=0.46]$ \\
\hline
\end{tabular}

$\bar{\tau}=0.62$, Standard Deviation of LOM: .059, F-Statistic: 325, N: 15,557

$f(l): 0(38 \%),(0,12](39 \%),(12,24](12 \%),(24,36](8 \%),(36,48](2 \%),(48,60](1 \%),[60, \infty)(1 \%)$

\section{Panel D: Repeat Offenders - Non-Drug Charge}

\begin{tabular}{lcccc}
$Y_{s}$ & $\bar{Y}_{s}$ & OLS & $\mathrm{RF}$ & $2 \mathrm{SLS}$ \\
\hline New Charge $<12 \mathrm{~m}$ & 0.12 & $-0.203(0.010)[\mathrm{p}<0.01]$ & $-0.173(0.061)[\mathrm{p}<0.01]$ & $-0.230(0.075)[\mathrm{p}<0.01]$ \\
New Charge $<24 \mathrm{~m}$ & 0.28 & $-0.169(0.010)[\mathrm{p}<0.01]$ & $-0.263(0.069)[\mathrm{p}<0.01]$ & $-0.349(0.082)[\mathrm{p}<0.01]$ \\
New Charge $<36 \mathrm{~m}$ & 0.40 & $-0.108(0.011)[\mathrm{p}<0.01]$ & $-0.259(0.072)[\mathrm{p}<0.01]$ & $-0.343(0.092)[\mathrm{p}<0.01]$ \\
New Charge $<48 \mathrm{~m}$ & 0.49 & $-0.068(0.011)[\mathrm{p}<0.01]$ & $-0.209(0.074)[\mathrm{p}<0.01]$ & $-0.277(0.102)[\mathrm{p}<0.01]$ \\
New Charge $<60 \mathrm{~m}$ & 0.55 & $-0.044(0.010)[\mathrm{p}<0.01]$ & $-0.064(0.074)[\mathrm{p}=0.39]$ & $-0.085(0.098)[\mathrm{p}=0.39]$ \\
New Charge $<72 \mathrm{~m}$ & 0.60 & $-0.023(0.010)[\mathrm{p}=0.02]$ & $-0.086(0.064)[\mathrm{p}=0.19]$ & $-0.114(0.085)[\mathrm{p}=0.18]$ \\
New Charge $<84 \mathrm{~m}$ & 0.63 & $-0.010(0.010)[\mathrm{p}=0.31]$ & $-0.096(0.064)[\mathrm{p}=0.14]$ & $-0.127(0.086)[\mathrm{p}=0.14]$ \\
\hline
\end{tabular}

$\bar{\tau}=0.70$, Standard Deviation of LOM: .043, F-Statistic: 134, N: 17,969

$f(l): 0(30 \%),(0,12](32 \%),(12,24](15 \%),(24,36](12 \%),(36,48](5 \%),(48,60](3 \%),[60, \infty)(4 \%)$

Notes: These panels present results that parallel the results in Panel B of Table 3. However, here we run separate models for repeat offenders charged with drug crimes versus repeat offenders who are not. We employ LOM measures of judge severity that are specific to samples defined by the interaction of repeat-offender status and an indicator for a lead charge that is a drug crime. 


\title{
Table 6 \\ Impact of Incarceration on New Charges \\ Offenders from High versus Low Crime Neigborhoods
}

\author{
Panel A: First Offenders - High Crime Neighborhoods
}

\begin{tabular}{lcccc}
$Y_{s}$ & $\bar{Y}_{s}$ & OLS & $\mathrm{RF}$ & 2 SLS \\
\hline New Charge $<12 \mathrm{~m}$ & 0.23 & $-0.180(0.009)[\mathrm{p}<0.01]$ & $-0.220(0.069)[\mathrm{p}<0.01]$ & $-0.289(0.086)[\mathrm{p}<0.01]$ \\
New Charge $<24 \mathrm{~m}$ & 0.37 & $-0.168(0.013)[\mathrm{p}<0.01]$ & $-0.253(0.089)[\mathrm{p}<0.01]$ & $-0.331(0.107)[\mathrm{p}<0.01]$ \\
New Charge $<36 \mathrm{~m}$ & 0.46 & $-0.132(0.012)[\mathrm{p}<0.01]$ & $-0.257(0.083)[\mathrm{p}<0.01]$ & $-0.336(0.098)[\mathrm{p}<0.01]$ \\
New Charge $<48 \mathrm{~m}$ & 0.51 & $-0.096(0.011)[\mathrm{p}<0.01]$ & $-0.240(0.077)[\mathrm{p}<0.01]$ & $-0.314(0.089)[\mathrm{p}<0.01]$ \\
New Charge $<60 \mathrm{~m}$ & 0.55 & $-0.078(0.011)[\mathrm{p}<0.01]$ & $-0.209(0.092)[\mathrm{p}=0.03]$ & $-0.273(0.112)[\mathrm{p}=0.01]$ \\
New Charge $<72 \mathrm{~m}$ & 0.58 & $-0.063(0.011)[\mathrm{p}<0.01]$ & $-0.186(0.090)[\mathrm{p}=0.04]$ & $-0.244(0.111)[\mathrm{p}=0.03]$ \\
New Charge $<84 \mathrm{~m}$ & 0.60 & $-0.051(0.009)[\mathrm{p}<0.01]$ & $-0.118(0.085)[\mathrm{p}=0.17]$ & $-0.154(0.106)[\mathrm{p}=0.14]$ \\
\hline
\end{tabular}

$\bar{\tau}=0.20$, Standard Deviation of LOM: .035, F-Statistic: 151, N: 20,605

$f(l): 0(80 \%),(0,12](8 \%),(12,24](4 \%),(24,36](4 \%),(36,48](2 \%),(48,60](1 \%),[60, \infty)(1 \%)$

\section{Panel B: First Offenders - Low Crime Neighborhoods}

\begin{tabular}{lcccc}
$Y_{s}$ & $\bar{Y}_{s}$ & OLS & $\mathrm{RF}$ & $2 \mathrm{SLS}$ \\
\hline New Charge $<12 \mathrm{~m}$ & 0.15 & $-0.127(0.006)[\mathrm{p}<0.01]$ & $-0.292(0.068)[\mathrm{p}<0.01]$ & $-0.594(0.152)[\mathrm{p}<0.01]$ \\
New Charge $<24 \mathrm{~m}$ & 0.24 & $-0.108(0.009)[\mathrm{p}<0.01]$ & $-0.281(0.091)[\mathrm{p}<0.01]$ & $-0.571(0.209)[\mathrm{p}<0.01]$ \\
New Charge $<36 \mathrm{~m}$ & 0.30 & $-0.079(0.010)[\mathrm{p}<0.01]$ & $-0.178(0.098)[\mathrm{p}=0.08]$ & $-0.363(0.199)[\mathrm{p}=0.07]$ \\
New Charge $<48 \mathrm{~m}$ & 0.34 & $-0.059(0.009)[\mathrm{p}<0.01]$ & $-0.175(0.100)[\mathrm{p}=0.09]$ & $-0.356(0.206)[\mathrm{p}=0.08]$ \\
New Charge $<60 \mathrm{~m}$ & 0.37 & $-0.043(0.011)[\mathrm{p}<0.01]$ & $-0.237(0.102)[\mathrm{p}=0.02]$ & $-0.482(0.212)[\mathrm{p}=0.02]$ \\
New Charge $<72 \mathrm{~m}$ & 0.40 & $-0.032(0.010)[\mathrm{p}<0.01]$ & $-0.295(0.102)[\mathrm{p}<0.01]$ & $-0.599(0.215)[\mathrm{p}<0.01]$ \\
New Charge $<84 \mathrm{~m}$ & 0.42 & $-0.024(0.011)[\mathrm{p}=0.03]$ & $-0.319(0.098)[\mathrm{p}<0.01]$ & $-0.649(0.225)[\mathrm{p}<0.01]$ \\
\hline
\end{tabular}

$\bar{\tau}=0.19$, Standard Deviation of LOM: .027, F-Statistic: 22, N: 16,450

$f(l): 0(81 \%),(0,12](8 \%),(12,24](4 \%),(24,36](4 \%),(36,48](2 \%),(48,60](1 \%),[60, \infty)(1 \%)$

Notes: These panels present results that parallel the results in Panel A of Table 3. However, here we run separate models for first offenders who grew up in high-crime neighborhoods versus first offenders who do not. We employ LOM measures of judge severity that are specific to samples defined by the interaction of first-offender status and an indicator for initial residence in a high-crime neighborhood. Appendix materials in section 15.10 describe how we identify high-crime neighborhoods. 


\title{
Table 6 (continued) Impact of Incarceration on New Charges
}

\author{
Panel C: Repeat Offenders - High Crime Neighborhoods
}

\begin{tabular}{lcccc}
$Y_{s}$ & $\bar{Y}_{s}$ & OLS & $\mathrm{RF}$ & $2 \mathrm{SLS}$ \\
\hline New Charge $<12 \mathrm{~m}$ & 0.14 & $-0.188(0.007)[\mathrm{p}<0.01]$ & $-0.193(0.067)[\mathrm{p}<0.01]$ & $-0.232(0.079)[\mathrm{p}<0.01]$ \\
New Charge $<24 \mathrm{~m}$ & 0.32 & $-0.158(0.009)[\mathrm{p}<0.01]$ & $-0.115(0.096)[\mathrm{p}=0.24]$ & $-0.138(0.113)[\mathrm{p}=0.22]$ \\
New Charge $<36 \mathrm{~m}$ & 0.45 & $-0.100(0.008)[\mathrm{p}<0.01]$ & $-0.157(0.090)[\mathrm{p}=0.09]$ & $-0.188(0.106)[\mathrm{p}=0.08]$ \\
New Charge $<48 \mathrm{~m}$ & 0.54 & $-0.059(0.008)[\mathrm{p}<0.01]$ & $-0.080(0.074)[\mathrm{p}=0.29]$ & $-0.096(0.088)[\mathrm{p}=0.28]$ \\
New Charge $<60 \mathrm{~m}$ & 0.60 & $-0.042(0.008)[\mathrm{p}<0.01]$ & $-0.021(0.082)[\mathrm{p}=0.80]$ & $-0.025(0.097)[\mathrm{p}=0.80]$ \\
New Charge $<72 \mathrm{~m}$ & 0.64 & $-0.022(0.008)[\mathrm{p}<0.01]$ & $0.023(0.073)[\mathrm{p}=0.76]$ & $0.027(0.086)[\mathrm{p}=0.75]$ \\
New Charge $<84 \mathrm{~m}$ & 0.67 & $-0.013(0.008)[\mathrm{p}=0.10]$ & $0.025(0.068)[\mathrm{p}=0.72]$ & $0.029(0.080)[\mathrm{p}=0.71]$ \\
\hline
\end{tabular}

$\bar{\tau}=0.68$, Standard Deviation of LOM: .044, F-Statistic: $351, \mathrm{~N}: 23,833$

$f(l): 0(32 \%),(0,12](37 \%),(12,24](14 \%),(24,36](10 \%),(36,48](3 \%),(48,60](2 \%),[60, \infty)(2 \%)$

\section{Panel D: Repeat Offenders - Low Crime Neighborhoods}

\begin{tabular}{lcccc}
$Y_{s}$ & $\bar{Y}_{s}$ & OLS & $\mathrm{RF}$ & $2 \mathrm{SLS}$ \\
\hline New Charge $<12 \mathrm{~m}$ & 0.13 & $-0.189(0.010)[\mathrm{p}<0.01]$ & $-0.155(0.068)[\mathrm{p}=0.03]$ & $-0.218(0.081)[\mathrm{p}<0.01]$ \\
New Charge $<24 \mathrm{~m}$ & 0.27 & $-0.136(0.012)[\mathrm{p}<0.01]$ & $-0.156(0.077)[\mathrm{p}=0.05]$ & $-0.219(0.102)[\mathrm{p}=0.03]$ \\
New Charge $<36 \mathrm{~m}$ & 0.39 & $-0.082(0.014)[\mathrm{p}<0.01]$ & $-0.152(0.087)[\mathrm{p}=0.09]$ & $-0.213(0.112)[\mathrm{p}=0.06]$ \\
New Charge $<48 \mathrm{~m}$ & 0.47 & $-0.053(0.014)[\mathrm{p}<0.01]$ & $-0.075(0.078)[\mathrm{p}=0.34]$ & $-0.106(0.106)[\mathrm{p}=0.32]$ \\
New Charge $<60 \mathrm{~m}$ & 0.53 & $-0.031(0.014)[\mathrm{p}=0.03]$ & $0.015(0.070)[\mathrm{p}=0.83]$ & $0.022(0.097)[\mathrm{p}=0.82]$ \\
New Charge $<72 \mathrm{~m}$ & 0.57 & $-0.019(0.013)[\mathrm{p}=0.15]$ & $0.009(0.070)[\mathrm{p}=0.90]$ & $0.012(0.097)[\mathrm{p}=0.90]$ \\
New Charge $<84 \mathrm{~m}$ & 0.60 & $-0.006(0.012)[\mathrm{p}=0.62]$ & $-0.020(0.073)[\mathrm{p}=0.78]$ & $-0.029(0.100)[\mathrm{p}=0.77]$ \\
\hline
\end{tabular}

$\bar{\tau}=0.66$, Standard Deviation of LOM: .055, F-Statistic: 118, N: 9,693

$f(l): 0(34 \%),(0,12](35 \%),(12,24](14 \%),(24,36](10 \%),(36,48](3 \%),(48,60](2 \%),[60, \infty)(2 \%)$

Notes: These panels present results that parallel the results in Panel B of Table 3. However, here we run separate models for repeat offenders who grew up in high-crime neighborhoods versus repeat offenders who do not. We employ LOM measures of judge severity that are specific to samples defined by the interaction of repeat-offender status and an indicator for initial residence in a high-crime neighborhood. Appendix materials in section 15.10 describe how we identify high-crime neighborhoods. 


\section{Appendix Tables}

\subsection{Balance}

\section{Appendix Table 14.1 Alternative Balance Tests}

\section{$\mathrm{LOM}=$ average deviations from year-specific incarcerations rates}

\begin{tabular}{|c|c|c|c|}
\hline & All & First Offenders & Repeat Offenders \\
\hline Black & $-0.000158(\mathrm{p}=0.936)$ & $-0.000527(\mathrm{p}=0.250)$ & $0.000640(\mathrm{p}=0.245)$ \\
\hline Age & $0.000026(\mathrm{p}=0.951)$ & $0.000044(p=0.179)$ & $0.000029(\mathrm{p}=0.601)$ \\
\hline Height & $0.000048(\mathrm{p}=0.523)$ & $-0.000002(p=0.946)$ & $0.000107(\mathrm{p}=0.184)$ \\
\hline Weight & $0.000001(\mathrm{p}=0.955)$ & $0.000001(\mathrm{p}=0.882)$ & $0.000002(\mathrm{p}=0.811)$ \\
\hline BMI & $-0.000013(\mathrm{p}=0.897)$ & $0.000006(\mathrm{p}=0.837)$ & $-0.000031(\mathrm{p}=0.561)$ \\
\hline Prior Cases & $0.000042(\mathrm{p}=0.982)$ & & $0.000174(\mathrm{p}=0.182)$ \\
\hline Indictment & $-0.000098(\mathrm{p}=0.827)$ & $0.000058(\mathrm{p}=0.881)$ & $-0.000323(\mathrm{p}=0.594)$ \\
\hline Multiple Defendant & $-0.000275(\mathrm{p}=0.508)$ & $-0.000176(\mathrm{p}=0.655)$ & $-0.000462(\mathrm{p}=0.455)$ \\
\hline Multiple Charge & $0.000136(\mathrm{p}=0.771)$ & $0.000444(\mathrm{p}=0.295)$ & $-0.000253(\mathrm{p}=0.693)$ \\
\hline Robbery & $-0.000224(\mathrm{p}=0.744)$ & $-0.000108(\mathrm{p}=0.873)$ & $-0.000525(\mathrm{p}=0.591)$ \\
\hline Assault & $0.000609(\mathrm{p}=0.341)$ & $0.001006(\mathrm{p}=0.190)$ & $0.000124(\mathrm{p}=0.870)$ \\
\hline Burglary & $-0.000135(\mathrm{p}=0.759)$ & $-0.000237(\mathrm{p}=0.583)$ & $-0.000136(\mathrm{p}=0.870)$ \\
\hline Theft & $-0.000274(\mathrm{p}=0.548)$ & $-0.000425(\mathrm{p}=0.421)$ & $-0.000191(\mathrm{p}=0.754)$ \\
\hline Other Non-Violent & $0.000568(\mathrm{p}=0.504)$ & $0.000334(\mathrm{p}=0.770)$ & $0.000718(\mathrm{p}=0.617)$ \\
\hline Drug & $0.000197(\mathrm{p}=0.567)$ & $0.000147(\mathrm{p}=0.676)$ & $0.000257(\mathrm{p}=0.425)$ \\
\hline Weapon & $-0.000220(\mathrm{p}=0.683)$ & $-0.000119(\mathrm{p}=0.761)$ & $-0.000089(\mathrm{p}=0.828)$ \\
\hline High-Crime Area & $-0.000076(p=0.961)$ & $-0.000410(\mathrm{p}=0.256)$ & $0.000393(\mathrm{p}=0.437)$ \\
\hline Class 0 & $0.000128(\mathrm{p}=0.789)$ & $-0.000119(\mathrm{p}=0.825)$ & $0.000436(\mathrm{p}=0.601)$ \\
\hline Class 1 & $0.000047(\mathrm{p}=0.937)$ & $-0.000068(\mathrm{p}=0.870)$ & $0.000159(\mathrm{p}=0.777)$ \\
\hline Class 2 & $-0.000176(\mathrm{p}=0.798)$ & $-0.000557(\mathrm{p}=0.153)$ & $0.000375(\mathrm{p}=0.437)$ \\
\hline Class 3 & $0.000825(\mathrm{p}=0.477)$ & $0.001461(\mathrm{p}<0.01)$ & $-0.000072(\mathrm{p}=0.866)$ \\
\hline Class 4 & $-0.000447(\mathrm{p}=0.787)$ & $0.000008(\mathrm{p}=0.980)$ & $-0.001028(\mathrm{p}=0.224)$ \\
\hline
\end{tabular}

Notes: Each row reports three regression coefficients, e.g. the row Age reports the coefficients on our LOM severity measure $z_{j(i, t)}$ from three regressions of age at arraignment on a dummies for year of case assignment and $z_{j(i, t)}$. The first regression pools all first and repeat offenders in one regression but employs $z_{j(i, t)}$ measures that are specific to the first-offender status of defendant $i$. The other regressions restrict the sample to cases that involve either first or repeat offenders. The LOM severity measures are sums of residuals taken from projections of $\tau_{j(i, t)}$ on dummies for year of case assignments. We report p-values derived from HAC standard errors, and we cluster at the judge level. 


\subsection{Alternative Models}

Appendix Table 14.2

Panel A: Alternative LOM severity Models

FIRST OFFENDERS

\begin{tabular}{|c|c|c|c|}
\hline & Model (1) & Model (2) & Model (3) \\
\hline & $2 S L S$ & $2 S L S$ & $2 S L S$ \\
\hline$<12 \mathrm{~m}$ & $-0.390(0.087)[p<0.01]$ & $-0.341(0.083)[p<0.01]$ & $-0.300(0.082)[p<0.01]$ \\
\hline$<24 \mathrm{~m}$ & $-0.416(0.117)[p<0.01]$ & $-0.364(0.114)[p<0.01]$ & $-0.310(0.114)[p<0.01$ \\
\hline$<36 \mathrm{~m}$ & $-0.389(0.106)[p<0.01]$ & $-0.349(0.105)[p<0.01]$ & $-0.286(0.103)[p<0.01]$ \\
\hline$<48 \mathrm{~m}$ & $-0.356(0.113)[p<0.01]$ & $-0.331(0.107)[p<0.01]$ & $-0.268(0.107)[p=0.01$ \\
\hline$<60 \mathrm{~m}$ & $-0.346(0.128)[p<0.01]$ & $-0.325(0.118)[p<0.01]$ & $-0.263(0.118)[p=0.03]$ \\
\hline$<72 \mathrm{~m}$ & $-0.346(0.126)[p<0.01]$ & $-0.342(0.116)[p<0.01]$ & $-0.278(0.115)[p=0.02]$ \\
\hline$<84 \mathrm{~m}$ & $-0.285(0.108)[p<0.01]$ & $-0.279(0.100)[p<0.01]$ & $-0.214(0.097)[p=0.03]$ \\
\hline
\end{tabular}

Model (1) - LOM = residuals from case-specific means, CONTROLS = year of assignment

Model (2) - LOM = residuals from yearly means, CONTROLS = year of assignment

Model (3) - LOM = residuals from yearly means, CONTROLS = all case characteristics

\section{REPEAT OFFENDERS}

\begin{tabular}{|c|c|c|c|}
\hline & Model (1) & Model (2) & Model (3) \\
\hline & $2 S L S$ & $2 S L S$ & $2 S L S$ \\
\hline$<12 \mathrm{~m}$ & $-0.226(0.071)[p<0.01]$ & $-0.216(0.076)[p<0.01]$ & $-0.217(0.078)[p<0.01]$ \\
\hline$<24 \mathrm{~m}$ & $-0.172(0.091)[p=0.06]$ & $-0.158(0.097)[p=0.10]$ & $-0.164(0.095)[p=0.08]$ \\
\hline$<36 \mathrm{~m}$ & $-0.182(0.086)[p=0.04]$ & $-0.178(0.092)[p=0.05]$ & $-0.193(0.086)[p=0.02$ \\
\hline$<48 m$ & $-0.084(0.076)[p=0.27]$ & $-0.079(0.079)[p=0.31]$ & $-0.096(0.071)[p=0.18]$ \\
\hline$<60 \mathrm{~m}$ & $0.008(0.084)[p=0.92]$ & $0.012(0.086)[p=0.89]$ & $-0.003(0.080)[p=0.97]$ \\
\hline$<72 \mathrm{~m}$ & $0.015(0.077)[p=0.84]$ & $0.017(0.078)[p=0.83]$ & $0.001(0.072)[p=0.99]$ \\
\hline$<84 \mathrm{~m}$ & $0.012(0.078)[p=0.88]$ & $0.012(0.078)[p=0.87]$ & $-0.003(0.072)[p=0.96]$ \\
\hline
\end{tabular}

Notes: We present results from 3 alternative 2SLS models that employ LOM severity measures as instruments for $\tau_{j(i t,)}$. Model (1) employs the same LOM measures we use in Table 3. Models (2) and (3) employ LOM severity measures that are sums of residuals taken from projections of $\tau_{j(i, t)}$ on dummies for year of case assignments. Models (1) and (2) condition only on dummies for year of case assignment.

Model (3) uses our full conditioning set. See section 4.2. Entries in bold type are treatment impacts that are statistically different among first versus repeat offenders given $p=.1$, and entries in bold italics are different given $p=.05$. 


\section{Panel B: $\quad z_{j(i, t)}=$ Vector of Judge Assignment Indicators}

\section{FIRST OFFENDERS}

\begin{tabular}{|c|c|c|c|c|}
\hline & \multicolumn{2}{|c|}{$2 S L S$} & \multicolumn{2}{|c|}{ 2SLS-UJIVE } \\
\hline & \multicolumn{2}{|c|}{ Controls } & \multicolumn{2}{|c|}{ Controls } \\
\hline & Year Only & Full & Year Only & Full \\
\hline$<12 \mathrm{~m}$ & $-0.296(0.063)[p<0.01]$ & $-0.319(0.063)[p<0.01]$ & $-0.331(0.079)[p<0.01]$ & $-0.353(0.076)[p<0.01]$ \\
\hline$<24 m$ & $-0.315(0.088)[p<0.01]$ & $-0.325(0.089)[p<0.01]$ & $-0.356(0.109)[p<0.01]$ & $-0.364(0.104)[p<0.01]$ \\
\hline$<36 \mathrm{~m}$ & $-0.296(0.082)[p<0.01]$ & $-0.293(0.079)[p<0.01]$ & $-0.342(0.101)[p<0.01]$ & $-0.333(0.093)[p<0.01]$ \\
\hline$<48 m$ & $-0.275(0.084)[p<0.01]$ & $-0.261(0.086)[p<0.01]$ & $-0.323(0.103)[p<0.01]$ & $-0.300(0.101)[p<0.01]$ \\
\hline$<60 m$ & $-0.264(0.091)[p<0.01]$ & $-0.244(0.098)[p=0.02]$ & $-0.315(0.113)[p<0.01]$ & $-0.283(0.116)[p=0.01]$ \\
\hline$<72 m$ & $-0.271(0.089)[p<0.01]$ & $-0.236(0.095)[p=0.02]$ & $-0.329(0.111)[p<0.01]$ & $-0.276(0.113)[p=0.01]$ \\
\hline$<84 \mathrm{~m}$ & $-0.221(0.077)[p<0.01]$ & $-0.189(0.081)[p=0.02]$ & $-0.268(0.095)[p<0.01]$ & $-0.220(0.095)[p=0.02]$ \\
\hline
\end{tabular}

\section{REPEAT OFFENDERS}

\begin{tabular}{|c|c|c|c|c|}
\hline & \multicolumn{2}{|c|}{ 2SLS } & \multicolumn{2}{|c|}{ 2SLS-UJIVE } \\
\hline & \multicolumn{2}{|c|}{ Controls } & \multicolumn{2}{|c|}{ Controls } \\
\hline & Year Only & Full & Year Only & Full \\
\hline$<12 \mathrm{~m}$ & $-0.210(0.066)[p<0.01]$ & $-0.221(0.065)[p<0.01]$ & $-0.213(0.075)[p<0.01]$ & $-0.214(0.074)[p<0.01]$ \\
\hline$<24 m$ & $-0.155(0.084)[p=0.07]$ & $-0.172(0.079)[p=0.03]$ & $-0.155(0.096)[p=0.10]$ & $-0.162(0.090)[p=0.07]$ \\
\hline$<36 \mathrm{~m}$ & $-0.161(0.080)[p=0.05]$ & $-0.178(0.072)[p=0.02]$ & $-0.173(0.091)[p=0.06]$ & $-0.181(0.083)[p=0.03]$ \\
\hline$<48 m$ & $-0.068(0.068)[p=0.32]$ & $-0.088(0.061)[p=0.16]$ & $-0.073(0.077)[p=0.34]$ & $-0.087(0.066)[p=0.19]$ \\
\hline$<60 \mathrm{~m}$ & $0.013(0.075)[p=0.86]$ & $-0.005(0.068)[p=0.94]$ & $0.017(0.085)[p=0.84]$ & $0.004(0.075)[p=0.96]$ \\
\hline$<72 \mathrm{~m}$ & $0.020(0.067)[p=0.77]$ & $0.003(0.063)[p=0.97]$ & $0.022(0.077)[p=0.78]$ & $0.012(0.067)[p=0.86]$ \\
\hline$<84 m$ & $0.017(0.068)[p=0.80]$ & $0.000(0.063)[p=1.00]$ & $0.016(0.077)[p=0.83]$ & $0.004(0.067)[\mathrm{p}=0.95]$ \\
\hline
\end{tabular}

Notes: These eight models employ a vector of judge assignment indicators as instruments for $\tau_{j(i, t)}$. As in panel A, some models control for our full set of case and defendant characteristics. See section 4.2. Other control on for year of case assignment. We present results from standard 2SLS and bias-corrected 2SLS results produced by using the Kolesar (2013) UJIVE estimator. Entries in bold type are treatment impacts that are statistically different among first versus repeat offenders given $p=.1$, and entries in bold italics are different given $p=.05$. 


\section{Panel C: $\quad z_{j(i, t)}$ is Top $1 / 3$ vs Bottom $1 / 3$ of Judge Severity}

\section{First Offenders}

\begin{tabular}{lcccc}
$Y_{s}$ & $\bar{Y}_{s}$ & OLS & RF & 2SLS \\
\hline New Charge $<12 \mathrm{~m}$ & 0.19 & $-0.160(0.006)[\mathrm{p}<0.01]$ & $-0.023(0.004)[\mathrm{p}<0.01]$ & $-0.385(0.070)[\mathrm{p}<0.01]$ \\
New Charge $<24 \mathrm{~m}$ & 0.31 & $-0.150(0.012)[\mathrm{p}<0.01]$ & $-0.023(0.006)[\mathrm{p}<0.01]$ & $-0.387(0.088)[\mathrm{p}<0.01]$ \\
New Charge $<36 \mathrm{~m}$ & 0.39 & $-0.114(0.010)[\mathrm{p}<0.01]$ & $-0.021(0.006)[\mathrm{p}<0.01]$ & $-0.345(0.084)[\mathrm{p}<0.01]$ \\
New Charge $<48 \mathrm{~m}$ & 0.44 & $-0.092(0.009)[\mathrm{p}<0.01]$ & $-0.017(0.006)[\mathrm{p}<0.01]$ & $-0.284(0.091)[\mathrm{p}<0.01]$ \\
New Charge $<60 \mathrm{~m}$ & 0.47 & $-0.077(0.010)[\mathrm{p}<0.01]$ & $-0.017(0.006)[\mathrm{p}=0.01]$ & $-0.287(0.099)[p<0.01]$ \\
New Charge $<72 \mathrm{~m}$ & 0.50 & $-0.062(0.010)[\mathrm{p}<0.01]$ & $-0.017(0.006)[p<0.01]$ & $-0.287(0.094)[p<0.01]$ \\
New Charge $<84 \mathrm{~m}$ & 0.52 & $-0.052(0.010)[\mathrm{p}<0.01]$ & $-0.014(0.005)[\mathrm{p}<0.01]$ & $-0.231(0.077)[p<0.01]$ \\
\hline
\end{tabular}

$\bar{\tau}=0.19$, Standard Deviation of LOM: .499, F-Statistic: $97, \mathrm{~N}: 24,299$

$f(l): 0(81 \%),(0,12](8 \%),(12,24](4 \%),(24,36](4 \%),(36,48](2 \%),(48,60](1 \%),[60, \infty)(1 \%)$

\section{Repeat Offenders}

\begin{tabular}{lcccc}
$Y_{s}$ & $\bar{Y}_{s}$ & OLS & $\mathrm{RF}$ & 2SLS \\
\hline New Charge $<12 \mathrm{~m}$ & 0.14 & $-0.189(0.009)[\mathrm{p}<0.01]$ & $-0.017(0.007)[\mathrm{p}=0.03]$ & $-0.182(0.072)[p=0.01]$ \\
New Charge $<24 \mathrm{~m}$ & 0.30 & $-0.152(0.011)[\mathrm{p}<0.01]$ & $-0.015(0.009)[\mathrm{p}=0.09]$ & $-0.165(0.089)[\mathrm{p}=0.06]$ \\
New Charge $<36 \mathrm{~m}$ & 0.43 & $-0.092(0.011)[\mathrm{p}<0.01]$ & $-0.016(0.009)[\mathrm{p}=0.06]$ & $-0.177(0.086)[\mathrm{p}=0.04]$ \\
New Charge $<48 \mathrm{~m}$ & 0.52 & $-0.053(0.011)[\mathrm{p}<0.01]$ & $-0.010(0.007)[\mathrm{p}=0.13]$ & $-0.111(0.068)[\mathrm{p}=0.11]$ \\
New Charge $<60 \mathrm{~m}$ & 0.58 & $-0.034(0.011)[\mathrm{p}<0.01]$ & $-0.002(0.007)[\mathrm{p}=0.81]$ & $-0.018(0.071)[p=0.80]$ \\
New Charge $<72 \mathrm{~m}$ & 0.62 & $-0.017(0.010)[\mathrm{p}=0.10]$ & $-0.001(0.006)[p=0.89]$ & $-0.009(0.060)[p=0.89]$ \\
New Charge $<84 \mathrm{~m}$ & 0.65 & $-0.008(0.010)[\mathrm{p}=0.43]$ & $-0.001(0.006)[\mathrm{p}=0.92]$ & $-0.006(0.060)[\boldsymbol{p}=0.92]$ \\
\hline
\end{tabular}

$\bar{\tau}=0.66$, Standard Deviation of LOM: .499, F-Statistic: 86, N: 21,805

$f(l): 0(34 \%),(0,12](34 \%),(12,24](14 \%),(24,36](10 \%),(36,48](4 \%),(48,60](2 \%),[60, \infty)(3 \%)$

Notes: These results parallel the results in Table 3. However, the samples are smaller. Here, in both the first and repeat offender samples, we only include cases assigned to either one the fifteen most lenient judges or one of the fifteen most severe judges. Further, the instruments we employ are not the LOM severity measures employed in Table 3 but indicators for assignment to one of the 15 judges in one of the high measured severity groups, i.e. severity toward first offenders or repeat offenders. Entries in bold type are treatment impacts that are statistically different among first versus repeat offenders given $p=.1$, and entries in bold italics are different given $p=.05$. 


\title{
14.3 Exclusion Tests
}

\author{
Appendix Table 14.3 \\ Exclusion Test \\ Additional Control for Judge-specific Conviction Rates
}

Panel A: First Offenders

\begin{tabular}{lcccc}
$Y_{s}$ & $\bar{Y}_{s}$ & OLS & RF & 2SLS \\
\hline New Charge $<12 \mathrm{~m}$ & 0.19 & $-0.158(0.006)[\mathrm{p}<0.01]$ & $-0.290(0.065)[\mathrm{p}<0.01]$ & $-0.357(0.079)[\mathrm{p}<0.01]$ \\
New Charge $<24 \mathrm{~m}$ & 0.31 & $-0.142(0.010)[\mathrm{p}<0.01]$ & $-0.309(0.090)[\mathrm{p}<0.01]$ & $-0.380(0.104)[\mathrm{p}<0.01]$ \\
New Charge $<36 \mathrm{~m}$ & 0.38 & $-0.108(0.008)[\mathrm{p}<0.01]$ & $-0.275(0.082)[\mathrm{p}<0.01]$ & $-0.338(0.095)[\mathrm{p}<0.01]$ \\
New Charge $<48 \mathrm{~m}$ & 0.44 & $-0.080(0.008)[\mathrm{p}<0.01]$ & $-0.253(0.087)[\mathrm{p}<0.01]$ & $-0.312(0.100)[\mathrm{p}<0.01]$ \\
New Charge $<60 \mathrm{~m}$ & 0.47 & $-0.063(0.008)[\mathrm{p}<0.01]$ & $-0.247(0.096)[p=0.01]$ & $-0.304(0.113)[p<0.01]$ \\
New Charge $<72 \mathrm{~m}$ & 0.50 & $-0.049(0.009)[\mathrm{p}<0.01]$ & $-0.247(0.090)[p<0.01]$ & $-0.304(0.109)[p<0.01]$ \\
New Charge $<84 \mathrm{~m}$ & 0.52 & $-0.039(0.008)[\mathrm{p}<0.01]$ & $-0.200(0.073)[p<0.01]$ & $-0.247(0.087)[p<0.01]$ \\
\hline
\end{tabular}

$\bar{\tau}=0.19$, Standard Deviation of LOM: .028, F-Statistic: 250, N: 37,055

$f(l): 0(81 \%),(0,12](8 \%),(12,24](4 \%),(24,36](4 \%),(36,48](2 \%),(48,60](1 \%),[60, \infty)(1 \%)$

Panel B: Repeat Offenders

\begin{tabular}{lcccc}
$Y_{s}$ & $\bar{Y}_{s}$ & OLS & $\mathrm{RF}$ & 2SLS \\
\hline New Charge $<12 \mathrm{~m}$ & 0.14 & $-0.188(0.007)[\mathrm{p}<0.01]$ & $-0.183(0.072)[\mathrm{p}=0.01]$ & $-0.207(0.078)[\mathrm{p}<0.01]$ \\
New Charge $<24 \mathrm{~m}$ & 0.31 & $-0.152(0.008)[\mathrm{p}<0.01]$ & $-0.129(0.087)[\mathrm{p}=0.14]$ & $-0.146(0.095)[\mathrm{p}=0.13]$ \\
New Charge $<36 \mathrm{~m}$ & 0.44 & $-0.095(0.008)[\mathrm{p}<0.01]$ & $-0.141(0.075)[\mathrm{p}=0.07]$ & $-0.159(0.082)[\mathrm{p}=0.05]$ \\
New Charge $<48 \mathrm{~m}$ & 0.52 & $-0.058(0.009)[\mathrm{p}<0.01]$ & $-0.072(0.068)[\mathrm{p}=0.29]$ & $-0.081(0.075)[\mathrm{p}=0.28]$ \\
New Charge $<60 \mathrm{~m}$ & 0.58 & $-0.039(0.009)[\mathrm{p}<0.01]$ & $\mathbf{0 . 0 1 4}(0.079)[p=0.86]$ & $\mathbf{0 . 0 1 6}(0.088)[p=0.86]$ \\
New Charge $<72 \mathrm{~m}$ & 0.62 & $-0.022(0.008)[\mathrm{p}<0.01]$ & $\mathbf{0 . 0 1 9}(0.073)[p=0.80]$ & $\mathbf{0 . 0 2 1}(0.082)[p=0.80]$ \\
New Charge $<84 \mathrm{~m}$ & 0.65 & $-0.012(0.008)[\mathrm{p}=0.13]$ & $\mathbf{0 . 0 1 3}(\mathbf{0 . 0 7 5 )}[p=0.87]$ & $\mathbf{0 . 0 1 4}(\mathbf{0 . 0 8 3 )}[p=0.86]$ \\
\hline
\end{tabular}

$\bar{\tau}=0.66$, Standard Deviation of LOM: .043, F-Statistic: 787, N: 33,526

$f(l): 0(34 \%),(0,12](35 \%),(12,24](14 \%),(24,36](10 \%),(36,48](3 \%),(48,60](2 \%),[60, \infty)(2 \%)$

Notes: These panels present results that parallel the results in of Table 3. However, these models include an extra conditioning variable in both the first and second stage equation. We condition on the LOM of conviction. We define these LOM measures at the judge level within cases that involve either first or repeat offenders using residuals. These LOM measures are averages of residuals taken from regressions of an indicator for conviction on our full set of defendant and case characteristics. 


\title{
14.4 Characteristics of Compliers
}

\subsubsection{Expected Recidivism Given No Incarceration}

\author{
Appendix Table 14.4.1 \\ Expected Recidivism Rates given $\tau_{j(i, t)}=0$ \\ All Non-Incarcerated, Never Takers, and Compliers
}

Panel A: First Offenders

\begin{tabular}{cccc}
\hline Horizon & $\mathrm{E}[\mathrm{Y}(0) \mid \tau=0]$ & $\mathrm{E}[\mathrm{Y}(0) \mid \mathrm{NT}=1]$ & $\mathrm{E}[\mathrm{Y}(0) \mid \mathrm{C}=1]$ \\
\hline & & & \\
12 months & .22 & .21 & .42 \\
24 months & .34 & .32 & .57 \\
36 months & .41 & .39 & .64 \\
48 months & .45 & .43 & .69 \\
60 months & .49 & .46 & .73 \\
72 months & .51 & .49 & .76 \\
84 months & .53 & .51 & .74 \\
\hline
\end{tabular}

\section{Panel B: Repeat Offenders}

\begin{tabular}{cccc}
\hline Horizon & $\mathrm{E}[\mathrm{Y}(0) \mid \tau=0]$ & $\mathrm{E}[\mathrm{Y}(0) \mid \mathrm{NT}=1]$ & $\mathrm{E}[\mathrm{Y}(0) \mid \mathrm{C}=1]$ \\
\hline & & & \\
12 months & .26 & .25 & .29 \\
24 months & .40 & .39 & .45 \\
36 months & .49 & .48 & .53 \\
48 months & .54 & .54 & .57 \\
60 months & .59 & .58 & .60 \\
72 months & .61 & .61 & .64 \\
84 months & .63 & .63 & .66 \\
\hline
\end{tabular}

The three columns in each panel present the expected values of our recidivism indicators given different conditioning information. The first column presents sample means among all offenders not sentenced to incarceration. The second column presents estimates of means among never takers. The final column presents estimates of means for the set of compliers who did not receive an incarceration sentence, i.e. their assigned judge did not sentence them to incarceration, but at least one more severe judge would have. We use the linear extrapolation method presented in Dahl et al. (2014) to create the estimates in the final two columns. Extrapolation is required because not all judges handle cases in all years. We extrapolate to estimate how many defendants the most and least severe judges would have sentenced to incarceration given a random sample a cases drawn from all years, and what the recidivism rates would be among those given non-incarceration sentences by the least severe judge. We estimate that among first offenders, $P(N T)=.735, P(C)=.137, P(A T)=.129$. For repeat offenders, $P(N T)=.259, P(C)=.223$, $P(A T)=.518$. 


\subsubsection{Expected Time-Served Given Incarceration}

Appendix Table 14.4.2

Expected Time Served given $\tau_{j(i, t)}=1$

All Incarcerated, Always Takers, and Compliers

Panel A: First Offenders

\begin{tabular}{cccc}
\hline Horizon & $\mathrm{E}\left[I_{s} \mid \tau=1\right]$ & $\mathrm{E}\left[I_{s} \mid A T=1, \tau=1\right]$ & $\mathrm{E}\left[I_{s} \mid C=1, \tau=1\right]$ \\
\hline & & & \\
12 months & .51 & .58 & .29 \\
24 months & .32 & .37 & .15 \\
36 months & .17 & .19 & .09 \\
48 months & .10 & .11 & .08 \\
60 months & .07 & .06 & .09 \\
72 months & .05 & .04 & .07 \\
84 months & .04 & .03 & .05 \\
\hline
\end{tabular}

\section{Panel B: Repeat Offenders}

\begin{tabular}{cccc}
\hline Horizon & $\mathrm{E}\left[I_{s} \mid \tau=1\right]$ & $\mathrm{E}\left[I_{s} \mid A T=1, \tau=1\right]$ & $\mathrm{E}\left[I_{s} \mid C=1, \tau=1\right]$ \\
\hline & & .50 & .40 \\
12 months & .48 & .25 & .24 \\
24 months & .25 & .12 & .10 \\
36 months & .12 & .07 & .05 \\
48 months & .07 & .05 & .03 \\
60 months & .04 & .03 & .03 \\
72 months & .03 & .02 & .02 \\
84 months & .02 & & \\
\hline
\end{tabular}

Notes: The three columns in each panel present the fraction of defendants sentenced to incarceration who remain incarcerated at different horizons. The first column presents sample means for all offenders sentenced to incarceration. The second column presents estimates of means for always takers. The final column presents estimates of means for the set of compliers. As in Table 14.4.1, we use the linear extrapolation method presented in Dahl et al. (2014) to create the estimates in the final two columns. Extrapolation is required for reasons that parallel those discussed in the notes to Table 14.4.1. We estimate that among first offenders, $P(N T)=.735, P(C)=.137, P(A T)=.129$. For repeat offenders, $P(N T)=.259, P(C)=.223, P(A T)=.518$. 


\section{Data Appendix}

Our raw data come from the Clerk of Court for Cook County, IL, and the Illinois Department of Corrections (IDOC). We begin with electronic records from the Clerk of Court that describe cases that were active in the court between January, 1984 and December, 2019. The data contain 531,388 defendants who were involved in 1,273,605 felony cases.

We only use a subset of these records. A later section of this appendix describes all of the sample selection rules we impose. Here, we comment on four key selection rules.

First, we do not include female defendants. The sample of female defendants is too small to analyze separately, and we are not willing to assume that judge severity is invariant to defendant gender.

Second, since we perform separate analyses for first and repeat offenders, we eliminate defendants born before 1967. We cannot determine whether those born before 1967 are facing their first felony charge in Cook County because they may have faced felony charges before 1984 .

Third, we do not consider cases that the Court initiates before 1990 or after 2007. For cases before 1990, we are not able to use IDOC data to help identify cases that involve a nominal prison sentence but no time served in prison. For cases that begin after 2007, we do not have a full seven years of IDOC data following sentencing. This means that we are not able to measure recidivism events that involve charges filed in other counties over the seven-year windows that form our longest observation period for recidivism events.

Finally, we only use cases that we feel confident are randomly assigned to judges who work in the main criminal court in Chicago. Below, we explain how we identify these judges.

Given these key sample restrictions and others motivated by missing data and measurement objectives, our final analysis sample consists of 55,285 defendants involved in 70,581 felony cases initiated between the 2nd of January, 1990 and the 17th of December, 2007.

The Clerk of Court of Cook County provides three types of data:

- the root data contain basic demographic information about the defendant and the case initiation date.

- the charge data describe each charge initiated by prosecutors.

- the dispositions file describes the 54 million dispositions filed during these felony cases.

We rely heavily on the root and charge data when creating variables that characterize defendants and the cases against them. We use the disposition data in concert with IDOC data to determine the effective sentencing decisions made by judges. We use the all court files in concert with IDOC data to mark recidivism events.

\subsection{Initial Cleaning}

After receiving the raw court data, we interviewed a former judge, a former public defender, a former prosecutor, employees of the office of the Clerk of the Circuit Court of Cook County, employees at the Adult Probation department, and representatives of nonprofits that specialize in the criminal justice system. Based on these conversations, we made the following edits:

1. The Clerk of Court occasionally mis-records credit for time served dispositions as probation sentences because the disposition codes are off by one digit. The disposition code for credit for time served is 521 and the disposition code for probation is 531 . We identified these typos by checking whether the sentence length was denominated in days. Probation sentences are never denominated in days, so if a probation sentence length is denominated in days, it is a typo, and the disposition represents credit for time served. We correct these typos in the raw data. In total, we corrected 1,019 dispositions for this reason. 
2. The clerk also occasionally mis-records probation sentences as Credit for Time Served dispositions. We correct 273 cases where we feel confident that this typo occurred.

3. The court occasionally indicates a sentence to CCDOC when the individual is under CCDOC's authority but not actually held in CCDOC. We recode 1,905 dispositions to mark that the defendant was not incarcerated. In these cases, the "free description" (notes) section for each disposition reveals what really happened. We code these as "other" sentences. This category contains all defendants who are found guilty but not required to be supervised by the probation department, IDOC, or the Bootcamp program run in CCDOC by the Sheriff. The "free description" codes associated with "other" sentences are:

- TASC - Treatment Alternatives for Safe Communities, see: https://www.tasc.org/tascweb/home. aspx

- ELECTRONIC - Electronic Monitoring, see: https://www. cookcountysheriff.org/ cook-county-department-of-corrections/electronic-monitoring-program-placement/

- GATEWAY - Drug treatment and other services/programming to reduce recidivism, see: http://gatewaycorrections.org/locations/illinois/

- HRDI - Drug and alcohol treatment. See https://www.hrdi.org/

- SFFP - Sheriff's Female Furlough Program, see: https://www. cookcountysheriff.org/ cook-county-department-of-corrections/sheriffs-female-furlough-program-sffp/

- HAYMARKET - Drug treatment program, see: http://www.hcenter.org/about-us

- WESTCARE - Primarily a drug treatment program, but they offer other interventions as well. See: https://www.westcare.com/page/what-we-do_01

4. If a CCDOC sentence free description included the substring "PROB", we recode it as a probation sentence. We recode 460 sentences for this reason.

5. If a CCDOC sentence free description included the substring "BOOT", we recode it as CCDOC Boot Camp. CCDOC Boot Camp is 4 months of incarceration in CCDOC and 8 months of probation. See: http://www.digibridge.net/bootcamp/facts.htm. We recode 68 dispositions as CCDOC Boot Camp.

\subsection{Identifying Sentences}

We use the raw disposition codes to identify and record the sentencing information for each case. We focus on the first four sentencing dates in each court case. While approximately $98 \%$ of the cases in the sample have two or fewer sentencing dates, a small subset of cases have 3 or more. 862 cases (less than $0.1 \%$ of the sample) have more than 4 sentencing dates. In those cases, we still limit our attention to the first four sentencing dates. If a defendant is not convicted, there is no sentence. And by state law, everyone who is found guilty must receive a sentence of some type. We use the sentencing disposition codes to place sentences into one of four categories:

1. Incarceration in IDOC

2. Incarceration in CCDOC Boot Camp

3. Probation

4. Other (a sentence without incarceration or supervision) 
Occasionally, sentences of multiple types will be given on the same day. We record all of the sentence types given on that date. Within each sentence type (IDOC, CCDOC, Probation, and Other), we record the longest sentence length. For example, if an individual is given two IDOC sentences, one for 6 months and one for 12 months, we record the most severe sentence as 12 months. There is one exception to this rule. If the sentences are set to run consecutively (as noted by a disposition in the disposition file), we set the sentence length for each type to be equal to the sum of the sentences of that type on that day. This is rare. Most sentences given on or near the same day run concurrently.

Next, we identify credit for time served information for each sentencing date. In many cases, the court records these credits in a separate disposition. We see some sentences marked as "Time Already Served." In these cases, although the court recorded an incarceration sentence, sometimes as a sentence to spend time in CCDOC, the judge is in effect releasing the defendant by asserting that the time he served in jail waiting for a verdict is his punishment. A variety of special disposition codes mark these sentences. If any of these codes appears on the sentencing date, we consider the sentence time already served.

The court does not always record time already served sentences correctly. Based on conversations with County employees who work with these data, we mark sentences to CCDOC that are denominated in days but not equal to 364 days or multiples of 30 days. When such sentences are not accompanied by any dispositions marking credit for time served, we assume that these are actually time already served sentences. This decision affects 13,192 sentences. We classify all time already served sentences as "other."

In the end, a small fraction of sentences appear to require defendants to serve some time in Cook County jail but not participate in the Boot Camp program. We do not code these sentences as incarceration sentences. If these sentences are paired with probation sentences, we treat them as probation. In the rare cases where these sentences are stand alone events, we classify them as "other."

We know that some credits for time-served are awarded by the judge but never recorded in the electronic files, and we know from conversations with representatives of the adult probation department that CCDOC Bootcamp and IDOC sentences were the expected forms of incarceration sentences during our sample period.

\subsection{Constructing a Case-Level Dataset}

The court assigns each case to a call. A call is a calendar of cases that a particular judge is responsible for handling. Other judges may work on cases in the call because vacations, sick leaves, and other factors make it impossible for one judge to handle all hearings for all cases assigned to a given call, but the Court organizes case assignment by calls. Calls have numbers, and in the electronic files produced by the Clerk, these numbers are labeled "Courtroom," but call numbers do not reveal physical locations in a particular Courthouse.

Case numbers identify both collections of charges and defendants. If a defendant is charged with multiple offenses, all of the offenses share the same case ID number. However, if a group of defendants are all charged with committing a crime together, the Clerk will record a separate case ID number for the charges against each defendant. We save case-level information from the disposition history by flagging various dispositions of interest. Our final case-level data set saves a single record for each case.

As we note above, sometimes the court fails to record the defendant's credit for time served. In these cases, we estimate the amount of time each defendant spent in jail. The raw disposition data includes dispositions indicating whether the defendant was in custody or on bond at each court appearance. The sum of periods that bookend dispositions indicating that the defendant was in custody are therefore an estimate of jail time. We record the sum of all jail spells during the case. When we see IDOC sentences, we assume that defendants receive credit for their jail time. We examine dispositions in the court data and jail time records in the IDOC data to measure these credits. If neither of these sources provide information about credits, we use our estimate of jail time to impute credits.

We determine whether a case was dropped by beginning with the data set containing all of the charges for 
each case. We mark a charge as dropped if any disposition code indicates that the prosecution dropped the charge. If every charge in the case was dropped, we consider the case dropped.

\subsection{Tracking Individuals}

To identify defendants, we rely on the fingerprint ID associated with each case. A fingerprint ID is a unique numerical identifier given by the Cook County Court system to each person upon intake. In some cases, the system assigns multiple IDs to the same individual, and we combine the two fingerprint IDs into a new unique individual identifier. We make these combinations on the basis of FBI numbers, IDOC numbers, and demographic information. In some cases, especially from the 1980s, a fingerprint ID is missing. In these cases, we use a defendant's name, race, sex, and exact birth date to try to find a different case he was involved in where a valid fingerprint ID exists. When there is no other case with a valid fingerprint ID for a defendant, we assign a synthetic fingerprint ID to defendants with unique names. We drop defendants who are missing both fingerprint IDs and valid demographic information.

\subsection{Matching Court Records to Prison Records}

To improve our measure of effective sentences and recidivism, we rely on both Court records and IDOC records. We match our case-level data from the Cook County Court system to IDOC records by creating a crosswalk between the unique individual identifiers in the court data and the unique individual identifiers in the prison data. The court and prison data both include demographic information as well as sentencing dates. We match individuals on the basis of shared demographic information and sentencing dates in the court and prison data.

To learn more about the time-served required by various sentences recorded in the Court records, we locate court cases that resulted in admissions to an IDOC prison. We start with IDOC admission records that result from sentences announced in a Cook County court. Next, we identify the sentences in the Cook County Court data that could produce an IDOC admission record. Our IDOC data begin in 1990 and end in early 2015.

We now match each individual's eligible court records to his eligible IDOC admissions. The court and IDOC data both contain sentencing dates, sentence length, crime category and class number variables. We match IDOC spells with any court sentence that has the same sentencing date and either the same sentence length, or the same crime category and class number.

\subsection{Combining Cases into Episodes}

Sometimes the court opens multiple cases against an individual simultaneously. We combine information from these simultaneous cases. We treat two cases as one case if the initiation date for the second case occurs before the terminal date for the first case. We define the terminal date as follows:

1. First sentencing date, if the case includes any sentences.

2. First not guilty disposition date if the case did not end in a sentence, and the case had a not guilty disposition.

3. First date of a disposition indicating the case was dismissed if the case did not end in a sentence, did not have a not guilty disposition, and did have a dismissed disposition.

4. The date the case was dropped if the case was dropped.

5. For all remaining cases, the final disposition date we have on record is the terminal date. 
Combining cases that were tried simultaneously decreases our sample of felony cases with valid fingerprint IDs from $1,231,946$ to $1,018,702$. We refer to combined cases as episodes.

The court occasionally initiates new cases against a defendant while the defendant is serving a prison spell in IDOC associated with a previous court sentence. These cases are not associated with crimes committed in prison. When inmates commit crimes in prison, the charges are filed in the County where the prison is located. There are no state prisons in Cook County. These cases appear to be the result of information gathered while investigating a previous case. We delete these cases from our data.

\subsection{Treatment Variable Creation}

This section explains how we define our key treatment variable, $\tau_{j(i, t)}$. This is an indicator for whether defendant $i$ received a sentence, after being assigned at $t$ to the call run by judge $j$, that required $i$ to serve time in a state prison or the CCDOC Bootcamp program. We set this indicator to zero if the case against $i$ at $t$ :

1. Contains no sentence to prison or CCDOC Bootcamp

2. Contains a sentence that results in a match to IDOC admission records followed by an exit within two weeks. We have learned that, even in cases where the defendant is admitted to the IDOC system, receives an MSR (parole) agent assignment, and exits prison on the same day, the exit may be recorded with a lag. Also, inmates who stay less than two weeks in reception centers are never evaluated and assigned to a regular prison.

3. Contains a sentence that matches to an IDOC admission record but there is no corresponding exit record, and the sentencing and credit for time served information in the prison records implies that the sentence required less than two weeks of additional time served.

4. Contains a sentence to prison that does not match any IDOC admission record, and the implied additional time-served based on court records is less than three weeks after the initiation date.

Else, $\tau_{j(i, t)}=1$

We based both the two and three week rules on observed relationships between the additional expected time-served implied by a common rule of thumb formula, i.e. .5(nominal sentence) - (credit for time already served), and the prevalence, among matched sentences, of admission and exit records that share a common date. When we see a prisoner enter and exit the IDOC system on the same day, we know that the prisoner did not owe any time. The purpose of the admission process is only to assign the offender to an MSR agent.

\subsection{Artificial Records of Recidivism Events}

If an individual commits a crime outside of Cook County, the offense is not recorded by the Clerk in Cook County. However, when these crimes result in IDOC admissions, we observe them in our IDOC data. We count these events as recidivism by creating artificial court records for them. We date these events by estimating initiation dates for the cases that created the admissions. Matched Court and IDOC data allow us to build a model of the time between the date a charge is filed in court and the date a sentenced defendant enters the prison system.

We create artificial records for admission from courts outside Cook County or MSR violations associated with a new court charge outside Cook County. We do not count technical MSR violations as recidivism events. 


\subsection{Outcome Variables}

Our key outcome variables are indicator variables for the presence of at least one new charge within 12, 24, $36,48,60,72$, or 84 months of the terminal date of a case. A new charge may be any of the following:

1. The initiation of a new court case in Cook County.

2. An imputed initiation date associated with a case outside of Cook County. Some of these cases may begin while the offender is on MSR.

We require that all recidivism events occur after the potential recidivism date for a case, which is the date when the offender is assumed to be at risk of recidivism. We ignore events that occur before these dates:

1. The terminal date of the case - if the case did not end in an IDOC sentence.

2. The date of exit from prison - if the case resulted in an IDOC sentence and a matched prison spell with an exit record.

3. An estimated exit date from prison (based on information in IDOC records) - if the case resulted in an IDOC sentence and matched prison spell without an exit record.

4. An estimated exit date from prison (based on information in Court records) - if the case resulted in an IDOC sentence and no matched prison spell in the IDOC admission records.

\subsection{Geography}

We create an indicator variable that marks offenders who likely grew up in a high-crime area. Cases in the Cook County Court data record the defendant's address at the initiation of the case. For each defendant in our analysis dataset, we use GIS software to geocode the first address associated with that defendant. We then project the resulting latitudes and longitudes onto a shapefile for Chicago's 77 community areas. A small number of addresses cannot be geocoded and are instead assigned to a community area by hand. If an address cannot be geocoded by hand or is located outside of Chicago, we treat the defendant as not coming from a high crime area.

A report by Rob Paral and Associates, Paral (2003), documents the average homicide rate in each Community Area over the five-year period 1994-1998. Twenty-five of the 77 areas had murder rates over 40 per 100,000 people during this period. We mark these 25 community as high-crime areas.

We explored several alternative methods. One designated defendants as having grown up in a high-crime community area based on per-capita charges in the Court system. Another employed reports from the Chicago Police Department concerning index crime rates by community areas in some years and police districts in others. Both procedures involved a number of necessarily arbitrary choices concerning the weighting of various offenses, interpolation methods, and imputation rules, but the results were always highly correlated with the designations we made based on the simple more than 40 per 100,000 homicide rate rule.

\subsection{MSR}

Figures 3 and 4 employ data on persons under MSR supervision. Our goal here is to explore how MSR impacts recidivism and re-entry. So, we use all MSR spells that we can identify, and not just spells associated with defendants in our main analysis samples.

To create our analysis sample of MSR spells, we begin with IDOC data on incarceration spells. For many of these spells, the expected MSR completion date is recorded in the IDOC data. When it is not available, 
we impute that date using the class of the inmate's holding offense. By statute, convictions for class 4 and 3 felonies carry 1 year of MSR; convictions for class 2 and 1 felonies carry 2 years of MSR; and convictions for class X felonies carry 3 years of MSR.

We then restrict our attention to MSR spells that meet the following criteria:

- The associated incarceration spell is marked as coming direct from court and could be linked to a Cook County Court case

- The projected MSR spell length is 12,24 , or 36 months

- The end date of the associated incarceration spell is known and not imputed

- The associated incarceration spell ended in 2010 or earlier - to allow for at least 5 years of followup IDOC data

- The most serious charge in the associated court case is Robbery, Assault, Burglary, Theft, Other Nonviolent (as defined elsewhere), Drug, or Weapons

- The defendant is male

- The defendant was born after Jan 1, 1967 - to allow for accurate information on prior convictions

Our two figures display empirical hazard rates associated with two different random failure times. In Figure 3, failure occurs when the released offender experiences a recidivism event. In Figure 4, failure occurs when the defendant enters prison as the result of a recidivism event or a technical MSR violation.

\subsection{Waterfall of Data Restrictions}

To give readers a sense of how we use the cleaning procedures discussed above and our standardized variables to arrive at a final sample of cases, we describe how various sample selection rules impact our sample. Our data has over 1 million cases. However, we only consider cases assigned at Leighton Criminal Court House, the main criminal court in Chicago, to calls that could have received randomized cases. We are not sure how cases are assigned in suburban courts, and we eliminate some calls in Leighton that did not receive random cases, e.g. Narcotics courts or Mental Health courts. We have 306,804 cases with valid identifiers that could have been randomly assigned at Leighton. Starting with this sample, we make the following sample restrictions:

1. We drop cases that either were not resolved by the first of January 2008 or were not initiated by the first of January 1990: $306,804 \rightarrow 219,651$ (87,153 dropped)

2. We drop cases associated with any defendants who were older than 17 in 1984 when our Court data begin. This allows us to observe the full criminal histories in Cook County for each defendant in our sample: $219,651 \rightarrow 130,433$ (89,218 dropped)

3. We drop cases where we have explicit or implicit evidence the defendant was on probation, because these cases are not randomized: $130,433 \rightarrow 109,139$ (dropped 21,294)

4. We drop all cases that begin while an individual is in prison if the prison spell began because of a court case. $109,139 \rightarrow 107,874$ (1,265 dropped)

5. We drop cases whose most severe charge by class is in one of the following crime categories: murder, sex crime, armed violence, prison, court, traffic, inchoate: 107,874 $\rightarrow$ 93,212 (dropped 14,662)

6. We drop cases with female defendants: $93,212 \rightarrow 83,800$ (dropped 9,412)

7. We drop cases with more than 4 defendants: 83,800 $\rightarrow 82,127$ (dropped 1,673) 
8. We drop cases where not all cases within the episode are assigned to the same courtroom: $82,127 \rightarrow$ 80,958 (dropped 1,169)

9. We drop cases with an IR number we believe may be a combination of multiple distinct individuals: $80,958 \rightarrow 78,435$ (dropped 2,523)

10. We drop cases that begin during a technical MSR prison spell if the case was initiated more than 30 days after the prison admission or if the preceding case was initiated within 30 days of the prison admission. $78,435 \rightarrow 78,358$ (dropped 77 cases)

11. We drop all cases where the felony had a class number which implied it was actually a misdemeanor: $78,358 \rightarrow 78,263$ (dropped 95)

12. We drop cases missing the defendant's age: $78,263 \rightarrow 78,231$ (dropped 32)

13. We drop cases missing the defendant's race: $78,231 \rightarrow 78,042$ (dropped 189)

14. We drop cases missing the defendant's gender: 78,042 $\rightarrow 78,041$ (dropped 1)

15. We drop cases missing the class of the charge: 78,041 $\rightarrow 78,037$ (dropped 4)

16. We drop cases missing the crime category of the charge: $78,037 \rightarrow 78,008$ (dropped 29)

17. We drop cases where the defendant was defrauding the state: $78,008 \rightarrow 77,977$ (dropped 31)

18. We drop cases where it was impossible to properly identify the marginal length on the defendant's sentence: $77,977 \rightarrow 77,909$ (dropped 68 )

19. We drop cases where the defendant died or fled, the case is ongoing, or the case ended but we are unable to determine how it was resolved: $77,909 \rightarrow 76,574$ (dropped 1,335)

20. We drop cases where the judge was a "floater" (temporary) judge: $76,574 \rightarrow 76,561$ (dropped 13)

21. We drop cases assigned to judges who did not have at least 500 cases in the analysis sample: 76,561 $\rightarrow 70,581$ (5,980 dropped)

Loeffler (2013) also used Cook County data, but he did not separate repeat offenders from first offenders, so he did not need to restrict his sample on birth year. Note that, in the second step above, we lost more than one-third of the sample by eliminating offenders born before 1967. Based on the observed relationship between age and first-offender status in later birth cohorts, we feel confident that the majority of these deleted cases involve charges against repeat offenders.

\subsection{Leave-Out Mean Creation}

To create the LOM instruments for our key regression models, we divide our analysis sample into first offenders and repeat offenders. We then regress $\tau_{j(i, t)}$ on the following variables

1. A vector of indicator variables for the case's initiation year

2. A vector of indicator variables for the class of the most severe charge in the case

3. A vector of indicator variables for interactions between class and year

4. A vector of indicator variables for interactions between class and the crime category for the most severe charge in the case

5. A vector of indicator variables for the number of prior charges on the defendants record

6. A vector of indicator variables for the defendant's age 
7. An indicator variable for the presence of multiple defendants

8. An indicator variable for the presence of multiple charges

9. An indicator variable for Black

10. An indicator for initial residence in a high-crime area.

We capture the residuals from these regressions, and we form LOM averages at the assigned judge level within first offenders and within repeat offenders. We form additional LOM measures for some subsample analyses, e.g. first offenders facing drug charges, by summing these residuals within specific subsets of first or repeat offender cases.

When forming these LOM averages for $j(i, t)$, we "leave out" the case in question, $(i, t)$, all cases against co-defendants that are bundled with the case in question at assignment, and all other cases involving defendant $i$. 


\section{Theory Appendix: Incapacitation and Deterrence}

Consider two groups of offenders charged with the same crime. All offenders in both groups have the same past criminal history and the same current propensities to re-offend. All are sentenced at a common age, and the court randomly assigns incarceration for $\tilde{m}>0$ periods to one group while assigning no incarceration to the other group. We assume that prison incapacitates offenders. So, offenders who go to prison are not at risk for recidivism until they are released.

\section{Notation}

We model the time that elapses between sentencing and the arrival of a new charge as a random failure time, $\tau$. Time is discrete. We employ the following notation:

- $a_{t}$ is the age at sentencing date $t$

- $m$ is the number of periods of incarceration imposed by the sentence.

- $\tau \sim F\left(n \mid m, a_{t}\right)$ where $n \in \mathbb{Z}^{+} \cup\{\infty\}$ and $F\left(0 \mid m, a_{t}\right)=0 \forall m, a_{t}$.

- $s\left(n \mid m, a_{t}\right)$, is the conditional survivor function, i.e. the probability that an offender will survive $n+1$ periods, without receiving a new charge given that he is age $a=a_{t}+n$ and has already survived $n$ periods after being sentenced to serve a sentence of $m$ periods. We assume that incarceration creates complete incapacitation. So,

$$
F\left(n \mid m, a_{t}\right)=0 \quad \forall 0 \leq n \leq m
$$

The conditional survivor function is

$$
s\left(n \mid m, a_{t}\right)=P\left((\tau>n+1 \mid \tau>n) \mid m, a_{t}\right)=\frac{1-F\left(n+1 \mid m, a_{t}\right)}{1-F\left(n \mid m, a_{t}\right)} \quad \forall n \geq 0
$$

This framework specifies conditional survival probabilities as functions of current duration, $n$, sentence length, $m$, and current age, $a=a_{t}+n$. Yet, our focus is a special case where, given $a$, the amount of prison time an offender has or has not served in the past does not impact current survival, as long as the offender is not currently incarcerated. Thus,

$$
s\left(n \mid m, a_{t}\right)=1 \quad \forall 0 \leq n<m, m>0
$$

and

$$
s\left(n \mid m, a_{t}\right)=s(a) \quad \forall n \geq m, a=a_{t}+n
$$

In this framework, prison time impacts recidivism by incapacitating offenders and by changing the ages at which offenders are at risk of re-offending. However, holding age constant, past incarceration has no impact on current recidivism rates, either through the direct effects of exposure to prison or through changes in exposure to various opportunities outside prison. ${ }^{58}$ The assumption $s\left(n \mid m, a_{t}\right)=s(a)$, among all non-incarcerated offenders, also rules out unobserved heterogeneity in age-specific offending rates among

\footnotetext{
${ }^{58}$ Among offenders of a given age who have not been charged with a new crime, time in prison is time not spent in community. So, it is not possible to separate the impacts of having served $m$ periods in prison from the impact of having $m$ fewer periods of exposure to family, community, and employer networks outside prison. However, we are not interested in this distinction. We are investigating how incarceration impacts survivorship through two specific channels: directly through incapacitation and indirectly by shifting the risk of recidivism to later ages.
} 
those not in prison. Given random assignment of cases to judges, this is a natural place to start, but we discuss the potential consequences of unobserved heterogeneity within the complier set below.

Given $s\left(n \mid m, a_{t}\right)=s(a)$ for the non-incarcerated, and our assumption that incarcerated persons are completely incapacitated, we can define the probability that a defendant survives at least $n$ periods without a new charge given a sentence of $m \geq 0$ :

$$
\begin{gathered}
S\left(n \mid m, a_{t}\right)=1 \quad \forall n \leq m \\
S\left(n \mid m, a_{t}\right)=\prod_{k=m}^{n-1} s\left(a_{t}+k\right) \quad \forall n>m
\end{gathered}
$$

Assume that $0<s(a)<1$ for all ages, $a$, and our first result follows immediately. If we consider survivor functions for two identical groups of defendants who randomly receive either prison sentences of $m=\tilde{m}>0$ or probation sentences, $m=0$, we can order these functions:

$$
S\left(n \mid \tilde{m}, a_{t}\right)>S\left(n \mid 0, a_{t}\right) \quad \forall t>0
$$

Each term in $S\left(n \mid \tilde{m}, a_{t}\right)$ has a corresponding term in the product that defines $S\left(n \mid 0, a_{t}\right)$. For $n<\tilde{m}$, the former is one and the later is less than one. For $n \geq \tilde{m}$, the terms are the same. Taken together, these observations confirm the inequality.

Next consider the difference between these survivor functions

$$
\Delta\left(n \mid \tilde{m}, a_{t}\right)=S\left(n \mid \tilde{m}, a_{t}\right)-S\left(n \mid 0, a_{t}\right)
$$

It is straightforward to establish two additional results concerning the evolution of this difference over time:

$$
\Delta\left(n-1 \mid \tilde{m}, a_{t}\right)-\Delta\left(n \mid \tilde{m}, a_{t}\right)<0 \quad \forall n \leq \tilde{m}
$$

and

$$
\Delta\left(n-1 \mid \tilde{m}, a_{t}\right)-\Delta\left(n \mid \tilde{m}, a_{t}\right)>0 \quad \forall n>\tilde{m}
$$

Result (R2) is immediate. For all $n \leq \tilde{m}, S\left(n \mid \tilde{m}, a_{t}\right)=1$ and $S\left(n \mid 0, a_{t}\right)$ declines monotonically in $n$. Thus, the gap between the two survivor functions grows with time. To understand our final result, (R3), form the following expression for the evolution of the difference between the survivor functions:

$$
\Delta\left(n-1 \mid \tilde{m}, a_{t}\right)-\Delta\left(n \mid \tilde{m}, a_{t}\right)=S\left(n-1 \mid \tilde{m}, a_{t}\right)-S\left(n \mid \tilde{m}, a_{t}\right)-S\left(n-1 \mid 0, a_{t}\right)+S\left(n \mid 0, a_{t}\right)
$$

From here, we can use the definition of $S\left(n \mid m, a_{t}\right)$ above to show:

$$
\Delta\left(n-1 \mid \tilde{m}, a_{t}\right)-\Delta\left(n \mid \tilde{m}, a_{t}\right)=\left[S\left(n-1 \mid \tilde{m}, a_{t}\right)-S\left(n-1 \mid 0, a_{t}\right)\right]\left[1-s\left(a_{t}+n-1\right)\right]>0 \quad \forall n>\tilde{m}
$$

This inequality holds because $S\left(n \mid \tilde{m}, a_{t}\right)>S\left(n \mid 0, a_{t}\right) \forall n$ and $0<s(a)<1$ for $n \geq \tilde{m}$. Thus, equation 4 shows that the difference between two survivor functions shrinks with $n$ for $n>\tilde{m}$.

We derived R3 under the null that, holding age constant, the experience of prison does not impact future survival probabilities either directly or indirectly. Thus, empirical violations of equation 4 constitute 
evidence that serving prison time does impact recidivism through mechanisms other than direct incapacitation or shifting recidivism risk to later ages.

If we see that $\Delta\left(n \mid \tilde{m}, a_{t}\right)$ remains constant or grows over ranges of $t$ that are well beyond the range of time-served, $\tilde{m}$, we must conclude that, relative to time spent on probation, time spent in prison creates some form of deterrence that increases $s(a)$, at some or all age levels. If on the other hand, we see that $\Delta\left(n \mid \tilde{m}, a_{t}\right)$ not only shrinks over time but actually becomes negative, we know that, relative to time spent outside prison, incarceration spells are criminogenic, i.e. time in prison lowers $s(a)$, at least for some ages, enough to offset the initial incapacitation effects of incarceration.

Our results are silent concerning the expected rate of convergence. We cannot rule out deterrence or criminogenic effects from simply observing that the data are consistent with results R2 and R3. We have shown that, when no deterrence or criminogenic effects are present, $S\left(n \mid \tilde{m}, a_{t}\right)$ converges to $S\left(n \mid 0, a_{t}\right)$ from above for $n>\tilde{m}>0$.

We have derived the results above without considering unobserved heterogeneity. However, if we consider the presence of heterogeneous types within the complier set, the logic behind our results remains. Consider a setting with $k=1,2, \ldots, K$ unobserved types, and let

$$
S\left(n \mid m, a_{t}\right)=\sum_{k} S_{k}\left(n \mid m, a_{t}\right) \omega_{m(k)}
$$

Here, $S_{k}\left(n \mid m, a_{t}\right)$ is the survivor function for a defendant of type $k$ sentenced to $m$ periods of incarceration at age $a$, and $\omega_{m(k)}$ is the probability, within the population of compliers sentenced to $m$ periods of incarceration, that a defendant is type $k$. If we assume that $\omega_{m(k)}=\omega_{k} \forall(m, k)$, then these weights are the same for the $m=\tilde{m}$ and $m=0$ samples, and results R1-R3 still hold. Our arguments clearly hold for any fixed type $k$. Therefore, they must hold for averages over $k$ given a common set of weights in the $m=\tilde{m}$ and $m=0$ samples.

In a setting with only two judges, random case assignment implies equal weights, $\omega_{k}$, within the complier set. Here, a sentence of $m=\tilde{m}$ versus $m=0$ provides no information about the defendant but only the random judge assignment. Equal weights is a stronger assumption given more than two judges. In this case, some defendants in the complier set face $m=0$ given assignment to any judges that are not among the most severe while others face $m=0$ only given assignment to one of the most lenient judges. So, a sentence of $m=0$ versus $m=\tilde{m}$ may contain information about unobserved propensities to re-offend.

Nonetheless, it is natural to conjecture that, if such differences in the distribution of types exists, the $m=0$ sample should contain more types with low unobserved propensities to re-offend. If so, the initial gap between $S\left(n \mid \tilde{m}, a_{t}\right)$ and $S\left(n \mid a_{t}, 0\right)$ that develops over the first $\tilde{m}$ periods must still narrow after period $n=\tilde{m}$, but now this gap narrows for two reasons. To begin, incapacitation during $n<\tilde{m}$ still creates a larger risk set, but now, this larger risk set also contains more high risk offenders. Thus, in contrast to our previous results, the two survivor functions could cross at some period $n>\tilde{m}$, even if past prison time has no direct impact age-specific survival rates, simply because the $\tilde{m}$ sample contains more high-risk types.

We proceed under the assumption that, given random case assignment and the extensive controls we include for defendant and case characteristics, differences in the distributions of unobserved recidivism types between incarcerated and non-incarcerated defendants in the complier set are a second order concern. The key results in this appendix show that, if the experience of prison does not impact age-specific recidivism rates after release, the survivor functions for incarcerated and not incarcerated offenders should converge steadily after the former group leaves prison. This result should be robust, given any reasonable treatment of unobserved heterogeneity, and as we note above, if compliers who are sentenced to incarceration have slightly higher age-specific offending rates, convergence should occur even more rapidly. Yet, in our samples of first offenders, we see long periods with no convergence, and these periods begin at least four years after sentencing. 